\title{
Guía sobre el manejo de la angina estable. Versión resumida
}

\author{
Grupo de Trabajo de la Sociedad Europea de Cardiología sobre el Manejo \\ de la Angina Estable
}

\begin{abstract}
Autores/Miembros del Grupo de Trabajo: Kim Fox (Coordinador*), María Ángeles Alonso García (Madrid, España), Diego Ardissino (Parma, Italia), Pawel Buszman (Katowice, Polonia), Paolo G. Camici (Londres, Reino Unido), Filippo Crea (Roma, Italia), Caroline Daly (Londres, Reino Unido), Guy de Backer (Ghent, Bélgica), Paul Hjemdahl (Estocolmo, Suecia), José López-Sendón (Madrid, España), Jean Marco (Toulouse, Francia), João Morais (Leiria, Portugal), John Pepper (Londres, Reino Unido), Udo Sechtem (Stuttgart, Alemania), Maarten Simoons (Rotterdam, Países Bajos) y Kristian Thygesen (Aarhus, Dinamarca).
\end{abstract}

\begin{abstract}
Comité de la Sociedad Europea de Cardiología para la elaboración de Guías de Práctica Clínica (GPC): Silvia G. Priori (Coordinadora, Italia), Jean-Jacques Blanc (Francia), Andrzej Budaj (Polonia), John Camm (Reino Unido), Veronica Dean (Francia), Jaap Deckers (Países Bajos), Kenneth Dickstein (Noruega), John Lekakis (Grecia), Keith McGregor (Francia), Marco Metra (Italia), João Morais (Portugal), Ady Osterspey (Alemania), Juan Tamargo (España) y José L. Zamorano (España)

Revisores del documento: José L. Zamorano (Coordinador de revisión, España), Felicita Andreotti (Italia), Harald Becher (Reino Unido), Rainer Dietz (Alemania), Alan Fraser (Reino Unido), Huon Gray (Reino Unido), Rosa Ana Hernández Antolín (España), Kurt Huber (Austria), Dimitris T. Kremastinos (Grecia), Attilio Maseri (Italia), Hans-Joachim Nesser (Austria), Tomasz Pasierski (Polonia), Ulrich Sigwart (Suiza), Marco Tubaro (Italia) y Michael Weis (Alemania)
\end{abstract}

Con permiso de The European Society of Cardiology (ESC).

\section{ÍNDICE DE CONTENIDOS}

Preámbulo . . . . . . . . . . . . . . . . . . . . . 920

Introducción . . . . . . . . . . . . . . 921

Definición y fisiopatología . . . . . . . . . . . . . . . . . . . . . . . 921

Epidemiología . . . . . . . . . . . . . . . . . . . . 921

Historia natural y pronóstico . . . . . . . . . . . . . . . . . . . 921

Diagnóstico y valoración ... . . . . . . . . . . . 922

Síntomas y signos . . . . . . . . . . . . . . . . . 922

Pruebas de laboratorio . . . . . . . . . . . . . . 924

Radiografía de tórax . . . . . . . . . . . . 925

Investigaciones cardiacas no invasivas . . . . . 925

ECG en reposo . . . . . . . . . . . . . . . . . . . . . . . . 925

ECG de esfuerzo . . . . . . . . . . . . . . . . 926

Prueba de esfuerzo combinada con técnicas de imagen . . . . . . . . . . . . . . . . . . 927

Ecocardiografía en reposo . . . . . . . . . . . 930

Técnicas no invasivas para la valoración de la calcificación y la anatomía coronarias . . . 930

Técnicas invasivas para la evaluación

de la anatomía coronaria

*Correspondencia: Kim Fox.

Department of Cardiology. Royal Brompton Hospital.

Sydney Street. London SW3 6NP. Reino Unido.

Correo electrónico: k.fox@rbh.nthames.nhs.uk

Los comentarios-anotaciones (*) incluidos en esta traducción de las Guías han sido realizados por la Dra. María Ángeles Alonso García (Madrid, España). Correo electrónico: angelesalonsog@ secardiologia.es.

Full English text available from: www.revespcardiol.org
Angiografía coronaria . . . . . . . . . . . . . . . . . . 931

Estratificación del riesgo . . . . . . . . . . . . 931

Estratificación del riesgo mediante evaluación clínica . . . . . . . . . . . 932

Estratificación del riesgo mediante la prueba de esfuerzo ................... 933

Estratificación del riesgo mediante la función ventricular ................. 935

Estratificación del riesgo mediante angiografía coronaria . . . . . . . . . 936

Consideraciones diagnósticas especiales: angina

con arterias coronarias «normales» . . . . . . . 936

Síndrome X . . . . . . . . . . . . . . . . . 937

Diagnóstico del síndrome X . . . . . . . . . . 939

Angina vasoespástica/variante . . . . . . . . . . 939

Tratamiento . . . . . . . . . . . . . . . . . . . . . . 940

Objetivos del tratamiento . . . . . . . . . . . . . . . . . . . . . . . . . 940

Manejo general . . . . . . . . . . . . . . . . . . 940

Hipertensión, diabetes y otras alteraciones . . . . 941

Actividad sexual . . . . . . . . . . . . . . . 941

Tratamiento farmacológico de la angina estable . . 941

Tratamiento farmacológico para mejorar el pronóstico . . . . . . . . . . . . . . . . . 941

Tratamiento farmacológico de los síntomas y la isquemia . . . . . . . . . . . . . . . . . . 946

Consideraciones terapéuticas especiales: síndrome X y la angina vasoespástica . . . 950

Revascularización miocárdica . . . . . . . . . 951 
Cirugía de bypass aortocoronario . . . . . . . . 951

Intervención coronaria percutánea . . . . . . 952

Revascularización frente a tratamiento médico 953

Intervención coronaria percutánea frente

a cirugía . . . . . . . . . . . . . . . 954

Subgrupos específicos de pacientes y lesiones . 955

Indicaciones para la revascularización . . . . . 955

Subgrupos especiales ................. 957

Mujeres ...................... 957

Diabetes mellitus . . . . . . . . . . . . . . 958

Pacientes ancianos ................ 959

Angina crónica rebelde al tratamiento . . . . . 959

Conclusiones y recomendaciones . . . . . . . . . 960

Bibliografía ...................... 961

\section{PREÁMBULO}

Las Guías de Práctica Clínica y los Documentos de Consenso de Expertos tienen como objetivo presentar todas las evidencias relevantes sobre un tema particular para ayudar a los médicos a seleccionar la mejor estrategia de manejo para cada paciente individual que tiene una afección concreta, teniendo en cuenta no sólo el resultado final, sino también los riesgos y los beneficios de un diagnóstico particular o de un procedimiento terapéutico. Numerosos estudios han demostrado que los resultados de los pacientes mejoran cuando se aplican las guías de práctica clínica basadas en la evaluación rigurosa de la evidencia derivada de investigaciones.

En los últimos años, la Sociedad Europea de Cardiología (ESC) y otras organizaciones y sociedades relacionadas han elaborado un gran número de Guías de Práctica Clínica y Documentos de Consenso de Expertos. Esta gran profusión puede poner en riesgo la autoridad y la validez de las Guías, particularmente si aparecen discrepancias sobre un mismo tema entre diferentes documentos, ya que puede crear confusión a los médicos. Ésta es una de las razones por las que la ESC y otras sociedades han hecho pública una serie de recomendaciones para abordar y formular las Guías de Práctica Clínica y los Documentos de Consenso de Expertos. Estas recomendaciones de la ESC se pueden consultar en el sitio www.escardio.org. En este preámbulo no pretendemos tratar este tema en profundidad y sólo se recordará las reglas básicas para la elaboración de guías de práctica clínica.

El Grupo de Trabajo de la ESC solicita a un panel de expertos una revisión en profundidad de la literatura disponible sobre un tema específico, para elaborar una evaluación crítica del uso de procedimientos diagnósticos y terapéuticos y de la relación riesgo/beneficio de las terapias recomendadas en el manejo y la prevención de una enfermedad determinada. Cuando se dispone de datos, se incluye también una estimación de los resultados clínicos. El peso de la evidencia a favor o en contra de un determinado procedimiento o tratamiento se clasifica en grados de evidencia y clases de recomendaciones de acuerdo con escalas predefinidas, como se describe más adelante.

El Grupo de Trabajo solicita a los expertos seleccionados para estos paneles que faciliten una declaración sobre todas sus posibles relaciones que se pueda considerar causa de un conflicto de interés real o potencial. Estos formularios se guardan en forma de ficheros en la Casa Europea del Corazón, la oficina central de la ESC, y están disponibles previa solicitud por escrito del presidente de la ESC. Los cambios que pudieran suscitarse respecto a conflicto de intereses deben ser notificados a la ESC.

Las guías y recomendaciones se presentan en formatos de fácil interpretación, para ayudar al médico en la toma diaria de decisiones, que describen distintas modalidades posibles de diagnóstico y tratamiento. En cualquier caso, la decisión última sobre los cuidados de los pacientes corresponde al médico tratante.

El Comité para las Guías de Práctica Clínica (GPC) de la ESC supervisa y coordina la preparación de nuevas Guías de Práctica Clínica y Documentos de Consenso de Expertos elaborados por los Grupos de Trabajo, grupos de expertos o paneles de consenso. El comité también es responsable de la aprobación de estas guías, documentos de consenso y declaraciones.

Cuando se ha finalizado el documento y ha sido aprobado por todos los expertos del Grupo de Trabajo, se envía a especialistas externos para su revisión. En algunos casos, el documento se presenta también a líderes de opinión europeos y otros especialistas disponibles para su discusión y revisión crítica. Si fuera necesario, se revisa el documento una vez más antes de que finalmente lo aprueben el comité de GPC y otros miembros directivos de la ESC.

Tras la publicación, la difusión de las Guías es de suma importancia. Con este propósito también se publican resúmenes ejecutivos, ediciones de bolsillo y versiones para PDA, que se puede descargar de internet. A pesar de estos esfuerzos, muchos usuarios finales desconocen la existencia de las guías de práctica clínica o, simplemente, no las utilizan. Por tanto, los programas de implementación son imprescindibles para la difusión del conocimiento. La ESC organiza para ello reuniones con las sociedades nacionales y líderes de opinión en Europa. Estas reuniones también se pueden desarrollar a escala nacional, una vez que la guía ha sido aprobada por las sociedades pertenecientes a la ESC y se ha traducido a las distintas lenguas.

\section{Clases de recomendaciones}

Clase I Evidencia y/o acuerdo general de que un determinado procedimiento diagnóstico/tratamiento es beneficioso, útil y efectivo. 
Clase II Evidencia conflictiva y/o divergencia de opinión acerca de la utilidad/eficacia del tratamiento.

Clase IIa El peso de la evidencia/opinión está a favor de la utilidad/eficacia.

Clase IIb La utilidad/eficacia está menos establecida por la evidencia/opinión.

Clase III Evidencia o acuerdo general de que el tratamiento no es útil/efectivo y en algunos casos puede ser perjudicial.

La tarea de elaboración de Guías de Práctica Clínica y Documentos de Consenso no sólo abarca la integración de la investigación más reciente, sino también la creación de herramientas de educación y programas de implementación. El ciclo que se establece entre la investigación clínica, la elaboración de guías de práctica clínica y su implementación sólo se puede completar si se realizan encuestas y se organizan registros que verifiquen el grado de aplicación de las recomendaciones. Dichas encuestas y registros también permiten evaluar el impacto en los resultados clínicos de la estricta implementación de las guías.

\section{Niveles de evidencia \\ Nivel de evidencia A Datos procedentes de múl- tiples ensayos clínicos ale- atorizados o metaanálisis. \\ Nivel de evidencia B Datos procedentes de un único ensayo clínico alea- torizado o de grandes estu- dios no aleatorizados. \\ Nivel de evidencia C Consenso de opinión de expertos y/o pequeños es- tudios, estudios retrospecti- vos, registros.}

\section{INTRODUCCIÓN}

La angina de pecho estable es un síndrome clínico frecuente $y$, en ocasiones, incapacitante. El desarrollo de nuevos medios de diagnóstico y de valoración pronóstica de los pacientes, junto con la continua evolución de las estrategias de tratamiento basadas en la evidencia, hacen necesaria la revisión y la actualización de las guías de práctica clínica ${ }^{1}$ publicadas hasta la fecha. Es por ello que el Grupo de Trabajo de la Sociedad Europea de Cardiología ha recogido las opiniones de una amplia representación de expertos, con la intención de alcanzar un acuerdo sobre las mejores estrategias actuales para el manejo de la angina estable, teniendo en cuenta no sólo la eficacia y la seguridad de los tratamientos, sino también el coste y la disponi- bilidad de los recursos. El Grupo de Trabajo considera que esta guía debe reflejar la fisiopatología y el manejo de la angina de pecho causada por isquemia miocárdica secundaria a enfermedad de las arterias coronarias, generalmente del lecho macrovascular, pero en algunos pacientes, también del lecho microvascular. Esta guía no contempla la prevención primaria, que ya ha sido tratada en otra guía recientemente publicada ${ }^{2}$, y se limita a la prevención secundaria. En la versión completa de esta guía, disponible en internet, se incluye una lista de las guías y los documentos de consenso de reciente publicación que en alguna medida se solapan con el presente documento.

\section{DEFINICIÓN Y FISIOPATOLOGÍA}

La angina estable es un síndrome clínico caracterizado por malestar en el pecho, mandíbulas, hombros, espalda o brazos, que aparece con el ejercicio o estrés emocional y remite con el descanso o con la administración de nitroglicerina. Con menos frecuencia, el malestar puede aparecer en la zona epigástrica. Habitualmente este término se confina a los casos en los que el síndrome es atribuido a isquemia miocárdica; no obstante, síntomas similares pueden estar causados por alteraciones en el esófago, pulmones o en la pared torácica. Aunque la causa más común de la isquemia miocárdica es la aterosclerosis coronaria, puede demostrarse isquemia miocárdica inducida por miocardiopatía hipertrófica o dilatada, estenosis aórtica u otras enfermedades cardiacas raras (no incluidas en esta guía) en ausencia de enfermedad coronaria ateromatosa obstructiva.

\section{EPIDEMIOLOGÍA}

En ambos sexos, la prevalencia de la angina aumenta marcadamente con la edad, de un $0,1-1 \%$ en mujeres de edades comprendidas entre 45 y 54 años a un $10-15 \%$ en mujeres de $65-74$ años y de un $2-5 \%$ en varones de 45-54 años a un 10-20\% en varones de 65-74 años. Con base en estos datos, se calcula que, en la mayoría de los países europeos, entre 20.000 y 40.000 individuos por millón de habitantes sufren angina.

\section{HISTORIA NATURAL Y PRONÓSTICO}

La información sobre el pronóstico relacionado con la angina crónica estable se deriva de estudios poblacionales prospectivos a largo plazo, de ensayos clínicos sobre terapias antianginosas y de registros observacionales, en los que la selección de pacientes produce un sesgo importante que tener en cuenta al evaluar y comparar los datos disponibles. Los datos derivados del estudio Framingham Heart ${ }^{3,4}$ mostraron que en varones y mujeres con una presentación clínica inicial de angina estable, la incidencia de infarto de miocardio no fatal y muerte por enfermedad coronaria 
a los 2 años era del 14,3 y el 5,5\% en varones y del 6,2 y el $3,8 \%$ en mujeres, respectivamente. Datos más recientes recogidos en ensayos clínicos sobre terapia antianginosa y/o revascularización indican que la tasa anual de mortalidad varía entre el 0,9 y el $1,4 \%$ por año ${ }^{5-9}$, con una incidencia anual de infarto de miocar-

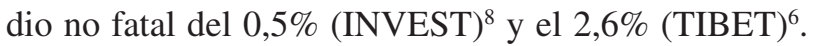
Esas estimaciones concuerdan con los datos del registro observacional ${ }^{10}$.

No obstante, entre la población con angina estable, el pronóstico individual puede variar considerablemente (hasta 10 veces) dependiendo de factores clíni$\cos$, funcionales y anatómicos basales, lo que hace necesario señalar la importancia de una cuidadosa estratificación del riesgo.

\section{DIAGNÓSTICO Y VALORACIÓN}

El diagnóstico y la valoración de la angina incluye la valoración clínica, pruebas de laboratorio y estudios cardiacos específicos. En este apartado se trata la valoración clínica relacionada con el diagnóstico y las pruebas básicas de laboratorio. Los estudios cardiacos específicos pueden ser invasivos o no invasivos y se puede utilizarlos para confirmar el diagnóstico de isquemia en pacientes en que hay sospecha de angina estable, para identificar o excluir enfermedades concomitantes o factores precipitantes para la estratificación del riesgo y para evaluar la eficacia del tratamiento. En la práctica, la valoración del diagnóstico y del pronóstico se realiza conjuntamente, y no de forma separada, y la mayoría de los estudios utilizados para el diagnóstico proporcionan también información pronóstica. Al objeto de describir y presentar la evidencia existente, cada técnica de estudio se presenta individualmente y se incluye recomendaciones para el diagnóstico. Los estudios cardiacos específicos utilizados habitualmente para la estratificación del riesgo se presentan separadamente en el apartado correspondiente. En la figura 1 se describe un algoritmo para la evaluación inicial de los pacientes con síntomas clínicos de angina.

\section{Síntomas y signos}

Una meticulosa elaboración de la historia clínica del paciente sigue siendo la piedra angular en el diagnóstico de la angina de pecho. En la mayoría de los casos es posible realizar un diagnóstico fiable basado solamente en la historia clínica, aunque la exploración física y las pruebas objetivas son necesarias para confirmar el diagnóstico y valorar la severidad de la enfermedad subyacente.

Las características del malestar relacionado con la isquemia miocárdica (angina de pecho) han sido ampliamente descritas y se puede dividirlas en 4 categorías según su localización, su carácter, su duración y su relación con el ejercicio u otros factores que acen- túan o alivian la angina. El malestar causado por la isquemia miocárdica se localiza normalmente en el pecho, cerca del esternón, pero se puede sentir en cualquier parte del cuerpo, desde el epigastrio a la mandíbula inferior o los dientes, entre los omóplatos o en cualquiera de los dos brazos hasta la muñeca y los dedos. El malestar se suele describir como opresión, tensión o pesadez y puede ir acompañado de sensación de estrangulamiento, constricción o quemazón. La severidad de la angina puede variar mucho y no está relacionada con la severidad de la enfermedad coronaria subyacente. La falta de aire puede acompañar a la angina, y el malestar torácico puede acompañarse de otros síntomas menos específicos como fatiga o desfallecimiento, náusea, eructos, ansiedad/inquietud o sensación de muerte inminente.

En la mayoría de los casos, el episodio de angina es breve, generalmente menos de $10 \mathrm{~min}$. Una característica importante es su relación con el ejercicio, una actividad específica o el estrés emocional. Es típico que se acentúen los síntomas con el aumento de ejercicio, como subir una cuesta o caminar contra el viento, y remitan rápidamente en unos minutos cuando desaparezcan los factores causales. Otra característica típica de la angina es la acentuación de los síntomas después de una comida pesada o a primera hora de la mañana. Los nitratos orales o sublinguales alivian rápidamente la angina; se observa también una respuesta similar con la toma de cápsulas de nifedipino masticables.

El malestar no anginoso carece de las características antes descritas, puede afectar a una pequeña porción del hemitórax izquierdo y se mantiene durante horas o incluso días. Normalmente no se alivia con nitroglicerina (aunque sí en el caso del espasmo esofágico) y se puede provocarlo con la palpación. En estos casos hay que evaluar otras causas no cardiacas de los síntomas.

En la tabla 1 se resumen las definiciones de la angina típica y la angina atípica que han sido publicadas con anterioridad ${ }^{11}$. Al realizar la historia clínica, es importante identificar a los pacientes con angina inestable que pudiera tener relación con una rotura de la placa, ya que estos pacientes están en mayor riesgo de

\section{TABLA 1. Clasificación clínica del dolor torácico}

\begin{tabular}{|c|c|}
\hline Angina típica (confirmada) & $\begin{array}{l}\text { Cumple } 3 \text { de las siguientes } \\
\text { características: } \\
\text { Malestar retroesternal de duración } \\
\text { y tipo característicos } \\
\text { Causado por ejercicio o estrés } \\
\text { emocional } \\
\text { Cede con reposo y/o nitroglicerina }\end{array}$ \\
\hline Angina atípica (probable) & $\begin{array}{l}\text { Cumple } 2 \text { de las características } \\
\text { citadas }\end{array}$ \\
\hline Dolor torácico no cardiaco & $\begin{array}{l}\text { Cumple una o ninguna } \\
\text { de las características citadas }\end{array}$ \\
\hline
\end{tabular}




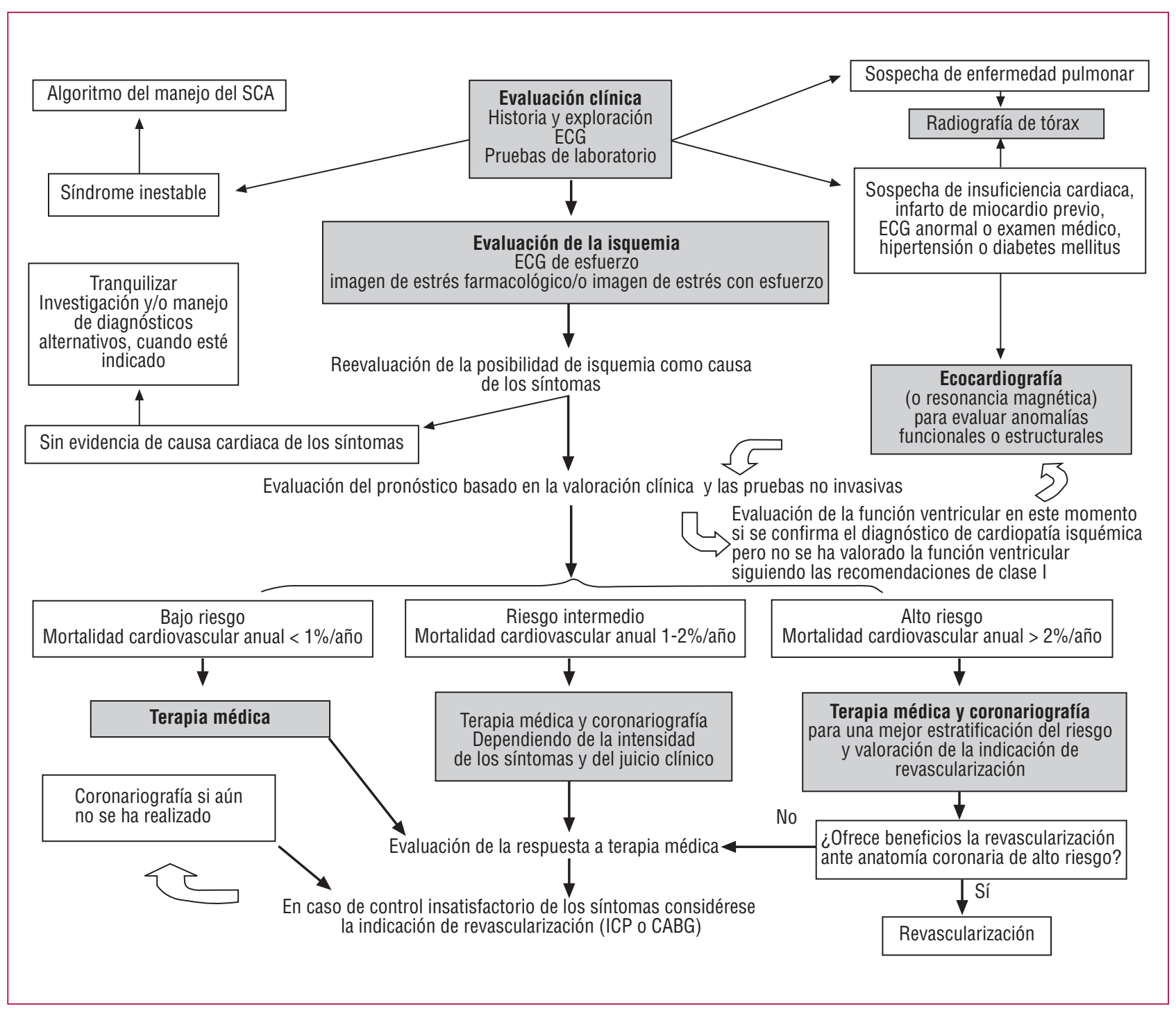

Fig. 1. Algoritmo para la evaluación inicial de los pacientes con síntomas clínicos de angina. CABG: cirugía coronaria; ECG: electrocardiograma; ICP: intervención coronaria percutánea.

evento coronario agudo a corto plazo. La angina inestable puede hallarse en una de estas 3 formas: $a$ ) angina en reposo (angina de naturaleza y localización características, que se presenta durante el reposo y períodos prolongados, de hasta $20 \mathrm{~min})$; $b$ ) angina in crescendo o que aumenta rápidamente (angina estable previa que evoluciona rápidamente en severidad e intensidad y con un umbral más bajo durante un período corto, de 4 semanas o menos), y c) angina de reciente aparición (episodio reciente de angina severa que limita marcadamente la actividad diaria del paciente y se presenta durante los 2 meses posteriores al episodio inicial). El estudio y el manejo del paciente ante la sospecha de angina inestable aparecen en las guías clínicas sobre síndromes coronarios agudos.

En los pacientes con angina estable resulta muy útil clasificar la severidad de los síntomas utilizando un sistema de gradación como el de la Canadian Cardio- vascular Society (tabla 2) ${ }^{12}$. Otros sistemas alternativos de clasificación, como el Duke Specific Activity Index ${ }^{13}$ y el cuestionario de angina de Seattle ${ }^{14}$, pueden ser utilizados para determinar el grado de afección funcional del paciente y para cuantificar la respuesta al tratamiento; además, estos métodos ofrecen un mayor poder pronóstico ${ }^{15}$.

La exploración física del paciente con sospecha de angina de pecho es importante para determinar la presencia de hipertensión, enfermedad valvular o miocardiopatía hipertrófica obstructiva. En la exploración física se debe incluir la determinación del índice de masa corporal (IMC) y la medición del perímetro de la cintura, para evaluar un posible síndrome metabólico ${ }^{16,17}$, y también signos de otras enfermedades no cardiovasculares que pudieran ser asintomáticas o de otras comorbilidades. Durante un episodio de isquemia miocárdica, o inmediatamente después, se puede oír un tercer o 
TABLA 2. Clasificación de la severidad de la angina según la Canadian Cardiovascular Society

\begin{tabular}{ll}
\hline Clase & \multicolumn{1}{c}{ Nivel de los síntomas } \\
\hline Clase I & «La actividad normal no causa angina» \\
& $\begin{array}{c}\text { Angina secundaria a ejercicio extenuante, rápido } \\
\text { o prolongado }\end{array}$ \\
Clase II & «Ligera limitación de la actividad normal» \\
& La angina se presenta al andar o subir escaleras \\
& rápidamente, subir cuestas o con el ejercicio después \\
& de las comidas, a temperaturas frías, con estrés \\
& emocional o sólo durante las primeras horas después \\
& de despertarse
\end{tabular}

${ }^{\mathrm{a} E q u i v a l e n t e}$ a $100-200 \mathrm{~m}$.

cuarto ruido y puede hacerse evidente una insuficiencia mitral. Sin embargo, estos signos son difíciles de interpretar y no se los considera específicos.

\section{Pruebas de laboratorio}

De forma general, las pruebas de laboratorio se pueden agrupar en pruebas que proporcionan información sobre las posibles causas de la isquemia, pruebas para establecer los factores de riesgo cardiovascular y enfermedades relacionadas y pruebas para estimar el pronóstico. Entre las primeras se encuentra la determinación de la hemoglobina y las hormonas tiroideas (cuando hay sospecha de afección del tiroides), es decir, proporcionan información relacionada con las posibles causas de la isquemia. El hemograma completo, que incluya recuento total de linfocitos y determinación de hemoglobina, puede proporcionar información pronóstica $^{18}$. La determinación de la creatinina sérica es un método simple aunque elemental para evaluar la función renal, recomendado en la evaluación inicial de todos los pacientes con sospecha de angina. En caso de sospecharse angina inestable, se determinará los marcadores bioquímicos de daño cardiaco como la troponina o la fracción MB de la creatincinasa (CK-MB), medida por CK-MB masa, para excluir daño miocárdico. En caso de que estos marcadores estén en valores elevados, el manejo del paciente se realizará de acuerdo con las recomendaciones para los síndromes coronarios agudos, en lugar de los de angina estable.

Tras la valoración inicial, no se recomienda repetir sistemáticamente esas pruebas en evaluaciones ulteriores.

En todos los pacientes con sospecha de isquemia, incluida la angina estable, se determinará la glucosa plasmática y el perfil lipídico en ayunas, incluido el colesterol total (CT), las lipoproteínas de alta densidad (HDL), las lipoproteínas de baja densidad (LDL) y los triglicéridos, para evaluar el perfil de riesgo del paciente y determinar la necesidad de tratamiento. El perfil lipídico y el estado glucémico se evaluarán periódicamente para determinar la eficacia del tratamiento $\mathrm{y}$, en los pacientes no diabéticos, para detectar un nuevo desarrollo de diabetes. No hay evidencia disponible que permita recomendar un período determinado para la repetición de las pruebas. Los documentos de consenso proponen una revisión anual. En los pacientes con elevadas concentraciones de lípidos o glucosa, en los que es preciso supervisar el progreso de cada tratamiento, se realizarán mediciones más frecuentes.

Se ha demostrado que la elevación de la glucemia basal o tras un test de tolerancia a la glucosa o de la glucohemoglobina $\left(\mathrm{HbA}_{1 \mathrm{C}}\right)$ es un predictor de resultado adverso con independencia de los factores de riesgo convencionales. La obesidad y, en particular, la evidencia de síndrome metabólico son predictoras de un resultado cardiovascular adverso tanto en pacientes cuya enfermedad está ya establecida como en poblaciones asintomáticas. La presencia del síndrome metabólico se determina mediante la medición del perímetro de la cintura (o el IMC), la presión arterial, las HDL, los triglicéridos y las concentraciones de glucosa en ayunas y ofrece información pronóstica adicional a la obtenida mediante la clasificación de riesgo de Framingham ${ }^{19}$, sin mayores costes adicionales que las pruebas de laboratorio. Otras pruebas de laboratorio, incluidas las subfracciones del colesterol (ApoA y ApoB), homocisteína, lipoproteína (a) $[\mathrm{Lp}(\mathrm{a})]$, anomalías hemostáticas ${ }^{20}$ y los marcadores inflamatorios como la proteína $\mathrm{C}$ reactiva $^{21}$, han suscitado gran interés como métodos para mejorar la actual predicción de riesgo ${ }^{21,22}$. Sin embargo, los marcadores inflamatorios fluctúan en el tiempo y no se puede considerarlos predictores fiables del riesgo a largo plazo $^{23}$. Recientemente se ha demostrado que la NT-BNP es un importante predictor de la mortalidad a largo plazo, independiente de la edad, la fracción de eyección ventricular (FE) y los factores de riesgo convencionales ${ }^{24}$. No obstante, no disponemos de información adecuada que permita determinar si la modificación de estos índices bioquímicos puede mejorar significativamente las estrategias actuales de tratamiento y recomendar su uso en todos los pacientes, especialmente si se considera las restricciones en los costes y la disponibilidad. Sin embargo, estas determinaciones analíticas tienen un papel importante en grupos seleccionados de pacientes: por ejemplo, en pacientes con infarto de miocardio previo sin factores de riesgo convencionales, para estudiar anomalías de la coagulación ${ }^{25}$, o en pacientes con historia familiar de enfermedad coronaria; también son recomendables en centros en que 
los recursos no están limitados. Se espera que en el futuro se realicen trabajos de investigación sobre su uso.

\section{Recomendaciones para las pruebas de laboratorio en la valoración inicial de la angina}

Clase I (en todos los pacientes)

- Perfil lipídico en ayunas, incluidos CT, LDL, HDL y triglicéridos (nivel de evidencia B).

- Glucosa en ayunas (nivel de evidencia B).

- Hemograma completo, incluida hemoglobina y recuento leucocitario (nivel de evidencia B).

- Creatinina sérica (nivel de evidencia C).

Clase I (si está específicamente indicado según la evaluación clínica)

- Marcadores de daño miocárdico, si la evaluación indica inestabilidad clínica o síndrome coronario agudo (nivel de evidencia A).

- Función tiroidea, si está clínicamente indicado (nivel de evidencia $\mathrm{C}$ ).

Clase IIa

- Test de tolerancia a la glucosa oral (nivel de evidencia B).

Clase IIb

- Proteína C reactiva de alta sensibilidad (PCR-Hs) (nivel de evidencia B).

- Lp(a), ApoA y ApoB (nivel de evidencia B).

- Homocisteína (nivel de evidencia B).

$-\mathrm{HbA}_{1 \mathrm{C}}$ (nivel de evidencia B).

- NT-BNP (nivel de evidencia B).

\section{Recomendaciones para análisis de sangre en la reevaluación habitual de los pacientes con angina estable crónica}

Clase IIa

- Perfil lipídico y glucosa en ayunas una vez al año (nivel de evidencia $\mathrm{C}$ ).

\section{Radiografía de tórax}

La radiografía de tórax (RT) se utiliza frecuentemente en la valoración de los pacientes con sospecha de enfermedad cardiaca. Sin embargo, en la angina estable la RT no ofrece información específica para el diagnóstico o la estratificación del riesgo. Sólo se solicitará esta prueba para los pacientes con sospecha de insuficiencia cardiaca, enfermedad valvular o enfermedad pulmonar. Se ha relacionado con el pronóstico la cardiomegalia, la congestión pulmonar, el crecimiento auricular y las calcificaciones cardiacas.
Recomendaciones para la radiografía torácica en la valoración del diagnóstico inicial de la angina

Clase I

- RT en pacientes con sospecha de insuficiencia cardiaca (nivel de evidencia $\mathrm{C}$ ).

- RT en pacientes con evidencia clínica de enfermedad pulmonar significativa (nivel de evidencia B).

\section{PRUEBAS CARDIACAS NO INVASIVAS}

En este apartado se describe los estudios utilizados en la valoración de la angina y se presenta las recomendaciones relativas al diagnóstico y la valoración de la eficacia del tratamiento, mientras que se presenta en el apartado siguiente las recomendaciones relativas a la estratificación del riesgo. Debido a que disponemos de pocos estudios aleatorizados que evalúen los resultados de las pruebas diagnósticas, la evidencia disponible ha sido clasificada de acuerdo con los datos recogidos en estudios no aleatorizados o al metaanálisis de éstos.

\section{ECG en reposo}

En todos los pacientes con sospecha de angina de pecho basada en los síntomas, se realizará un ECG en reposo (12 derivaciones). Es preciso señalar que un ECG normal en reposo es bastante frecuente, incluso en pacientes con angina severa, y no excluye el diagnóstico de isquemia. El ECG en reposo puede mostrar signos de cardiopatía isquémica, como un infarto de miocardio previo o alteraciones de la repolarización. El ECG es útil en el diagnóstico diferencial si se realiza durante un episodio de angina, porque permite la detección de cambios dinámicos en el segmento ST y también permite identificar signos de enfermedad pericárdica. El ECG realizado durante el episodio anginoso es especialmente útil en caso de sospecha de vasoespasmo. También puede mostrar otras anomalías, como hipertrofia del ventrículo izquierdo, bloqueo completo de rama izquierda, preexcitación, arritmias o defectos de conducción. Esta información puede ayudar a identificar los mecanismos desencadenantes del dolor torácico, seleccionar las pruebas diagnósticas que se debe realizar y establecer el tratamiento adecuado a cada paciente. El ECG en reposo tiene también un papel importante en la estratificación del riesgo, como se describe más adelante. No existe suficiente evidencia para recomendar la repetición sistemática del ECG en reposo a intervalos frecuentes, excepto cuando sea posible obtener un ECG durante un episodio anginoso o si se ha observado cambios en la clase funcional. 
Recomendaciones para la realización de un ECG en reposo en la valoración del diagnóstico inicial de angina

\author{
Clase I (en todos los pacientes) \\ - ECG en reposo sin angina (nivel de evidencia C). \\ - ECG en reposo durante un episodio de angina (si \\ fuera posible) (nivel de evidencia B).
}

\section{Recomendaciones para la realización de un ECG en reposo en la reevaluación habitual de pacientes con angina estable crónica}

\author{
Clase IIb \\ - ECG periódico habitual en ausencia de cambios \\ clínicos (nivel de evidencia C).
}

\section{ECG de esfuerzo}

El ECG de esfuerzo es más sensible y específico que el ECG de reposo para detectar isquemia miocárdica y, según criterios de coste y disponibilidad, es la prueba de elección para identificar la isquemia inducible en la mayoría de los pacientes con sospecha de angina estable. Existen numerosos informes y metaanálisis sobre el ECG de esfuerzo en el diagnóstico de la enfermedad coronaria ${ }^{26-29}$. Utilizando la depresión del segmento ST durante el ejercicio para definir la positividad de la prueba, se ha demostrado una sensibilidad y una especificidad en la detección de la enfermedad coronaria significativa que varía entre el 23 y el $100 \%$ (media, 68\%) y entre el 17 y el $100 \%$ (media, $77 \%$ ), respectivamente. La mayoría de los informes procede de estudios en los que la población estudiada no presentaba anomalías importantes en el ECG basal ni estaba recibiendo tratamiento antianginoso o se le había retirado dicho tratamiento al objeto de realizar la prueba. El ECG de esfuerzo no ofrece valor diagnóstico en presencia de bloqueo completo de rama izquierda, marcapasos o síndrome de Wolff-Parkinson-White (WPW); en estos casos, no se puede interpretar los cambios en el ECG. Además, los resultados falsos positivos son más frecuentes en pacientes con un ECG anormal en reposo e hipertrofia del ventrículo izquierdo, desequilibrio electrolítico, anomalías en la conducción intraventricular y tratamiento con digital. El ECG de esfuerzo es menos sensible y específico en mujeres ${ }^{30}$.

La interpretacion de los hallazgos del ECG de esfuerzo requiere el método bayesiano para el diagnóstico. En ese método, la estimación pretest de la enfermedad por el médico se combina con los resultados de las pruebas diagnósticas para generar posteriormente una serie de probabilidades de la enfermedad individualizadas para cada paciente. La probabilidad antes de la prueba está influida por la prevalencia de la enfermedad en la población estudiada y por las caracte- rísticas clínicas del paciente ${ }^{31}$. Por tanto, en la detección de la enfermedad coronaria, la probabilidad antes de la prueba está influida, en primer lugar, por la edad y el sexo, y luego se modifica por la naturaleza de los síntomas del paciente individual, antes de que se utilicen los resultados de la prueba de esfuerzo para determinar las probabilidades posteriores a la prueba.

Al valorar el significado de la prueba, se debe tener en consideración no sólo los cambios electrocardiográficos, sino también la carga de trabajo, el aumento de la frecuencia cardiaca y la respuesta de la presión arterial, la recuperación de la frecuencia cardiaca después del ejercicio y el contexto clínico ${ }^{32}$. Se ha propuesto que la evaluación de los cambios del segmento ST en relación con la frecuencia cardiaca mejora la fiabilidad del diagnóstico ${ }^{33}$, aunque este extremo quizá no se pueda aplicar a poblaciones sintomáticas ${ }^{34}$.

La prueba de esfuerzo sólo se realizará tras una meticulosa evaluación clínica de los síntomas y una exploración física que incluya un ECG en reposo. La ergometría no se realizará de forma sistemática en pacientes con un diagnóstico de estenosis aórtica severa o miocardiopatía hipertrófica, aunque en pacientes seleccionados se podrá realizar bajo estrecha vigilancia para valorar la capacidad funcional.

En caso de que sea necesario interrumpir la prueba, se registrarán las razones que lo justifican y los síntomas y su gravedad en ese momento. Se evaluará el momento de aparición de los cambios electrocardiográficos y/o los síntomas, la duración total de la prueba de esfuerzo, la presión arterial y la respuesta de la frecuencia cardiaca, el alcance y la severidad de los cambios en el ECG, la tasa de recuperación de los cambios electrocardiográficos después del ejercicio y la frecuencia cardiaca. Cuando se repita la prueba de esfuerzo, se utilizará la escala de Borg u otro método similar que permita cuantificar y comparar los síntomas ${ }^{35}$. Las razones para interrumpir una prueba de esfuerzo aparecen listadas en la tabla 3.

En algunos pacientes la ergometría puede no ser concluyente, por ejemplo, si no se alcanza como mínimo el $85 \%$ de la frecuencia cardiaca máxima en ausencia de síntomas o isquemia, si el ejercicio está limitado por problemas ortopédicos u otras causas no cardiacas o si los cambios en el ECG son ambiguos. Tras una prueba de esfuerzo no concluyente, se realizarán otras pruebas diagnósticas no invasivas, excepto en el caso de pacientes con una probabilidad pretest de la enfermedad muy baja (probabilidad $<10 \%$ ). Además, pruebas «normales» de pacientes en tratamiento antiisquémico no excluyen la posibilidad de enfermedad coronaria significativa ${ }^{36}$. Si se realiza con finalidad diagnóstica, los pacientes no deben recibir fármacos antiisquémicos, aunque esto no siempre es posible o no se considere seguro.

La prueba de esfuerzo puede se útil también para evaluar la eficacia del tratamiento tras el control de la 
angina mediante terapia farmacológica o mediante revascularización y para prescribir ejercicio tras el control de los síntomas. No obstante, no se ha evaluado formalmente el efecto de las habituales pruebas de esfuerzo periódicas en los resultados de los pacientes.

\section{Recomendaciones para el ECG de esfuerzo en la valoración diagnóstica inicial de la angina}

\section{Clase I}

- Pacientes con síntomas de angina y probabilidad pretest intermedia-alta de tener la enfermedad, según la edad, el sexo y los síntomas, excepto pacientes incapacitados para el ejercicio o con cambios electrocardiográficos no evaluables (nivel de evidencia B).

\section{Clase IIb}

- Pacientes con una depresión ST $\geq 1 \mathrm{~mm}$ en el ECG en reposo o en tratamiento con digoxina (nivel de evidencia B).

- Pacientes con baja probabilidad pretest $(<10 \%)$ de enfermedad coronaria, según la edad, el sexo y los síntomas (nivel de evidencia B).

\section{Recomendaciones para el ECG de esfuerzo en la reevaluación habitual de pacientes con angina estable crónica}

\section{Clase IIb}

- Prueba de esfuerzo periódica habitual en ausencia de cambios clínicos (nivel de evidencia C).

\section{Prueba de esfuerzo combinada con técnicas de imagen}

Hasta la fecha, las técnicas de imagen mejor establecidas son la ecocardiografía de estrés y la tomogammagrafía de perfusión miocárdica. Ambas técnicas se pueden utilizar en combinación con la ergometría convencional o con estrés farmacológico, y su uso diagnóstico y pronóstico ha sido estudiado en numerosos ensayos clínicos. Entre las técnicas de imagen más modernas, se encuentra la obtención de imágenes por resonancia magnética (RM) que, por limitaciones logísticas, se suele realizar con estrés farmacológico en lugar de estrés por esfuerzo.

Las técnicas de imagen con estrés presentan varias ventajas sobre la ergometría de esfuerzo convencional; entre otras, una mayor capacidad diagnóstica (tabla 4) para la detección de la enfermedad coronaria obstructiva, la capacidad de cuantificar y localizar zonas de isquemia, la capacidad de ofrecer información diagnóstica en presencia de anomalías en el ECG en reposo y la posibilidad de realizar la prueba cuando el paciente presenta limitaciones físicas. Por lo general, se prefiere las técnicas de imagen para los pacientes con una intervención coronaria percutánea (ICP) previa o

\section{TABLA 3. Motivos para interrumpir la prueba} de esfuerzo

La prueba de esfuerzo debe interrumpirse por uno de los siguientes motivos:

1. Limitación sintomática, como dolor, fatiga, disnea y claudicación

2. Combinación de síntomas como el dolor con cambios significativos del segmento ST

3. Razones de seguridad como:

a) Marcada depresión del segmento ST (una depresión $>2 \mathrm{~mm}$ del segmento ST es una indicación relativa para la interrupción de la prueba y una depresión ST $\geq 4$ mm es una indicación absoluta)

b) Elevación ST de aproximadamente $1 \mathrm{~mm}$

c) Arritmia significativa

d) Caída mantenida de la presión sistólica $>10 \mathrm{mmHg}$

e) Hipertensión marcada (presión sistólica $>250$ mmHg 0 presión diastólica $>115 \mathrm{mmHg}$ )

4. A discreción del médico, se podrá terminar la prueba en caso de alcanzarse la frecuencia cardiaca máxima prevista en pacientes con una excelente tolerancia al ejercicio que no están cansados

TABLA 4. Resumen de las características de las pruebas utilizadas en el diagnóstico de la angina estable

\begin{tabular}{lcc}
\hline & \multicolumn{2}{c}{ Diagnóstico de cardiopatía isquémica } \\
\cline { 2 - 3 } & Sensibilidad, \% & Especificidad, \% \\
\hline ECG de esfuerzo & 68 & 77 \\
Ecografía de esfuerzo & $80-85$ & $84-86$ \\
$\begin{array}{l}\text { Perfusión miocárdica de esfuerzo } \\
\text { Ecografía de estrés }\end{array}$ & $85-90$ & $70-75$ \\
$\quad$ con dobutamina & $40-100$ & $62-100$ \\
$\begin{array}{l}\text { Ecografía de estrés } \\
\quad \text { con vasodilatadores }\end{array}$ & $56-92$ & $87-100$ \\
$\begin{array}{c}\text { Perfusión miocárdica de esfuerzo } \\
\quad \text { con vasodilatores }\end{array}$ & $83-94$ & $64-90$ \\
\hline
\end{tabular}

con bypass aortocoronario (CABG) debido a su superioridad para localizar la isquemia.

En pacientes con estenosis coronarias intermedias confirmadas mediante angiografía, la evidencia de isquemia en el territorio anatómico correspondiente es predictora de futuros eventos, mientras que una prueba negativa puede servir para identificar a los pacientes de bajo riesgo cardiaco y, por tanto, para tranquilizarlos.

\section{Ecocardiografía de estrés}

La ecocardiografía de estrés se ha desarrollado como una técnica alternativa a la ergometría «clásica» y como una técnica adicional que permite establecer la presencia o la localización y el alcance de la isquemia miocárdica durante el ejercicio. Tras reali- 
zar un ecocardiograma en reposo, se realiza la ecocardiografía de estrés, generalmente con un ergómetro de bicicleta, limitada por los síntomas, para obtener, siempre que sea posible, imágenes en las distintas fases del ejercicio y en el momento de máximo esfuerzo. La prueba puede presentar dificultades técnicas $^{37}$. La sensibilidad y la especificidad para la detección de enfermedad coronaria significativa varían entre el 53 y el $93 \%$ y entre el 70 y el 100\%, respectivamente. Dependiendo de los metaanálisis consultados, la ecocardiografía de estrés ofrece unas sensibilidad y especificidad del $80-85 \%$ y el $84-86 \%$, respectivamente ${ }^{38-41}$. Los nuevos avances tecnológicos mejoran la delimitación del borde endocárdico con el uso de agentes de contraste que facilitan la identificación de anomalías en la contractilidad miocárdica regional y con el uso de agentes inyectables para visualizar la perfusión miocárdica ${ }^{42}$.

Los avances desarrollados en las técnicas de imagen con Doppler tisular y strain rate son muy prometedores.

Las imágenes con Doppler tisular permiten la cuantificación de la contractilidad miocárdica regional (velocidad), mientras que las técnicas de strain y strain rate ayudan a determinar deformaciones regionales, definida strain (deformación) como la diferencia de velocidades entre regiones adyacentes y strain rate (tasa de deformación) como la diferencia por unidad de longitud. Las técnicas de imagen con Doppler tisular y strain rate han mejorado el poder diagnóstico de la ecocardiografía de estrés ${ }^{43} \mathrm{y}$, por lo tanto, la capacidad de la ecocardiografía para detectar la isquemia en una fase más temprana de la «cascada isquémica». Debido a la naturaleza cuantitativa de estas técnicas, se reducen la variabilidad y la subjetividad del interobservador a la hora de interpretar los resultados. Por todo ello se espera que las técnicas de imagen con Doppler tisular y strain rate complementen las técnicas ecocardiográficas actuales para la detección de la isquemia mejorando la precisión y la reproducibilidad de la ecocardiografía de estrés en un ámbito clínico más amplio. También hay alguna evidencia de que la imagen con Doppler tisular puede mejorar la utilidad pronóstica de la ecocardiografía de esfuerzo ${ }^{44}$.

\section{Prueba de estrés con tomogammagrafía de perfusión miocárdica}

Los radiofármacos más frecuentemente utilizados como trazadores son el talio-201 y el tecnecio-99m, empleados con tomografía computarizada por emisión monofotónica (SPECT) combinada con una prueba de esfuerzo (limitada por los síntomas) en ergómetro de bicicleta o en cinta sin fin. Aunque inicialmente se utilizaron imágenes planares en múltiples proyecciones, esta técnica ha sido ampliamente sustituida por la
SPECT, ya que ofrece una capacidad de localización y cuantificación de la isquemia y una calidad de imagen superiores. La gammagrafía de perfusión con SPECT se realiza para obtener imágnes regionales del trazador que reflejan el flujo sanguíneo miocárdico regional relativo. En esta técnica, la hipoperfusión miocárdica está caracterizada por la escasa presencia del trazador durante el estrés, comparada con la captación en reposo. El aumento del agente de contraste de perfusión miocárdica en los campos pulmonares indica que el paciente tiene una cardiopatía isquémica severa y extensa. La SPECT proporciona un método de predicción de la cardiopatía isquémica más sensible y específico que la electrocardiografía de esfuerzo. La tomografía de estrés tiene una sensibilidad del 70 al $98 \%$ y una especificidad del 40 al $90 \%$, con valores medios del $85-90 \%$ y del $70-75 \%$, dependiendo del metaanálisis ${ }^{40,41,45,46}$ y sin realizar ajustes al sesgo en la selección de pacientes introducido por los médicos solicitantes de la prueba.

\section{Prueba de estrés farmacológico con técnicas de imagen}

Aunque siempre que sea posible se debería utilizar técnicas de imagen de estrés, ya que permiten reproducir mejor la isquemia y una valoración más adecuada de los síntomas, la prueba de estrés farmacológico también es útil. Combinada con la tomografía de perfusión o con la ecocardiografía, la prueba de estrés farmacológico está indicada en pacientes con limitaciones para el ejercicio físico y también se puede considerarla una alternativa a la prueba de esfuerzo. La prueba se puede realizar de 2 formas: a) con una infusión de un fármaco simpaticomimético de acción rápida, como la dobutamina, siguiendo un protocolo de incremento gradual de la dosis para incrementar el consumo de oxígeno del miocardio y simular el efecto del ejercicio físico, y b) con una infusión de vasodilatadores coronarios (como adenosina o dipiridamol), que permite observar la diferencia entre las regiones que reciben riego sanguíneo de arterias sanas, donde se observa un aumento de la perfusión, y las regiones perfundidas por arterias con una estenosis hemodinámicamente significativa, donde la perfusión aumenta discretamente o incluso disminuye (fenómeno de robo).

Por lo general, la prueba de estrés farmacológico es segura y bien tolerada por los pacientes. Se tomarán las debidas precauciones para que los pacientes que reciban vasodilatadores (adenosina o dipiridamol) no estén recibiendo tratamiento antiplaquetario (u otro) con dipiridamol y que se evite la cafeína en las 12-24 h previas, ya que interfiere con el metabolismo de estos fármacos. La adenosina puede precipitar un episodio de broncospasmo en pacientes asmáticos $\mathrm{y}$, en estos casos, se administra dobutamina como agente alternativo. El poder diagnóstico de la ecocardiografía o de la 
prueba de perfusión con estrés farmacológico es similar al de otras técnicas de imagen de estrés. La ecocardiografía de estrés con dobutamina o con vasodilatadores registra una sensibilidad y una especificidad del 40 al $100 \%$ y del 62 al $100 \%$ y del 56 al $92 \%$ y del 87 al $100 \%$, respectivamente ${ }^{39,40}$. La sensibilidad y especificidad para la detección de la enfermedad coronaria con SPECT y adenosina varían del 83 al 94\% y del 64 al $90 \%$, respectivamente ${ }^{40}$.

En términos generales, tanto la ecocardiografía de estrés como la tomografía de perfusión, mediante estrés bien por ejercicio, bien farmacológico, tiene aplicaciones similares. La elección de la técnica depende básicamente de las instalaciones del centro y de la experiencia del grupo. Las ventajas de la ecocardiografía de estrés sobre la tomografía de perfusión son una mayor especificidad, la posibilidad de una evaluación más extensa de la anatomía y la función cardiacas y mayor disponibilidad a menor coste, además de no necesitar radiación. Sin embargo, el 5-10\% de los pacientes no tienen una ventana ecocardiográfica adecuada. El desarrollo de técnicas ecocardiográficas cuantitativas, como el Doppler tisular, supone un paso adelante en la mejora del acuerdo interobservadores y en la fiabilidad de la ecografía de estrés.

Aunque la evidencia disponible avala la superioridad de las técnicas de imagen de estrés comparadas con el ECG de esfuerzo en cuanto a su poder diagnóstico, el coste de la utilización de las técnicas de imagen como primer estudio en todos los pacientes ingresados es muy elevado. No obstante, las técnicas de imagen de estrés tienen un papel importante en la evaluación de pacientes con baja probabilidad de la enfermedad pretest, especialmente si son mujeres ${ }^{47,48}$, cuando la prueba de esfuerzo no es concluyente, en la selección de lesiones para revascularización y en la evaluación de la isquemia tras la revascularización ${ }^{49,50}$.

La descripción de los métodos de detección de viabilidad miocárdica escapa al alcance de esta guía, pero el grupo de trabajo de la ESC ha publicado con anterioridad un informe sobre miocardio hibernado ${ }^{51}$. Por último, aunque durante el seguimiento las técnicas de imagen de estrés permitan una evaluación adecuada de cambios en la localización y la intensidad de la isquemia y de la respuesta al tratamiento, no se recomienda la realización periódica sistemática de estos estudios si no se observa cambios en el estado clínico del paciente.

\section{Recomendaciones para el uso de las pruebas de estrés con técnicas de imagen (ecocardiografía o perfusión) en la valoración del diagnóstico inicial de la angina}

\section{Clase I}

- Pacientes con anomalías en el ECG en reposo, bloqueo completo de rama izquierda (BCRI), depre- sión del segmento ST > $1 \mathrm{~mm}$, marcapasos o síndrome de WPW que impiden la correcta interpretación de los cambios electrocardiográficos durante el ejercicio (nivel de evidencia $\mathrm{B}$ ).

- Pacientes con ECG de esfuerzo no concluyente pero con tolerancia razonable al ejercicio que no presentan alta probabilidad de enfermedad coronaria significativa y cuyo diagnóstico es dudoso (nivel de evidencia B).

\section{Clase IIa}

- Pacientes con revascularización previa (ICP o $\mathrm{CABG}$ ) en los que la localización de la isquemia es importante (nivel de evidencia B).

- Como prueba alternativa al ECG de esfuerzo en centros que dispongan de las instalaciones, el presupuesto y los recursos humanos adecuados (nivel de evidencia B).

- Como alternativa al ECG de esfuerzo en pacientes con baja probabilidad pretest de tener la enfermedad, como mujeres con dolor torácico atípico (nivel de evidencia B).

- Para valorar la severidad funcional de estenosis intermedias observadas en la coronariografía (nivel de evidencia $\mathrm{C}$ ).

- Para localizar la isquemia a la hora de decidir las opciones de revascularización en pacientes a los que se ha realizado una coronariografía (nivel de evidencia B).

\section{Recomendaciones para el uso de estrés farmacológico con técnicas de imagen (ecocardiografía o perfusión) en la valoración del diagnóstico inicial de la angina}

Las indicaciones de las clases I, IIa y IIb mencionadas anteriormente cuando el paciente es inacapaz de realizar ejercicio.

\section{Cardiorresonancia magnética de estrés}

La RM de estrés combinada con la infusión de dobutamina se puede utilizar para detectar anomalías en la contractilidad miocárdica causadas por isquemia o alteraciones en la perfusión. Se ha demostrado que, debido a una mejor calidad de imagen, esta técnica es superior a la ecocardiografía de estrés con dobutamina para detectar anomalías de la contractilidad miocárdi$\mathrm{ca}^{52}$. Aunque las aplicaciones clínicas de la RM de perfusión están todavía en fase de estudio, los resultados obtenidos hasta la fecha son muy buenos a la luz de los hallazgos en la coronariografía, la tomografía por emisión de positrones y la SPECT.

Un panel de expertos ha consensuado recientemente las indicaciones actuales de la RM y han establecido una recomendación de clase II para el estudio de la contractilidad miocárdica y la perfusión mediante RM 
(la clase II proporciona información clínicamente relevante que, por lo general, resulta de gran utilidad; se puede obtener información similar mediante otras técnicas; recomendación basada una literatura escasa $)^{53}$.

\section{Ecocardiografía en reposo}

La ecocardiografía bidimensional y por Doppler en reposo es útil para detectar o descartar la posibilidad de otras enfermedades, como las valvulopatías ${ }^{54}$ o la miocardiopatía hipertrófica ${ }^{55}$, como causa de los síntomas y para evaluar la función ventricular ${ }^{38}$. Con un propósito puramente diagnóstico, la ecocardiografía es útil en pacientes en los que se ha detectado soplos, en pacientes con cambios electrocardiográficos o una historia clínica compatible con miocardiopatía hipertrófica y en pacientes con infarto de miocardio previo y síntomas o signos de insuficiencia cardiaca. La RM puede ser útil también para definir anomalías cardiacas estructurales y para evaluar la función ventricular, aunque su uso habitual está limitado por su escasa disponibilidad.

Los últimos avances en Doppler tisular y strain rate han mejorado notablemente la posibilidad de estudio de la función diastólica, aunque las implicaciones clínicas de la disfunción diastólica aislada, en cuanto a tratamiento y pronóstico, están menos definidas ${ }^{56,57}$.

Aunque el rendimiento diagnóstico de la evaluación de la estructura y la función cardiacas en pacientes con angina se dirige fundamentalmente a determinados subgrupos, la valoración de la función ventricular es muy importante a la hora de estratificar el riesgo, donde la ecocardiografía (u otros métodos alternativos de estudio de la función ventricular) tiene una indicación más amplia.

\section{Recomendaciones para la ecocardiografía en la valoración del diagnóstico inicial de la angina}

Clase I

- Pacientes con auscultación anormal que indique valvulopatía o miocardiopatía hipertrófica (nivel de evidencia B).

- Pacientes con sospecha de insuficiencia cardiaca (nivel de evidencia B).

- Pacientes con infarto de miocardio previo (nivel de evidencia $\mathrm{B}$ ).

- Pacientes con BCRI, ondas Q u otros cambios patológicos significativos en el ECG, incluido el hemibloqueo anterior izquierdo (nivel de evidencia $\mathrm{C}$ ).

\section{Electrocardiografía ambulatoria}

La electrocardiografía ambulatoria (método de Holter) puede revelar evidencia de isquemia miocárdica durante las actividades «diarias» normales ${ }^{58}$, pero rara vez aporta más información diagnóstica o pronóstica de importancia que la prueba de esfuerzo en la angina estable crónica ${ }^{59,60}$. Sin embargo, la monitorización ambulatoria puede ser útil en los pacientes con sospecha de angina vasoespástica. Por último, en los pacientes con angina estable y sospecha de arritmias importantes, la monitorización con Holter es un buen método para diagnosticar las arritmias. No se recomienda la repetición sistemática del ECG ambulatorio para la evaluación de pacientes con angina estable crónica.

\section{Recomendaciones para la electrocardiografía ambulatoria en la valoración del diagnóstico inicial de la angina}

Clase I

- Angina con sospecha de arritmia (nivel de evidencia B).

\section{Clase IIa}

- Sospecha de angina vasoespástica (nivel de evidencia C).

\section{Técnicas no invasivas para la valoración de la calcificación y la anatomía coronarias}

\section{Tomografía computarizada}

La tomografía computarizada de haz de electrones (EBCT) y la tomografía multicorte (MDTC) son técnicas validadas en la detección y la cuantificación del grado de afección de la calcificación coronaria. La escala de Agatston ${ }^{61}$, la más utilizada, se basa en el área y la densidad de las placas calcificadas. Se utiliza para cuantificar el grado de calcificación coronaria, que se calcula mediante un software específico. En estudios basados en la población, la detección del calcio coronario puede identificar a los pacientes en más riesgo de enfermedad coronaria; sin embargo, la evaluación sistemática de la calcificación coronaria no está recomendada para la evaluación diagnóstica de los pacientes con angina estable $e^{62,63}$

Los tiempos de captación y la resolución de las imágenes para la EBCT y la MDCT se han acortado de tal forma que una coronariografía se puede realizar con una inyección intravenosa de contraste ${ }^{64}$. Comparando las dos técnicas, la MDCT es la más prometedora para la obtención no invasiva de imágenes de las arterias coronarias, ya que, según se deduce de diversos estudios preliminares, ofrece una excelente definición y la posibilidad de examinar las características de la pared arterial y la placa. Se ha registrado una sensibilidad y una especificidad de la angiografía por TC para la detección de enfermedad coronaria del 95 y el $98 \%$ respectivamente, utilizando equipos de 16 cortes $^{65}$. En los estudios que han utilizado detectores de 64 cortes, se ha informado de una sensibilidad y una especificidad del $90-94 \%$ y del $95-97 \%$, respectivamente, y, lo que es muy importante, un valor de predicción negativo del $93-99 \%{ }^{66,67}$. 
Una actitud conservadora con respecto a la angiografía por TC incluiría a los pacientes con una baja probabilidad pretest $(<10 \%)$ de enfermedad coronaria y una prueba no concluyente de capacidad funcional (ECG de esfuerzo o técnica de imagen de estrés).

\section{Recomendaciones para el uso de la angiografía por TC en la angina estable}

\section{Clase IIb}

- Pacientes con baja probabilidad pretest de enfermedad coronaria, con una prueba de esfuerzo (ECG o técnica de imagen) no concluyente (nivel de evidencia $\mathrm{C}$ ).

\section{Arteriografía por resonancia magnética}

$\mathrm{Al}$ igual que sucede con la TC, los avances en la tecnología de la RM permiten la realización de coronariografías mediante contraste y $\mathrm{RM}^{53}$. Sin embargo, hasta la fecha sólo se puede considerarla una valiosa herramienta de investigación y no se recomienda su uso en la práctica clínica habitual para el diagnóstico de la angina estable.

\section{TÉCNICAS INVASIVAS PARA LA EVALUACIÓN DE LA ANATOMÍA CORONARIA}

\section{Angiografía coronaria}

La angiografía coronaria forma parte de la batería de pruebas que se realizan para establecer el diagnóstico y determinar las opciones de tratamiento. Las pruebas no invasivas pueden establecer una posible enfermedad coronaria obstructiva con un grado de certeza aceptable y, tras una adecuada estratificación del riesgo, se determina la necesidad de realizar una angiografía coronaria con el objeto de establecer con más precisión la estratificación del riesgo. Sin embargo, la angiografía podría estar contraindicada por incapacidad o comorbilidad seria, y también puede ofrecer resultados no concluyentes. Tras una parada cardiaca con reanimación o una arritmia ventricular potencialmente mortal, el diagnóstico definitivo de presencia o ausencia de enfermedad coronaria es muy útil a la hora de tomar decisiones clínicas ${ }^{68,69}$. Además, las pruebas no invasivas no permiten valorar si es posible realizar una revascularización coronaria, que podría plantearse tanto para tratar los síntomas como para mejorar el pronóstico. La angiografía coronaria tiene un papel fundamental en la valoración de los pacientes con angina estable, ya que proporciona información anatómica fiable que permite identificar la presencia o ausencia de estenosis en la luz coronaria, definir las opciones terapéuticas (indicación de tratamiento médico o revascularización miocárdica) y determinar el pronóstico. La tasa combinada de complicaciones serias del cateterismo diagnóstico habitual es del 1-2\% y la tasa combinada de muerte, infarto de miocardio o accidente cerebral está en un $0,1-0,2 \%{ }^{70}$.

La coronariografía permite identificar el grado de obstrucción de la luz arterial; sin embargo, otras técnicas invasivas, como los ultrasonidos intravasculares (IVUS) o las mediciones fisiológicas intracoronarias, permiten una evaluación más completa de las lesiones intracoronarias. Los IVUS, la medición de la velocidad del flujo coronario (reserva coronaria vasodilatadora) o la presión arterial intracoronaria (reserva fraccional de flujo) pueden ser muy útiles en el manejo de los pacientes con estenosis de severidad intermedia en la angiografía u optimizar una intervención percutánea, aunque estas pruebas no son necesarias habitualmente en el estudio de la angina estable (consúltese el texto completo de la guía en: www.escardio.org).

\section{Recomendaciones para la angiografía coronaria en la determinación del diagnóstico en la angina estable}

Clase I

- Angina estable severa (clase 3 o mayor de la clasificación de la Canadian Cardiovascular Society), con una alta probabilidad pretest de enfermedad coronaria, especialmente si los síntomas no responden al tratamiento médico (nivel de evidencia B).

- Supervivientes de parada cardiaca (nivel de evidencia B).

- Pacientes con arritmias ventriculares severas (nivel de evidencia $\mathrm{C}$ ).

- Pacientes previamente sometidos a revascularización miocárdica (ICP, CABG) con recurrencia temprana de angina de pecho moderada o severa (nivel de evidencia C).

\section{Clase IIa}

- Pacientes con un diagnóstico no concluyente realizado mediante técnicas no invasivas o resultados conflictivos de diferentes pruebas no invasivas y riesgo intermedio o alto de enfermedad coronaria (nivel de evidencia $\mathrm{C}$ ).

- Pacientes con alto riesgo de reestenosis tras ICP, cuando la intervención haya sido realizada en un segmento de relevancia pronóstica (nivel de evidencia C).

\section{ESTRATIFICACIÓN DEL RIESGO}

El pronóstico a largo plazo de la angina estable es variable y las opciones de tratamiento se han ampliado considerablemente y abarcan desde el simple control de los síntomas a potentes (y normalmente caras) estrategias para mejorar el pronóstico. Cuando se discute sobre la estratificación del riesgo en la angina estable, por riesgo se entiende fundamentalmente el riesgo de muerte cardiovascular, aunque este término se utiliza frecuentemente de forma más amplia incorporando 
muerte cardiovascular e infarto de miocardio y, en algunos casos, incluso amplias combinaciones de complicaciones cardiovasculares. El proceso de estratificación del riesgo obedece a dos objetivos diferentes: por un lado, sirve para ofrecer una respuesta informada sobre el pronóstico a los propios pacientes, los empleados, las aseguradoras y los especialistas no cardiológicos cuando tienen que considerar opciones de tratamiento para otras enfermedades concurrentes y otras; y en segundo lugar, para decidir el tratamiento cardiológico adecuado.

En el caso de ciertas opciones de tratamiento, especialmente revascularización y/o terapia farmacológica intensiva, el beneficio pronóstico sólo es aparente en subgrupos de alto riesgo, con poco o ningún beneficio en pacientes con buen pronóstico. Esto obliga a identificar a los pacientes de alto riesgo, que se beneficiarán de un tratamiento más agresivo desde el inicio de la valoración de su angina.

Cuando se implementan guías de prevención primaria, se considera de alto riesgo una mortalidad cardiovascular $>5 \%$ a los 10 años $(>0,5 \% \text { por año })^{71}$. Sin embargo, para los pacientes con enfermedad cardiovascular establecida, los valores absolutos de lo que constituye alto y bajo riesgo no están claramente definidos $^{72,73}$. Este problema tiene relación con la dificultad de comparar sistemas de predicción entre distintos grupos de población, determinar la precisión de predicciones de riesgo individuales y hacer una síntesis de múltiples factores de riesgo (a menudo estudiados separadamente) en la predicción de riesgo de un individuo. Si consideramos además la continua evolución (en las últimas 4 o 5 décadas desde que se definió los primeros predictores de riesgo) de la percepción pública y profesional de lo que constituye alto y bajo riesgo, las razones para esta falta de definición no son fácilmente superables.

No obstante, mientras se espera el desarrollo de un modelo integral y transferible de predicción del riesgo, que incorpore todos los aspectos potenciales de la estratificación del riesgo, existe una alternativa pragmática basada en datos de los ensayos clínicos. Aunque es preciso reconocer el sesgo a la hora de interpretar y generalizar los datos clínicos, éstos ofrecen una estimación de los niveles de riesgo absoluto que se puede obtener con los tratamientos convencionales modernos, incluso en pacientes con enfermedad vascular demostrada. Por otra parte, esto facilita la estimación de lo que podría aceptarse como riesgo alto, bajo e intermedio en una situación clínica actual al objeto de determinar el umbral para la indicación de estudios invasivos o para la intensificación de la terapia farmacológica.

La tasa de muerte cardiovascular en el estudio $\mathrm{PEACE}^{74}$ fue $<1 \%$ anual, mientras que en los estudios con población de «alto riesgo», como el estudio MICRO-HOPE ${ }^{75}$ (diabéticos) y el estudio $\mathrm{IONA}^{76}$, la tasa anual de mortalidad cardiovascular fue $>2 \%$. Para el propósito de esta guía salvo que se indique lo contrario, si según un modelo de predicción validado se establece que un individuo con angina tiene un riesgo de mortalidad anual $>2 \%$, se lo considera de alto riesgo, mientras que se considera de bajo riesgo una mortalidad anual $<1 \%$ y de riesgo intermedio una del $1-2 \%$.

La valoración clínica, la respuesta a la prueba de estrés, la cuantificación de la función ventricular y el grado de cardiopatía isquémica son los 4 datos clave para la estratificación del riesgo de un paciente. Por lo general, la estratificación del riesgo sigue una estructura piramidal en la que el requisito básico para todos los pacientes es la evaluación clínica, y se continúa en la mayoría de los casos con estudios no invasivos de la isquemia y de la función ventricular y, por último, con angiografía coronaria en grupos de población seleccionados.

\section{Estratificación del riesgo mediante evaluación clínica}

La historia clínica y la exploración física pueden proporcionar importante información pronóstica. En este nivel de la estratificación del riesgo, la integración del estudio electrocardiográfico y los resultados de las pruebas de laboratorio descritas anteriormente permite modificar la estimación del riesgo. La diabetes, la hipertensión, el síndrome metabólico, el tabaquismo y los valores de CT elevados (sin tratar o elevados a pesar del tratamiento) se han mostrado predictores de resultado adverso en pacientes con angina estable o en otras poblaciones con enfermedad coronaria establecida. El aumento de la edad es un factor importante a tener en cuenta, así como el infarto de miocardio previo $^{77,78}$, los síntomas y signos de insuficiencia cardiaca $^{77-79}$ y el modo de aparición (episodio reciente o progresivo) y la severidad de la angina, especialmente si no responde al tratamiento ${ }^{80-82}$.

Aunque se ha demostrado que la angina típica es un factor significativo del pronóstico en pacientes sometidos a una angiografía coronaria, su relación con el pronóstico está mediada por su relación con el grado de enfermedad coronaria. El modo de aparición de la angina, su frecuencia y las anomalías en el ECG en reposo son predictores independientes de supervivencia y supervivencia libre de infarto de miocardio que, combinados en una escala simple (fig. 2), pueden predecir la evolución del paciente, especialmente durante el primer año tras la valoración. El efecto de la escala de la angina en el pronóstico no es útil después de 3 años y es mayor cuando se mantiene la función ventricular $^{72,80}$.

La exploración física también puede ayudar a determinar el riesgo. La presencia de enfermedad vascular periférica (de miembros inferiores o carotídea) identi- 
Escala $=$ curso de la angina $\times(1+$ frecuencia $)+$ anomalías en el segmento ST/T

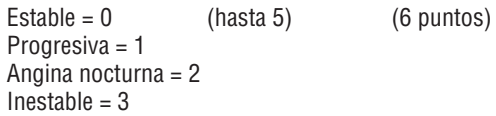

Fig. 2. Escala pronóstica de la angina. El modelo de recurrencia de la angina ${ }^{80}$ puede ser utilizado para estimar el pronóstico.

fica a los pacientes con mayor riesgo de eventos cardiovasculares tras la angina estable. Además, los signos relacionados con la insuficiencia cardiaca (que reflejan la función ventricular izquierda) conllevan un pronóstico adverso.

Los pacientes con angina estable que presentan anomalías en el ECG en reposo: evidencia de infarto de miocardio previo, BCRI, hemibloqueo anterior izquierdo, hipertrofia ventricular izquierda, bloqueo auriculoventricular de segundo o tercer grado o fibrilación auricular (FA) tienen mayor riesgo de futuros eventos cardiovasculares que los pacientes con un ECG normal. Es posible que en una población no seleccionada con angina estable el riesgo basal sea menor que en los estudios citados, teniendo en cuenta que la mayoría de esos estudios se realizaron con pacientes referidos a evaluación angiográfica.

\section{Recomendaciones para la estratificación del riesgo en la angina estable mediante la evaluación clínica que incluya ECG y pruebas de laboratorio}

\section{Clase I}

- Historia clínica detallada y exploración física que incluya el IMC y/o el perímetro de la cintura en todos los pacientes, descripción completa de los síntomas, cuantificación de la afección funcional, historia médica y perfil de riesgo cardiovascular (nivel de evidencia B).

- ECG en reposo en todos los pacientes (nivel de evidencia B).

\section{Estratificación del riesgo mediante la prueba de esfuerzo}

Las pruebas de esfuerzo se pueden realizar mediante ejercicio o mediante estrés farmacológico, con o sin técnicas de imagen. La información pronóstica obtenida en las pruebas de esfuerzo está relacionada con la detección de la isquemia no sólo entendida como una respuesta binaria sencilla, sino también con el umbral isquémico, la extensión y la severidad de la isquemia (por técnicas de imagen) y la capacidad funcional (prueba de esfuerzo). Por sí sola, la prueba de esfuerzo no es suficiente para valorar el riesgo de futuros eventos cardiovasculares. La estratificación del riesgo mediante la prueba de esfuerzo debe formar parte de un proceso que incluya los datos obtenidos en la evaluación clínica y no se debe realizarla de forma aislada. La prueba de esfuerzo se efectúa para obtener información adicional sobre el estado de riesgo del paciente. Los pacientes sintomáticos con sospecha o confirmación de cardiopatía isquémica deben ser sometidos a una prueba de esfuerzo para valorar el riesgo de futuros eventos cardiacos, excepto cuando esté indicado un cateterismo cardiaco urgente.

No obstante, hasta la fecha no se han publicado estudios aleatorizados sobre la prueba de esfuerzo y, por tanto, la evidencia disponible está basada solamente en estudios observacionales. La elección de una prueba de esfuerzo inicial se basará en el ECG en reposo del paciente, su capacidad física para hacer ejercicio, la experiencia del centro y la disponibilidad de los recursos.

\section{Electrocardiografía de esfuerzo}

El ECG de esfuerzo ha sido ampliamente validado como una importante herramienta para la estratificación del riesgo en pacientes sintomáticos con sospecha o confirmación de enfermedad coronaria. Los marcadores pronósticos de la prueba de esfuerzo incluyen la capacidad de ejercicio y la isquemia inducida por el ejercicio (clínica y electrocardiográfica). La capacidad máxima de ejercicio es un marcador pronóstico consistente, que está influida en parte por el grado de disfunción ventricular en reposo y por la cantidad de disfunción del ventrículo izquierdo inducida por el ejercicio $^{29,83}$. Sin embargo, la capacidad de ejercicio también está afectada por la edad, la condición física general, las comorbilidades y el estado psicológico. La capacidad de ejercicio se puede estimar a partir de la duración máxima del ejercicio, el nivel máximo de MET alcanzado, la máxima carga de trabajo en vatios, la frecuencia cardiaca máxima y el doble producto (frecuencia $\times$ presión). La variable específica utilizada para medir la capacidad de esfuerzo tiene menos importancia que la inclusión de este marcador en la valoración. En pacientes con cardiopatía isquémica conocida y una función ventricular izquierda normal o ligeramente afectada, la supervivencia a los 5 años es mayor que en los pacientes con más tolerancia al ejercicio $^{29,77,84-86}$.

En diversos ensayos clínicos se ha intentado incorporar múltiples variables de ejercicio en una escala de pronóstico. El valor clínico de la prueba de esfuerzo mejora considerablemente con un análisis multivariable que incluya distintas variables de ejercicio en un paciente dado, como la combinación de frecuencia cardiaca en ejercicio máximo, depresión del segmento ST, la presencia o ausencia de angina durante la prue- 


\begin{tabular}{|c|c|c|}
\hline \multicolumn{3}{|l|}{ Escala de Duke } \\
\hline Tiempo de ejercicio en mir & & $n$ \\
\hline Depresión ST en $\mathrm{mm} \times 5$ & & $-n$ \\
\hline Angina (no limitante $\times 4$ ) & & $-n$ \\
\hline Angina (limitante $\times 8$ ) & & $-n$ \\
\hline Riesgo & & talidad al año \\
\hline Bajo riesgo & $\geq 5$ & $0,25 \%$ \\
\hline Intermedio & de $4 a-10$ & $1,25 \%$ \\
\hline Alto & $\leq-11$ & $5,25 \%$ \\
\hline
\end{tabular}

Fig. 3. Escala de Duke ${ }^{88}$ para la cinta sin fin.

ba, la máxima carga de trabajo y la pendiente del segmento $\mathrm{ST}^{84,87-89}$.

La escala de Duke en cinta sin fin (DTS) es un método validado que combina la duración del ejercicio, la desviación del segmento ST y la aparición de angina durante el ejercicio para calcular el riesgo del paciente $^{84,88}$ (fig. 3). En la descripción inicial de esta escala realizada en una población con sospecha de cardiopatía isquémica, 2 de cada 3 pacientes con una escala indicativa de bajo riesgo tuvieron una tasa de supervivencia a los 4 años del 99\% (tasa media de mortalidad anual, $0,25 \%$ ), mientras que los pacientes clasificados de alto riesgo (4\%) tuvieron una tasa de supervivencia a los 4 años del 79\% (tasa media de mortalidad anual, 5\%). La combinación de parámetros clínicos y de ejercicio, con o sin el uso de escalas como la de Duke, ha demostrado ser un método efectivo para discriminar los grupos de alto y bajo riesgo en una población con enfermedad coronaria conocida o sospechada.

\section{Ecocardiografía de estrés}

La ecocardiografía de estrés es efectiva a la hora de estratificar a los pacientes de acuerdo con el riesgo de futuros eventos cardiovasculares ${ }^{41,90}$ y ofrece un excelente valor de predicción negativa ${ }^{91,92}$ con una tasa anual de eventos mayores (muerte o infarto de miocardio) $<0,5 \%$. El riesgo de futuros eventos varía con el número de anomalías en la contractilidad regional en reposo y con las anomalías de la contractilidad inducidas por la ecocardiografía de estrés, de modo que un mayor número de anomalías en reposo y mayor isquemia inducida tiene relación con mayor riesgo ${ }^{38}$. La identificación de la cohorte de alto riesgo permite planificar los estudios diagnósticos adecuados y/o la intervención.

\section{Gammagrafía de perfusión miocárdica de esfuerzo}

Las imágenes normales de perfusión miocárdica de esfuerzo son altamente predictivas de un pronóstico benigno. En varios ensayos clínicos que incluían a miles de pacientes, se observó que los resultados normales de una prueba de perfusión de esfuerzo estaban asociados a una tasa anual de muerte cardiaca e infarto de miocardio $<1 \%$, casi tan baja como la tasa de la población general. Las únicas excepciones corresponden a pacientes con imágenes normales de perfusión, con una valoración de alto riesgo en la ergometría o con disfunción ventricular izquierda severa en reposo $^{93}$.

Por el contrario, los hallazgos anormales en la gammagrafía de esfuerzo se asocian a cardiopatía isquémica severa y al desarrollo de eventos cardiacos. Los defectos de perfusión importantes, inducidos por estrés, los defectos en múltiples territorios coronarios, la dilatación isquémica transitoria del ventrículo izquierdo tras estrés y, en los pacientes estudiados con talio-201, la captación pulmonar aumentada tras el ejercicio o el estrés farmacológico son indicadores de mal pronósti$\mathrm{co}^{46,94}$

Las imágenes obtenidas con estrés por esfuerzo ofrecen más información pronóstica que las obtenidas con estrés farmacológico debido a que se obtiene más información sobre los síntomas, la tolerancia del ejercicio y la respuesta hemodinámica al ejercicio, que se suma a los datos obtenidos sólo por perfusión o ecocardiografía.

\section{Recomendaciones para la estratificación del riesgo según el ECG de esfuerzo en la angina estable en pacientes capacitados para el ejercicio}

\section{Clase I}

- Todos los pacientes sin anomalías significativas en el ECG en reposo que están siendo evaluados (nivel de evidencia B).

- Pacientes con enfermedad coronaria estable tras un cambio significativo en la intensidad de los síntomas (nivel de evidencia C).

\section{Clase IIa}

- Pacientes que han sido revascularizados y presentan un deterioro significativo del estado sintomático (nivel de evidencia B).

\section{Recomendaciones para la estratificación del riesgo según las técnicas de imagen de esfuerzo (perfusión o ecocardiografía) en la angina estable de pacientes capacitados para el ejercicio}

Clase I

- Pacientes con anomalías en el ECG en reposo, BCRI, depresión del segmento ST $>1 \mathrm{~mm}$, marcapasos o síndrome de WPW que impiden la correcta interpretación de los cambios del ECG durante el ejercicio (nivel de evidencia C). 
- Pacientes con un ECG de esfuerzo no concluyente, pero con una probabilidad intermedia o alta de tener la enfermedad (nivel de evidencia B).

\section{Clase IIa}

- Pacientes con un deterioro de los síntomas después de la revascularización (nivel de evidencia B).

- Como alternativa al ECG de esfuerzo en los centros que dispongan de instalaciones, presupuesto y recursos humanos adecuados (nivel de evidencia B).

\section{Recomendaciones para la estratificación del riesgo según las técnicas de imagen con estrés farmacológico (perfusión o ecocardiografía) en la angina estable (*)}

Clase I

- Pacientes incapacitados para el ejercicio.

El resto de las indicaciones de clase I y II son similares a las indicaciones para las técnicas de imagen de esfuerzo (perfusión o ecocardiografía) en la angina estable de pacientes capacitados para el ejercicio, pero en centros que no dispongan de técnicas de imagen con esfuerzo.

\section{Estratificación del riesgo mediante la función ventricular}

La función del ventrículo izquierdo es el predictor más poderoso de la supervivencia a largo plazo. En los pacientes con angina estable, al disminuir la fracción de eyección (FE) del ventrículo izquierdo (VI), aumenta la mortalidad. Una FE en reposo $<35 \%$ se relaciona con una tasa anual de mortalidad $>3 \% \%^{77,79,95,96}$. Los datos del seguimiento a largo plazo del registro CASS mostraron que el $72 \%$ de las muertes ocurrieron en el $38 \%$ de la población que tenía disfunción del VI o enfermedad coronaria severa. La tasa de supervivencia a los 12 años de los pacientes con fracciones de eyección $>50 \%$, del 35 $49 \%{ }^{96} \mathrm{y}<35 \%$ fueron del 73 , el 54 y el $21 \%$, respectivamente ( $\mathrm{p}<0,0001)$. Por otra parte, el pronóstico de los pacientes con un ECG normal y bajo riesgo clínico de cardiopatía isquémica es excelente ${ }^{82}$. Además la función ventricular ofre-ce información adicional a la de la anatomía coronaria.

Como se ha señalado anteriormente, la valoración clínica permite identificar a pacientes con insuficiencia cardiaca y, por tanto, con mayor riesgo de futuros eventos cardiovasculares. Sin embargo, la prevalencia

(*) La ecocardiografía con dobutamina aporta información pronóstica adicional sobre los pacientes con angina estable a quienes se ha estimado un riesgo bajo o intermedio de eventos coronarios mediante la historia clínica y la prueba de esfuerzo (Castillo-Moreno JA, Ramos-Martín JL, Molina-Laborda E, Florenciano-Sánchez R, Ortega-Bernal J. Ecocardiografía con dobutamina en pacientes con angina crónica estable y ergometría de riesgo bajo o intermedio: utilidad en la valoración del pronóstico a largo plazo. Rev Esp Cardiol. 2005;58:916-23). de la disfunción ventricular asintomática no es desdeñable ${ }^{97-99}$ y se ha valorado en, al menos, el doble de la prevalencia de la insuficiencia cardiaca, por lo que la cardiopatía isquémica es un importante factor de riesgo de que se desarrolle.

En el seguimiento a 2 años de una población de pacientes con angina estable, se demostró que las dimensiones ventriculares añaden información pronóstica de utilidad, que se suma a la de los resultados de la ergometría $^{100}$. En un estudio de pacientes hipertensos sin angina, el uso de la ecocardiografía para valorar la estructura y función ventricular tuvo relación con una reclasificación de los pacientes de riesgo bajo-intermedio a alto riesgo en el $37 \%$ de todos los pacientes ${ }^{101}$. La guía de la ESC para el manejo de la hipertensión recomienda la realización de un ecocardiograma a los pacientes hipertensos ${ }^{102}$. También requieren una atención especial los pacientes diabéticos con angina. En estos pacientes, la ecocardiografía tiene la ventaja de identificar la hipertrofia ventricular izquierda y las disfunciones diastólica y sistólica, que tienen mayor prevalencia en la población diabética. Por todo ello, es recomendable valorar la función ventricular para la estratificación del riesgo de los pacientes con angina estable y para la evaluación de la hipertrofia ventricular (por ecocardiografía o RM); además, la valoración de la función ventricular es particularmente pertinente en pacientes con hipertensión o diabetes. Para el resto de los pacientes, la elección de la prueba para determinar la función ventricular dependerá de las pruebas que se haya realizado o programado o del nivel de riesgo estimado por otros métodos. Por ejemplo, en un paciente al que se haya realizado una técnica de imagen con estrés, se puede estimar la función ventricular a partir de dicha prueba sin necesidad de realizar otros estudios; o en el caso de un paciente programado para angiografía coronaria por los resultados claramente positivos de la prueba de esfuerzo con baja carga de trabajo, en ausencia de infarto de miocardio previo u otras indicaciones para ecocardiografía, la función ventricular se puede estimar en el momento de la angiografía.

\section{Recomendaciones para la estratificación del riesgo mediante la evaluación ecocardiográfica de la función ventricular en la angina estable}

\section{Clase I}

- Ecocardiografía en reposo en pacientes con infarto de miocardio previo, síntomas o signos de insuficiencia cardiaca o anomalías en el ECG en reposo (nivel de evidencia B).

- Ecocardiografía en reposo en pacientes con hipertensión (nivel de evidencia B).

- Ecocardiografía en reposo en pacientes con diabetes (nivel de evidencia C). 
Clase IIa

- Ecocardiografía en reposo en pacientes con un ECG normal en reposo, sin infarto de miocardio previo, en los que no está indicada la angiografía coronaria (nivel de evidencia $\mathrm{C}$ ).

\section{Estratificación del riesgo mediante angiografía coronaria}

A pesar de las conocidas limitaciones de la angiografía coronaria para identificar placas vulnerables que puedan originar eventos coronarios agudos, se ha demostrado que la extensión y la severidad de la obstrucción de la luz del vaso y la localización de la enfermedad coronaria, determinadas mediante angiografía, son importantes indicadores del pronóstico en pacientes con angina ${ }^{79,95,103,104}$.

Se han utilizado diferentes índices pronósticos para relacionar la severidad de la enfermedad con el riesgo de eventos cardiacos ulteriores; el más simple y utilizado es la clasificación de la cardiopatía isquémica en enfermedad de un vaso, dos vasos, tres vasos o tronco común izquierdo. En el registro CASS de pacientes con tratamiento farmacológico, la supervivencia a 12 años de los pacientes con arterias coronarias normales fue del $91 \%$, comparado con el $74 \%$ de los pacientes con enfermedad de un vaso, el $59 \%$ de los pacientes con enfermedad de dos vasos y el $50 \%$ de los pacientes con enfermedad de tres vasos $(\mathrm{p}<0,001)^{96}$. Los pacientes con estenosis severa del tronco común izquierdo tienen un mal pronóstico cuando sólo reciben tratamiento farmacológico. La estenosis proximal severa de la descendente anterior también reduce significativamente la tasa de supervivencia. En la enfermedad de tres vasos y estenosis proximal de la descendente anterior $>95 \%$, se ha registrado una tasa de supervivencia a los 5 años del 54\%, comparada con el $79 \%$ en la enfermedad de tres vasos sin estenosis en la descendente anterior ${ }^{104}$.

Cuando se utilizan adecuadamente, las pruebas no invasivas tienen un aceptable valor de predicción de eventos adversos. Esto suele ser cierto cuando hay baja probabilidad (pretest) de cardiopatía isquémica severa. Si la tasa anual de mortalidad cardiovascular estimada es $\leq 1 \%$, la indicación de angiografía coronaria para identificar a pacientes cuyo pronóstico puede ser mejorado probablemente sea inadecuada. Sin embargo, sí está indicada para los pacientes en los que se estima una tasa de mortalidad cardiovascular $>2 \%$. La decisión de realizar una coronariografía en los pacientes del grupo de riesgo intermedio (tasa anual de mortalidad entre el 1 y el $2 \%$ ) se tomará con base en diversos factores, como los síntomas, la clase funcional, el estilo de vida, la ocupación, las comorbilidades y la respuesta a la terapia inicial.

Debido al creciente interés público y de los medios de comunicación en los avances de la tecnología médi- ca y al acceso generalizado a internet y otras fuentes de información, con frecuencia los pacientes están bastante informados sobre las pruebas y las opciones de tratamiento para su enfermedad. El deber del médico es informar al paciente sobre los riesgos y los beneficios potenciales, o la ausencia de tales, para que el paciente tome una decisión adecuada. Algunos pacientes prefieren el tratamiento médico a una intervención o dudan del diagnóstico a pesar de la evidencia que se les presenta. No se debe realizar angiografía coronaria a pacientes con angina que rechazan los procedimientos invasivos, prefieren evitar la revascularización o no son candidatos a ICP o CABG o en los que los hallazgos en la coronariografía no contribuirían a mejorar su calidad de vida.

\section{Recomendaciones para la estratificación de riesgo mediante angiografía coronaria en pacientes con angina estable}

\section{Clase I}

- Pacientes considerados de alto riesgo de resultados adversos por las pruebas no invasivas aunque presenten síntomas leves o moderados de angina (nivel de evidencia B).

- Angina estable severa (clase 3 de la clasificación de la Canadian Cardiovascular Society), especialmente cuando los síntomas no responden adecuadamente a tratamiento médico (nivel de evidencia B).

- Angina estable en pacientes considerados para cirugía mayor no cardiaca, especialmente cirugía vascular (reparación de aneurisma de aorta, bypass femoral, endarterectomía carotídea), con un perfil de riesgo intermedio o alto en los estudios no invasivos (nivel de evidencia B).

\section{Clase IIa}

- Pacientes con diagnóstico no concluyente o resultados conflictivos en los estudios no invasivos (nivel de evidencia $\mathrm{C}$ ).

- Pacientes con alto riesgo de reestenosis tras una ICP, si ésta ha sido realizada en una zona con impacto en el pronóstico (nivel de evidencia $\mathrm{C}$ ).

En las tablas 5 y 6 se presenta un resumen de las recomendaciones para el uso habitual de los estudios diagnósticos en la evaluación de la angina estable, con los correspondientes niveles de evidencia relacionados con el diagnóstico y el pronóstico.

\section{CONSIDERACIONES DIAGNÓSTICAS ESPECIALES: ANGINA CON ARTERIAS CORONARIAS «NORMALES»}

Un considerable número de pacientes, especialmente mujeres, que son sometidos a una angiografía coro- 
TABLA 5. Resumen de las recomendaciones para la realización de las habituales pruebas no invasivas en la evaluación de la angina estable

\begin{tabular}{|c|c|c|c|c|}
\hline \multirow{2}{*}{ Test } & \multicolumn{2}{|c|}{ Para el diagnóstico } & \multicolumn{2}{|c|}{ Para el pronóstico } \\
\hline & $\begin{array}{l}\text { Grado de } \\
\text { recomendación }\end{array}$ & $\begin{array}{l}\text { Nivel de } \\
\text { evidencia }\end{array}$ & $\begin{array}{l}\text { Grado de } \\
\text { recomendación }\end{array}$ & $\begin{array}{l}\text { Nivel de } \\
\text { evidencia }\end{array}$ \\
\hline \multicolumn{5}{|l|}{ Pruebas de laboratorio } \\
\hline Hemograma completo, creatinina & I & C & I & B \\
\hline Glucosa en ayunas & I & $\mathrm{B}$ & i & B \\
\hline Perfil lipídico en ayunas & i & $\mathrm{B}$ & i & B \\
\hline $\begin{array}{l}\text { Proteína C reactiva de alta sensibilidad, homocisteína, Lp(a), ApoA, ApoB } \\
\text { ECG }\end{array}$ & Ilb & B & Ilb & B \\
\hline Evaluación inicial & I & c & । & B \\
\hline Durante el episodio de angina & i & $\mathrm{B}$ & & \\
\hline ECG periódico sistemático en consultas ulteriores & $\| \mathrm{lb}$ & $\mathrm{c}$ & $\mathrm{Ilb}$ & C \\
\hline \multicolumn{5}{|l|}{ ECG ambulatorio (Holter) } \\
\hline Sospecha de arritmia & I & B & & \\
\hline Sospecha de angina vasoespástica & Ila & $\mathrm{C}$ & & \\
\hline Sospecha de angina con prueba de esfuerzo normal & Ila & $\mathrm{C}$ & & \\
\hline \multicolumn{5}{|l|}{ Radiografía torácica } \\
\hline Sospecha de insuficiencia cardiaca o auscultación cardiaca anormal & I & B & I & B \\
\hline Sospecha de afección pulmonar significativa & i & B & & \\
\hline \multicolumn{5}{|l|}{ Ecocardiograma } \\
\hline \multicolumn{5}{|l|}{ Sospecha de insuficiencia cardiaca, auscultación anormal, ECG anormal, } \\
\hline $\begin{array}{l}\text { en el segmento ST } \\
\text { Infarto de miocardio previo }\end{array}$ & 1 & B & I & $\begin{array}{l}B \\
B\end{array}$ \\
\hline Hipertensión o diabetes mellitus & I & c & i & $\mathrm{B} / \mathrm{C}$ \\
\hline $\begin{array}{l}\text { Pacientes con riesgo intermedio o bajo en los que no se va a evaluar } \\
\text { la función del VI }\end{array}$ & & & Ila & C \\
\hline \multicolumn{5}{|l|}{ ECG de esfuerzo } \\
\hline $\begin{array}{l}\text { Primera opción en la evaluación inicial, excepto con pacientes } \\
\text { incapacitados para el ejercicio o ECG no valorable }\end{array}$ & I & B & I & B \\
\hline $\begin{array}{l}\text { Pacientes con cardiopatía conocida y significativo empeoramiento } \\
\text { de Jos síntomas }\end{array}$ & & & 1 & $B$ \\
\hline Pruebas periódicas de rutina cuando la angina está controlada & $\| l b$ & C & Ilb & $\mathrm{C}$ \\
\hline Técnicas de imagen de esfuerzo (ecograma o radionúclidos) & & & & \\
\hline Evaluación inicial en pacientes con ECG no interpretable & I & B & I & B \\
\hline Pacientes con prueba de esfuerzo no concluyente (pero con adecuada & & & & \\
\hline tolerancia al ejercicio) & I & B & I & B \\
\hline Angina tras revascularización & Ila & B & Ila & B \\
\hline $\begin{array}{l}\text { Para identificar la localización de la isquemia antes de la revascularización } \\
\text { Evaluación del deteriorn funcional de lesiones intermedias observadas }\end{array}$ & Ila & $\mathrm{B}$ & & \\
\hline $\begin{array}{l}\text { Evaluación del deterioro funcional de lesiones intermedias observadas } \\
\text { en el angiograma }\end{array}$ & Ila & C & & \\
\hline $\begin{array}{l}\text { Técnicas de imagen de estrés farmacológico } \\
\text { Pacientes incapacitados para el ejercicio }\end{array}$ & I & B & I & B \\
\hline Pacientes con prueba de esfuerzo no concluyente por escasa & & & & \\
\hline tolerancia al ejercicio & I & B & I & B \\
\hline Para evaluar la viabilidad miocárdica & Ila & B & & \\
\hline Otras indicaciones, como recursos hospitalarios que sólo permiten & & & & \\
\hline $\begin{array}{l}\text { la realización de la prueba con estrés farmacológico } \\
\text { Coronariografía no invasiva con TC }\end{array}$ & $\mathrm{II}$ a & B & Ila & B \\
\hline $\begin{array}{l}\text { Pacientes con baja probabilidad de enfermedad y con prueba } \\
\text { de estrés positiva o no concluyente }\end{array}$ & $\| \mathrm{lb}$ & C & & \\
\hline
\end{tabular}

naria por los síntomas de angina no tienen afección coronaria significativa ${ }^{105}$. En estos pacientes, las características del dolor torácico pueden indicar algunas de las siguientes probabilidades: a) dolor no anginoso; b) angina atípica, incluida la angina vasoespástica, y c) síndrome $\mathrm{X}$ cardiaco.

\section{Síndrome X}

\section{Descripción clínica}

Aunque no hay una definición universalmente aceptada, la descripción clásica del «síndrome $\mathrm{X}{ }^{106}$ requiere la presencia de la tríada: 
TABLA 6. Resumen de las recomendaciones para la revascularización en la angina estable

\begin{tabular}{|c|c|c|c|c|c|}
\hline \multirow[b]{2}{*}{ Indicación } & \multicolumn{2}{|c|}{ Para el pronóstico ${ }^{\mathrm{a}}$} & \multicolumn{2}{|c|}{ Para los síntomas ${ }^{b}$} & \multirow[b]{2}{*}{ Estudios } \\
\hline & $\begin{array}{l}\text { Grado de } \\
\text { recomendación }\end{array}$ & $\begin{array}{l}\text { Nivel de } \\
\text { evidencia }\end{array}$ & $\begin{array}{l}\text { Grado de } \\
\text { recomendación }\end{array}$ & $\begin{array}{l}\text { Nivel de } \\
\text { evidencia }\end{array}$ & \\
\hline \multicolumn{6}{|c|}{ ICP (suponiendo una anatomía adecuada para ICP, estratificación adecuada del riesgo y discusión con el paciente) } \\
\hline \multicolumn{6}{|c|}{$\begin{array}{l}\text { Angina con clase I-IV de la CCS a pesar } \\
\text { del tratamiento médico y enfermedad }\end{array}$} \\
\hline de un vaso & & & I & A & ACME, MASS \\
\hline \multicolumn{6}{|l|}{$\begin{array}{l}\text { Angina con clase I-IV de la CCS a pesar } \\
\text { del tratamiento médico y enfermedad }\end{array}$} \\
\hline multivaso (no diabéticos) & & & I & A & RITA-2, VA-ACME \\
\hline \multicolumn{6}{|l|}{$\begin{array}{l}\text { Angina estable con síntomas mínimos } \\
\text { (clase I de la CCS) tratados } \\
\text { farmacológicamente y enfermedad } \\
\text { de 1, } 2 \text { o } 3 \text { vasos y evidencia de }\end{array}$} \\
\hline isquemia extensa & IIb & C & & & ACIP \\
\hline \multicolumn{6}{|c|}{ CABG (suponiendo una anatomía adecuada para la cirugía, estratificación adecuada del riesgo y discusión con el paciente) } \\
\hline \multicolumn{6}{|c|}{ Angina y enfermedad de tronco común } \\
\hline izquierdo & I & A & I & A & $\begin{array}{l}\text { CASS, European Coronary } \\
\text { Surgery, VA, metaanálisis } \\
\text { de Yusuf }\end{array}$ \\
\hline \multicolumn{6}{|l|}{ Angina y enfermedad de 3 vasos } \\
\hline con isquemia extensa objetiva & I & A & I & A & \\
\hline \multicolumn{6}{|l|}{ Angina y enfermedad de 3 vasos } \\
\hline con afección de la función ventricular & I & A & I & A & \\
\hline \multicolumn{6}{|l|}{$\begin{array}{l}\text { Angina con enfermedad de } 203 \text { vasos, } \\
\text { incluida enfermedad severa proximal } \\
\text { de la descendente anterior izquierda }\end{array}$} \\
\hline proximal & I & A & I & A & \\
\hline \multicolumn{6}{|l|}{ Angina clase I-IV de la CSS con } \\
\hline enfermedad multivaso (diabéticos) & Ila & B & I & B & $\begin{array}{l}\text { BARI, GABI, ERACI-I, SoS, ARTs, } \\
\text { Yusuf et al, Hoffman et al }\end{array}$ \\
\hline \multicolumn{6}{|l|}{ Angina clase I-IV de la CSS con } \\
\hline enfermedad multivaso (no diabéticos) & & & 1 & A & \\
\hline \multicolumn{6}{|l|}{$\begin{array}{l}\text { Angina clase I-IV de la CCS a pesar } \\
\text { de terapia médica y enfermedad de } \\
\text { un vaso, incluida enfermedad severa } \\
\text { de la descendente anterior izquierda }\end{array}$} \\
\hline proximal & & & I & B & MASS \\
\hline \multicolumn{6}{|l|}{$\begin{array}{l}\text { Angina clase I-IV de la CCS a pesar } \\
\text { de terapia médica y enfermedad de } \\
\text { un vaso, sin incluir enfermedad severa de }\end{array}$} \\
\hline $\begin{array}{l}\text { Angina estable con síntomas mínimos } \\
\text { (clase I tratados farmacológicamente } \\
\text { y enfermedad de 1, } 203 \text { vasos y }\end{array}$ & & & & & \\
\hline evidencia objetiva de isquemia extensa & IIb & C & & & ACIP \\
\hline
\end{tabular}

CCS: Cardiac Canadian Society.

Las recomendaciones para la revascularización según los síntomas tienen en consideración el grado de severidad de los síntomas para los que hay evidencia y así se debe interpretarlas, nunca como una recomendación de revascularización en toda la gama de síntomas.

aEl pronóstico se refiere a los efectos en la mortalidad, la mortalidad cardiaca o cardiovascular y la mortalidad combinada con infarto de miocardio.

bos síntomas incluyen cambios en la clase de la angina, la duración del ejercicio, el tiempo de presentación de la angina en cinta sin fin, el reingreso por angina y otros parámetros sobre la capacidad funcional o la calidad de vida.

1. Angina inducida típicamente por el ejercicio (con o sin angina en reposo o disnea).

2. Resultados positivos en el ECG de esfuerzo u otras técnicas de imagen de esfuerzo.

3. Arterias coronarias normales.
El dolor torácico ocurre frecuentemente y los ataques de angina pueden presentarse varias veces a la semana, pero de forma estable. Por ello, el síndrome $\mathrm{X}$ recuerda a la angina estable crónica. Sin embargo, la presentación clínica de los pacientes incluidos en los 
estudios sobre el síndrome $\mathrm{X}$ es muy variable y la angina en reposo suele estar presente además del dolor torácico originado por el ejercicio ${ }^{107}$. En un subgrupo de pacientes con síndrome $\mathrm{X}$ se puede observar disfunción microvascular; esta entidad se denomina comúnmente «angina microvascular» ${ }^{108}$.

La hipertensión arterial, con o sin hipertrofia ventricular relacionada, se puede observar frecuentemente en la población con dolor torácico y «arterias coronarias normales». La cardiopatía hipertensiva se caracteriza por disfunción endotelial ${ }^{109}$, hipertrofia ventricular izquierda, fibrosis intersticial y perivascular con disfunción diastólica ${ }^{110}$, cambios en la ultraestructura miocárdica y coronaria ${ }^{111}$ y reserva del flujo coronario reducida ${ }^{112}$. Juntos o por separado, esos cambios pueden comprometer el flujo coronario relativo a la demanda miocárdica de oxígeno y causar la angina. En la mayoría de los casos, el tratamiento debe estar dirigido al control de la hipertensión para restaurar la integridad funcional y estructural del sistema cardiovascu$\operatorname{lar}^{113}$.

\section{Pronóstico}

Aunque el pronóstico en cuanto a mortalidad de los pacientes con síndrome $\mathrm{X}$ parece favorable ${ }^{114}$, la morbilidad es alta ${ }^{115,116}$ y el síndrome se relaciona con continuos episodios de angina y reingresos hospitala$\operatorname{rios}^{117}$. Hay indicios en aumento de que la identificación de disfunción endotelial en estos pacientes puede identificar a un subgrupo con riesgo de que se desarrolle enfermedad aterosclerótica coronaria ${ }^{118}$, que tendría un pronóstico menos benigno de lo que se pensaba anteriormente ${ }^{116}$.

\section{Diagnóstico del síndrome $\mathbf{X}$}

Se puede realizar un diagnóstico de síndrome $\mathrm{X}$ en el caso de pacientes con angina inducida por el ejercicio y arterias coronarias normales o sin obstrucciones (por angiografía) pero con signos objetivos de isquemia inducida por el ejercicio (depresión del segmento ST en el ECG de esfuerzo, cambios isquémicos en la gammagrafía). Es preciso diferenciar ese dolor del dolor torácico no cardiaco producido por dismotilidad esofágica, fibromialgia o costocondritis. También es necesario descartar un espasmo de las arterias coronarias usando tests de provocación adecuados. La disfunción endotelial se puede identificar por los cambios en el diámetro de las arterias coronarias epicárdicas inducido por la acetilcolina. Los estudios invasivos de provocación con acetilcolina pueden servir a dos propósitos: excluir el vasoespasmo y poner en evidencia la disfunción endotelial, que podría relacionarse con un peor pronóstico. En algunas circunstancias, como un extenso defecto de perfusión de radionúclido o anomalías de motilidad de la pared arterial y arterias angio- gráficamente irregulares, se puede considerar el uso de ultrasonidos intracoronarios para descartar posibles lesiones ocultas. Hay que señalar que, si no se observa disfunción endotelial, el pronóstico es excelente y se debe informar y tranquilizar al paciente sobre el curso benigno de su enfermedad.

\section{Recomendaciones para el estudio de los pacientes con la tríada clásica del síndrome $X$}

\section{Clase I}

- Ecocardiograma en reposo en pacientes con angina $\mathrm{y}$ arterias coronarias normales o sin lesiones significativas para evaluar la presencia de hipertrofia ventricular y/o disfunción diastólica (nivel de evidencia C).

\section{Clase IIb}

- Acetilcolina intracoronaria durante la angiografía si el angiograma es visualmente normal, para evaluar la reserva de flujo coronario dependiente del endotelio y excluir el vasoespasmo (nivel de evidencia C).

\section{Clase IIb}

- Ultrasonidos intracoronarios, medición de la reserva de flujo coronario o de la reserva fraccional de flujo para excluir lesiones obstructivas ocultas, si las imágenes angiográficas indican una lesión no obstructiva, más que arterias normales, y las técnicas de imagen de estrés indentifican una zona extensa de isquemia (nivel de evidencia $\mathrm{C}$ ).

\section{Angina vasoespástica/variante}

Descripción clínica. Los pacientes con angina variante o vasoespástica presentan dolor de localización típica, que ocurre en reposo o sólo ocasionalmente, durante el ejercicio. Normalmente los nitratos alivian el dolor en unos minutos. Para describir estos síntomas se utilizan generalmente los términos angina vasoespástica o variante, aunque también se conoce como «angina de Prinzmetal» ${ }^{119}$. La angina en reposo con la tolerancia al ejercicio conservada también puede tener relación con enfermedad coronaria obstructiva significativa sin vasoespasmo demostrable; su manejo es similar al descrito para los síntomas típicos. En caso de dolor torácico sin enfermedad coronaria significativa o espasmo coronario e isquemia no demostrable, se estudiará otras causas para el dolor y se seguirá las pautas convencionales de prevención primaria.

Un considerable porcentaje de pacientes con historia compatible con angina vasoespástica presenta enfermedad coronaria obstructiva y, en dichos pacientes, la angina vasoespástica puede coincidir con la angina típica de esfuerzo por lesiones coronarias fijas. El vasoespasmo puede ocurrir como respuesta al consumo de tabaco, alteraciones electrolíticas (potasio, magnesio), consumo de cocaína, estimulación por frío, enferme- 
dades autoinmunitarias, hiperventilación o resistencia a la insulina.

Historia natural y pronóstico. El pronóstico de la angina vasoespástica depende del grado de cardiopatía isquémica subyacente. Aunque pueden ocurrir, la muerte y el infarto de miocardio no son frecuentes en pacientes sin enfermedad obstructiva angiográficamente significativa ${ }^{120}$. En la población con lesiones no obstructivas se ha registrado un tasa anual de muerte coronaria de un $0,5 \%{ }^{121}$, pero los pacientes con espasmo que sobreviene a lesiones estenóticas tienen un pronóstico menos favorable ${ }^{122}$.

\section{Diagnóstico de la angina vasoespástica}

$E C G$. Durante el vasoespasmo, el ECG muestra clásicamente la elevación del segmento $\mathrm{ST}^{119}$. En otros casos se ha documentado la depresión del segmento $\mathrm{ST}^{123}$, mientras que en otros no se ha observado ningún cambio en dicho segmento ${ }^{124,125}$. Sin embargo, debido a que los episodios suelen resolverse rápidamente, resulta difícil documentarlos con un ECG de 12 derivaciones. Con repetidas monitorizaciones del ECG durante $24 \mathrm{~h}$, en algunos casos es posible documentar alteraciones en el segmento ST vinculadas a síntomas anginosos en estos pacientes ${ }^{126}$.

Angiografía coronaria. A pesar de que la demostración de una elevación del segmento ST en el momento de la angina y una angiografía coronaria normal refuerzan el diagnóstico de angina variante, el diagnóstico es más incierto en casos menos documentados o clínicamente menos claros. Es más, no hay una definición aceptada unánimemente de lo que es el espasmo coronario.

Sólo ocasionalmente se ha observado el espasmo espontáneo durante la angiografía en pacientes con síntomas de angina vasoespástica. Por esta razón se utilizan frecuentemente pruebas de provocación para demostrar la presencia de vasoespasmo coronario. La hiperventilación y el test del frío ofrecen una sensibilidad limitada para la detección del espasmo coronario ${ }^{127}$. Por ello, en la mayoría de los centros se utiliza la acetilcolina intracoronaria ${ }^{128}$, aunque el test de provocación con ergonovina intracoronaria ofrece resultados similares ${ }^{129,130}$. No se recomienda la realización de tests de provocación sin angiografía coronaria o a pacientes con lesiones angiográficamente muy obstructivas.

\section{Recomendaciones para las pruebas diagnósticas ante sospecha de angina vasoespástica}

\section{Clase I}

- ECG durante la angina siempre que sea posible (nivel de evidencia B).

- Angiografía coronaria a pacientes con dolor torácico episódico característico y cambios en el segmento
ST que se resuelven con nitratos y/o antagonistas del calcio, para determinar el grado de enfermedad coronaria subyacente (nivel de evidencia B).

\section{Clase IIa}

- Test intracoronario de provocación para identificar el espasmo coronario en pacientes con hallazgos normales o lesiones no obstructivas en la angiografía coronaria y cuadro clínico de espasmo coronario (nivel de evidencia B).

- ECG ambulatorio para la monitorización del segmento ST e identificación de desviaciones del segmento (nivel de evidencia C).

\section{TRATAMIENTO}

\section{Objetivos del tratamiento}

\section{Mejorar el pronóstico evitando el infarto de miocardio y la muerte}

Los esfuerzos para prevenir el infarto de miocardio y la muerte se centran fundamentalmente en reducir la incidencia de eventos trombóticos agudos y el desarrollo de disfunción ventricular. Los cambios en el estilo de vida y el tratamiento médico tienen un papel fundamental en la modificación del proceso de la enfermedad aterosclerótica y la «estabilización» de la placa, además de reducir la activación plaquetaria y las alteraciones fibrinolíticas e inflamatorias que predisponen a la rotura aguda de la placa y la oclusión trombótica. Estas medidas pueden paralizar el progreso e incluso inducir la regresión de la enfermedad coronaria aterosclerótica. En algunos casos, como en los pacientes con lesiones severas en arterias coronarias que irrigan zonas amplias de miocardio isquémico, la revascularización aporta más oportunidades de mejorar el pronóstico mejorando la perfusión existente o proporcionando rutas alternativas de perfusión.

\section{Minimizar o eliminar los síntomas}

Los cambios en el estilo de vida, los fármacos y la revascularización tienen un papel importante en la atenuación o eliminación de los síntomas de angina, aunque no siempre son necesarios todos en un mismo paciente.

\section{Manejo general}

El paciente y las personas allegadas deben estar informados sobre la naturaleza de la angina de pecho, las implicaciones del diagnóstico y los tratamientos que se puede recomendar. Se debe aconsejar a los pacientes que descansen, aunque sea un descanso breve, cuando realicen la actividad que causó la angina, y se recomendará el uso de nitratos sublinguales para el ali- 
vio inmediato de los síntomas. También es aconsejable prevenir a los pacientes sobre el potencial efecto hipotensor de los nitratos y recomendarles que se sienten en las primeras ocasiones que los utilicen; además, es preciso informarles de otros posibles efectos secundarios, como el dolor de cabeza. Se recomendará el uso profiláctico de nitratos para prevenir episodios predecibles de angina como respuesta al ejercicio. Los pacientes deben saber que tienen que acudir al médico si la angina persiste más de 10-20 min después de descansar o si los nitratos sublinguales no alivian los síntomas.

Se prestará especial atención a las cuestiones relacionadas con el estilo de vida que pudieran haber contribuido al desarrollo de la enfermedad, como la actividad física, el consumo de tabaco y los hábitos alimentarios. Se seguirá las recomendaciones del Grupo de Trabajo de la Tercera Reunión de las Sociedades Europeas $^{71}$ para la prevención de la enfermedad cardiovascular en la práctica clínica.

Se aconsejará al paciente que deje de fumar y adopte una dieta «mediterránea» rica en fruta, hortalizas, pescado y aves. La intensidad del cambio en la dieta estará basada en el CT, las LDL y otras alteraciones lipídicas ${ }^{131}$. Los pacientes con sobrepeso se pondrán a dieta para reducir su peso. El consumo moderado de alcohol puede ser beneficioso ${ }^{132}$, el consumo excesivo es perjudicial. Los aceites de pescado ricos en ácidos grasos omega-3 (ácidos grasos poliinsaturados n-3) ayudan a reducir la hipertrigliceridemia; en el estudio GISSI-Prevenzione, el sumplemento de una cápsula diaria de aceite de pescado (Omacor) demostró una reducción del riesgo de muerte súbita en pacientes con infarto de miocardio reciente ${ }^{133}$. Se recomedará el consumo de pescado al menos una vez a la semana ${ }^{134,135}$. No se recomienda los suplementos vitamínicos con antioxidantes u otras vitaminas.

Se animará al paciente a realizar actividades físicas adaptadas a sus posibilidades, de esta forma se aumenta la tolerancia al ejercicio, se reducen los síntomas y se obtiene efectos favorables en el peso, los lípidos sanguíneos, la presión arterial, la tolerancia a la glucosa y la sensibilidad a la insulina. Mientras que el papel del estrés en la génesis de la cardiopatía isquémica es un tema controvertido, sin duda los factores psicológicos son importantes en el origen de los ataques de angina. Además, el diagnóstico de angina suele causar un exceso de ansiedad. En la medida de lo posible, es importante tranquilizar a los pacientes, que podrán beneficiarse con la práctica de técnicas de relajación y otros métodos de control del estrés.

\section{Hipertensión, diabetes y otras alteraciones}

El manejo adecuado de alteraciones concomitantes, como la hipertensión o la diabetes, es importante. Cabe señalar el informe del Grupo de Trabajo sobre prevención de las enfermedades cardiovasculares ${ }^{71}$ que propone considerar un umbral más bajo para la institución de terapia farmacológica en la hipertensión $(130 / 85 \mathrm{mmHg})$ en pacientes con enfermedad coronaria establecida (que incluye a pacientes con angina y enfermedad coronaria confirmada por estudios invasivos y no invasivos). Los pacientes con diabetes concomitante y/o enfermedad renal deben recibir tratamiento para alcanzar una presión arterial < 130/80 $\mathrm{mmHg}^{102}$. La diabetes es un poderoso factor de riesgo de complicaciones cardiovasculares y se debe tratarla adecuadamente con el control de la glucemia y otros factores de riesgo ${ }^{102,136,137}$. En los pacientes diabéticos, una actuación multifactorial puede reducir de forma importante las complicaciones cardiovasculares y las complicaciones de la diabetes ${ }^{138}$. Recientemente se ha demostrado que la adición de pioglitazona a otros hipoglucemiantes redujo un $16 \%$ la incidencia de muerte, infarto de miocardio o accidente cerebral en pacientes con diabetes tipo 2 , aunque no se observó una reducción en el objetivo primario, que incluía una serie de complicaciones vasculares ${ }^{139}$. También se debe corregir la anemia o el hipertiroidismo, caso de haberlos.

\section{Actividad sexual}

La actividad sexual puede causar angina. Antes del acto sexual, el uso de nitroglicerina puede ser de utilidad. Los inhibidores de la fosfodiesterasa, como el sildenafilo, el tadafilo o el vardenafilo, utilizados en el tratamiento de la disfunción eréctil, pueden aportar beneficios en términos de duración del ejercicio y se puede prescribirlos sin riesgo a los varones con cardiopatía isquémica, aunque no a los tratados con nitratos de acción prolongada ${ }^{140}$.

\section{TRATAMIENTO FARMACOLÓGICO DE LA ANGINA DE PECHO}

El tratamiento farmacológico de la angina de pecho pretende mejorar el pronóstico del paciente y su calidad de vida reduciendo la severidad o la frecuencia de los síntomas.

\section{Tratamiento farmacológico para mejorar el pronóstico}

\section{Fármacos antitrombóticos}

El tratamiento antiplaquetario está indicado para la prevención de la trombosis coronaria, debido a la favorable relación entre el beneficio y el riesgo en pacientes con cardiopatía isquémica estable. En la mayoría de los casos, el fármaco de elección es la aspirina en dosis bajas; se puede considerar la administración de clopidogrel en algunos pacientes. 


\section{Aspirina en dosis bajas}

La aspirina continúa siendo la pieza clave en la prevención farmacológica de la trombosis arterial. Actúa mediante la inhibición irreversible de la ciclooxigenasa 1 (COX-1) plaquetaria y, por tanto, de la producción de tromboxano, que normalmente es completa con una dosis diaria indefinida de aproximadamente $75 \mathrm{mg}^{141}$. La dosis antitrombótica óptima de aspirina se sitúa en 75-150 mg/día, ya que la reducción relativa del riesgo que ofrece la aspirina puede ser menor con una dosis inferior o superior a este rango ${ }^{142}$.

Al contrario que los efectos antiplaquetarios, los efectos secundarios gastrointestinales de la aspirina aumentan con dosis mayores ${ }^{141}$. Si bien el riesgo relativo de hemorragia intracraneal aumenta en un $30 \%{ }^{143}$, el riesgo absoluto de dicha complicación atribuible a la terapia antiplaquetaria con aspirina en dosis próximas a los $75 \mathrm{mg} /$ día es inferior a 1/1.000 pacientes por año de tratamiento ${ }^{141,144}$. No hay evidencia de riesgo de sangrado intracraneal dependiende de la dosis con aspirina en rango terapéutico. En pacientes con enfermedad aterosclerótica vascular, en los que la etiología más frecuente de los accidentes cerebrales es la isquemia, el efecto neto del tratamiento con aspirina en los accidentes cerebrales es claramente beneficioso ${ }^{141,144}$. Por tanto, la dosis de aspirina debe ser la menor dosis efectiva para optimizar el equilibrio entre los beneficios terapéuticos y los efectos secundarios gastrointestinales durante el tratamiento indefinido.

\section{Inhibidores de la ciclooxigenasa 2 (COX-2) $y$ antiinflamatorios no esteroideos (AINE)}

Los inhibidores de la COX-2 reducen la producción de prostaciclina, que tiene efectos vasodilatadores e inhibidores de las plaquetas. La atenuación de la formación de la prostaciclina puede predisponer a la elevación de la presión arterial, la aceleración de la aterogénesis y la trombosis tras la rotura de la placa $^{145}$. La reciente retirada del rofecoxib (Vioxx), un inhibidor de la COX-2 altamente selectivo, fue porque se halló un aumento del riesgo de eventos coronarios mayores en un ensayo clínico controlado con placebo sobre prevención del cáncer ${ }^{146}$. En un metaanálisis de estudios aleatorizados sobre el rofecoxib, se demostró un aumento de riesgo de sufrir un infarto de miocardio fatal o no fatal ${ }^{147}$. Hay, pues, datos derivados de estudios con distintos inhibidores de la COX-2 que indican un aumento del riesgo de eventos trombóticos coronarios en poblaciones de pacientes con distinto grado de riesgo cardiovascular. Además, los inhibidores de la COX-2 aumentan el riesgo de accidentes cerebrales, insuficiencia cardiaca e hipertensión ${ }^{148}$. El uso de una inhibición de la COX-2 sin oposición (es decir, sin una inhibición plaquetaria efectiva de la COX-1) debe evitarse en pacientes con angina estable.
Cuando esté indicado por otras razones, el tratamiento con inhibidores de la COX no selectivos y reversibles (AINE) se combinará con dosis bajas de aspirina para asegurar una inhibición plaquetaria efectiva en los pacientes con angina estable. En esos casos se evitará el uso de ibuprofeno, ya que el uso de AINE previene la acetilación irreversible de la enzima COX1 plaquetaria por la aspirina, al igual que el naproxeno. El diclofenaco es un AINE relativamente selectivo de la COX-2 y, por tanto, no es un buen inhibidor plaquetario $^{149}$, aunque no interfiere con el efecto antiplaquetario de la aspirina y puede estar indicado en combinación con ella.

\section{Clopidogrel}

El clopidogrel y la ticlopidina son tienopiridinas que actúan como antagonistas no competitivos de los receptores de difosfato de adenosina y tienen efectos antitrombóticos similares a los de la aspirina ${ }^{141}$. La ticlopidina ha sido sustituida por el clopidogrel debido al riesgo de neutropenia y trombocitopenia y otros efectos secundarios más sintomáticos de la ticlopidina. El mayor estudio sobre el uso del clopidogrel en la cardiopatía isquémica estable es el CAPRIE ${ }^{150}$, que incluía 3 grupos con el mismo número de pacientes con infarto de miocardio previo, accidente cerebral previo o enfermedad vascular periférica. Comparado con $325 \mathrm{mg} /$ día de aspirina, el clopidogrel en una dosis de $75 \mathrm{mg} /$ día fue ligeramente más efectivo (RRA $0,51 \%$ por año; $p=0,043$ ) en la prevención de complicaciones cardiovasculares en pacientes de alto ries$\mathrm{go}^{150}$. Al comparar los resultados de los 3 subgrupos de pacientes incluidos en el estudio CAPRIE, el beneficio del clopidogrel sólo se observó en el subgrupo de pacientes con enfermedad vascular periférica ${ }^{150}$. La hemorragia gastrointestinal fue ligeramente inferior con el uso de clopidogrel que con aspirina (el 1,99 frente al 2,66\% durante 1,9 años de tratamiento), a pesar de la dosis relativamente alta de aspirina ${ }^{150}$. El estudio CAPRIE no incluyó a pacientes con intolerancia a la aspirina y no conocemos el riesgo de hemorragia gastrointestinal con clopidogrel comparado con placebo. El clopidogrel es mucho más caro que la aspirina, pero se puede considerar para el tratamiento de pacientes con intolerancia a la aspirina y con riesgos significativos de trombosis arterial. Sin embargo, la intolerancia gastrointestinal se puede manejar de diferente manera (véase más adelante). Tras la implantación de stents coronarios o tras un síndrome coronario agudo, se puede administrar clopidogrel combinado con aspirina durante un plazo determinado, pero la terapia combinada no está justificada en la angina estable.

Aunque se parte de datos no concordantes, hay una gran controversia sobre si la variabilidad de las respuestas antiplaquetarias al clopidogrel obedece a inte- 
racciones fármaco-fármaco, ya que el clopidogrel forma su(s) metabolito(s) activos a través del metabolismo mediado por la enzima CYP3A4. Hasta la fecha, en los análisis post hoc de los resultados de los pacientes tratados con clopidogrel más una estatina interactiva no muestran diferencias en los resultados y no existen estudios prospectivos diseñados para este fin.

\section{Tratamiento antiplaquetario en pacientes con intolerancia gastrointestinal a la aspirina}

La aspirina causa un daño en la mucosa gástrica relacionado con la dosis y puede producir síntomas y aumentar la incidencia de hemorragia gastrointestinal. El clopidogrel es un antiplaquetario alternativo que no tiene efectos directos en la mucosa gástrica y puede producir menos síntomas de dispepsia, pero la incidencia de hemorragias gastrointestinales puede aumentar con cualquier régimen antiplaquetario. Se desconoce con exactitud el efecto del clopidogrel debido a la inexistencia de estudios controlados por placebo. En los casos de erosión de la mucosa producida por la aspirina o AINE, se puede aliviarla inhibiendo la secreción ácida gástrica. En caso de infección por Helicobacter pylori, eliminarlo también reduce el riesgo de hemorragia gastrointestinal por aspirina ${ }^{151}$. Un reciente estudio ha mostrado que la adición de esomeprazol a la aspirina $(80 \mathrm{mg} / \mathrm{día})$ fue mejor que la sustitución por clopidogrel para la prevención de la úlcera sangrante recurrente en pacientes con úlcera y enfermedad vascular $^{152}$.

\section{Dipiridamol y anticoagulantes}

El dipiridamol no está recomendado en el tratamiento antitrombótico de la angina estable debido a su escasa eficacia antitrombótica ${ }^{142}$ y el riesgo de empeorar los síntomas anginosos por un fenómeno de «robo coronario». Los fármacos anticoagulantes (warfarina o inhibidores de la trombina) que se utilizan en la terapia combinada con aspirina en algunos pacientes de alto riesgo (tras infarto de miocardio) no están indicados en la población general de la angina estable si no hay una indicación concreta, como, por ejemplo, la fibrilación auricular.

\section{Resistencia a la aspirina}

Los posibles problemas relacionados con la «resistencia a la aspirina» ${ }^{133,154}$ y también con la «resistencia al clopidogrel» ${ }^{155}$ son de gran interés, pero dada la falta de conclusiones claras sobre este tema y sin contar con un patrón estándar que permita evaluar la resistencia a la aspirina, es preciso esperar a futuras investigaciones antes de establecer recomendaciones para su manejo.

\section{Fármacos hipolipemiantes}

El tratamiento con estatinas reduce el riesgo de complicaciones cardiovasculares ateroscleróticas tanto en la prevención primaria como en la secundaria ${ }^{156}$. En pacientes con enfermedad vascular aterosclerótica, la simvastatina y la pravastatina ${ }^{157-159}$ reducen la incidencia de complicaciones cardiovasculares serias en un $30 \%$ aproximadamente. Los análisis de subgrupos indican un efecto beneficioso en los pacientes diabéticos con enfermedad vascular y los beneficios del tratamiento con estatinas también han sido demostrados en ancianos (mayores de 70 años) ) $^{160,161}$. En los pacientes diabéticos sin enfermedad vascular manifiesta, 40 $\mathrm{mg} /$ día de simvastatina ${ }^{162}$ y $10 \mathrm{mg} /$ día de atorvastatina $^{163}$ proporcionan una protección primaria similar contra eventos cardiacos mayores. También se observó una reducción de eventos cardiovasculares mayores en el estudio controlado con placebo ASCOT-LLA (Anglo-Scandinavian Cardiac Outcomes Trial-Lipid Lowering Arm $)^{164}$, en el que se evaluó el tratamiento con atorvastatina en la prevención primaria de la enfermedad coronaria en pacientes hipertensos con valores de CT alrededor de $6,5 \mathrm{mmol} / \mathrm{l}$. No se ha realizado ningún estudio específicamente en pacientes con angina estable, pero los estudios mencionados incluían un porcentaje significativo de dichos pacientes. En el estudio HPS (Heart Protection Study), por ejemplo, el $41 \%$ de los pacientes habían tenido un infarto de miocardio y el $24 \%$ tenía otro tipo de cardiopatía isquémica.

Las estatinas son efectivas en la reducción del colesterol ${ }^{156}$, pero otros mecanismos distintos de la inhibición de la síntesis del colesterol, como sus efectos antiinflamatorios y antitrombóticos, pueden contribuir a la reducción del riesgo cardiovascular. En un estudio controlado con placebo, se demostró que en los pacientes con angina estable pretratados durante 7 días con $40 \mathrm{mg} /$ día de atorvastatina antes de una ICP, se reducía el daño miocárdico relacionado con el procedimiento, medido mediante marcadores bioquímicos ${ }^{165}$. La protección miocárdica mediante el tratamiento con atorvastatina a corto plazo y dosis altas puede estar relacionada con los efectos no lipídicos de las estatinas. Se ha observado beneficios similares del tratamiento a largo plazo con estatinas en pacientes con distintas concentraciones séricas de colesterol, incluso en pacientes con cifras «normales» ${ }^{161,163}$. Por lo tanto, la indicación del tratamiento con estatinas puede estar guiada tanto por el riesgo cardiovascular del paciente como por la concentración de colesterol (de normal a moderadamente elevada). El riesgo relacionado con el colesterol aumenta de forma semilogarítmica desde los valores bajos o normales ${ }^{156} \mathrm{y}$, por tanto, es difícil evaluar la importancia relativa de la disminución del colesterol y otros efectos del tratamiento con estatinas respecto a los beneficios observados. 
Las actuales guías europeas sobre prevención indican como deseable una cifra de CT $<4,5 \mathrm{mmol} / \mathrm{l}$ $(175 \mathrm{mg} / \mathrm{dl})$ y de $2,5 \mathrm{mmol} / \mathrm{l}(96 \mathrm{mg} / \mathrm{dl})$ para las LDL en pacientes con enfermedad coronaria establecida o incluso para pacientes que continúan con alto riesgo multifactorial persistente (riesgo de eventos cardiovasculares fatales en 10 años > 5\%). Sin embargo, cabe la posibilidad de que la terapia dirigida solamente al control del colesterol no aproveche en su totalidad los beneficios del tratamiento con estatinas.

Sobre la base de un elevado riesgo y la evidencia del beneficio de disminuir el colesterol a lo «normal», siempre se considerará el tratamiento con estatinas en los pacientes con cardiopatía isquémica estable y angina estable ${ }^{166}$. Se intentará implementar las dosis de estatinas con que se haya demostrado reducir la morbilidad/mortalidad en ensayos clínicos. Si estas dosis no son suficientes para alcanzar los valores deseados de CT y LDL mencionados anteriormente, se aumentará la dosis para alcanzar los objetivos propuestos en la medida que lo tolere el paciente. Las dosis de estatinas documentadas en los estudios antes citados son $40 \mathrm{mg}$ de simvastatina, $40 \mathrm{mg}$ de pravastatina y $10 \mathrm{mg}$ de atorvastatina. Recientemente se ha demostrado que altas dosis diarias de atorvastatina ( $80 \mathrm{mg} /$ día) reducen el riesgo de eventos cardiovasculares, comparada con $10 \mathrm{mg} /$ día de atorvastatina en pacientes con cardiopatía isquémica estable ${ }^{167}$. El aumento de la eficacia con altas dosis de atorvastatina estuvo acompañado por un aumento de 6 veces (del 0,2 al 1,2\%; p < 0,001) de los marcadores de daño hepático, pero sin cambios sensibles en la mialgia. El tratamiento con altas dosis de atorvastatina se reservará a los pacientes de alto riesgo.

El tratamiento con estatinas está asociado a escasos efectos secundarios, aunque se podría producir daño del músculo esquelético (síntomas, elevación de la CK y, rara vez, rabdomiólisis) y conviene controlar las enzimas hepáticas desde el inicio del tratamiento. La presencia de alteraciones gastrointestinales puede obligar a limitar la dosis. En caso de que el paciente no tolere bien las estatinas a altas dosis o que no se obtenga un control lipídico con las dosis de estatinas más altas, se reducirá la dosis y se combinará las estatinas con un inhibidor de la absorción del colesterol (ezetimiba) para intentar un adecuado control del colesterol ${ }^{168}$. Sin embargo, hasta el momento no se ha documentado el efecto de la terapia combinada en la morbilidad y la mortalidad.

Otros fármacos hipolipemiantes, como los fibratos, el ácido nicotínico de liberación prolongada y su combinación con estatinas y otros, podrían ayudar al control de los valores lipídicos entre los pacientes con dislipidemia severa, especialmente en los pacientes con escasez de HDL y altas concentraciones de triglicéridos. El torcetrapib es un nuevo agente que ha demostrado elevar eficazmente las HDL ${ }^{169}$, pero hasta el mo- mento no hay suficiente evidencia que permita establecer recomendaciones universales relativas a los valores de HDL o triglicéridos deseables mediante tratamiento farmacológico en la población general con angina. Se puede considerar de forma individualizada la terapia combinada con estatinas en pacientes con dislipemia severa que siguen estando en alto riesgo tras las medidas convencionales (mortalidad anual estimada $>2 \%$ ).

\section{Inhibidores de la enzima de conversión de angiotensina}

El uso de inhibidores de la enzima de conversión de angiotensina (IECA) está bien establecido en el tratamiento de la hipertensión y la insuficiencia cardiaca. Por la reducción de la incidencia de infarto de miocardio y muerte cardiaca observada en ensayos clínicos sobre IECA en la insuficiencia cardiaca y tras infarto de miocardio, se ha investigado su utilidad para la prevención secundaria en pacientes con enfermedad coronaria sin insuficiencia cardiaca ${ }^{170-174}$.

En los estudios HOPE y EUROPA la reducción relativa del riesgo de los objetivos primarios se situaba en el orden del 20\%, mientras que en el estudio PEACE no se observó una reducción significativa con el uso de IECA. Lamentablemente, los resultados de esos 3 estudios no son directamente comparables, ya que la selección de objetivos era diferente.

La diferencia de resultados en estos estudios podría estar relacionada con los 3 IECA utilizados y/o las dosis utilizadas. En términos generales, los pacientes del estudio PEACE presentaron un riesgo absoluto más bajo que los pacientes de los estudios HOPE o EURO$\mathrm{PA}$. Las diferencias en el riesgo basal y en el tratamiento no relacionado con el estudio pueden haber contribuido de forma importante a las diferencias en los resultados cardiovasculares con el uso de IECA. Los efectos relativos del ramipril y del perindopril en las complicaciones cardiovasculares fueron similares en la población de alto riesgo y en la de riesgo intermedio, aunque, por razones obvias, la reducción de riesgo absoluto fue mayor en la población de riesgo absoluto más alto.

Los efectos del ramipril y el perindopril en la reducción de la presión arterial, comparados con placebo, también pueden haber influido en la reducción del riesgo en los estudios HOPE y EUROPA, aunque los IECA podrían aportar una cardioprotección adicional ${ }^{172}$. Además, los IECA son un tratamiento bien establecido en la insuficiencia cardiaca y en la disfunción del VI ${ }^{173}$ y en pacientes diabéticos ${ }^{136}$. Por todo ello, el tratamiento con IECA está indicado en pacientes con angina estable e hipertensión, diabetes, insuficiencia cardiaca, disfunción asintomática del VI concomitantes y después de infarto de miocardio. En pacientes con angina pero sin otras indicaciones para el tratamiento con IECA, se debe sopesar el beneficio antici- 
pado de esta terapia (posible reducción del riesgo total) y los costes y los riesgos de efectos secundarios, además de la eficacia probada del agente y la dosis utilizados.

\section{Tratamiento hormonal de sustitución}

La evidencia epidemiológica ha indicado beneficios cardiovasculares sustanciales con el tratamiento de sustitución hormonal (THS) en la posmenopausia. Sin embargo, más recientemente, ensayos clínicos prospectivos, diseñados adecuadamente, a doble ciego y controlados con placebo, han demostrado que el THS (combinación de estrógeno y progestina orales) no ofrece beneficios cardiovasculares en mujeres con enfermedad establecida ${ }^{174,175}$, que se produce un aumento de riesgo de desarrollo de enfermedad coronaria en prevención primaria y también un aumento de riesgo de cáncer de mama ${ }^{176}$. En prevención primaria, la terapia estrogénica sin oposición en pacientes histerectomizadas no ofrece protección cardiovascular ${ }^{177}$. Es por ello que las nuevas guías de práctica clínica no recomiendan el uso de THS en enfermedades crónicas ${ }^{178}$ y recomiendan la reducción gradual de la dosis hasta llegar a la interrupción del tratamiento en mujeres que están siendo tratadas ${ }^{179}$.

\section{Bloqueadores beta}

En estudios sobre el uso de bloqueadores beta después del infarto de miocardio, se ha observado una reducción aproximada de muerte cardiovascular o infarto de miocardio del $30 \%{ }^{180}$. En un reciente análisis de metarregresión del efecto de distintos bloqueadores beta en la mortalidad, no se observó beneficios significativos del tratamiento agudo, pero sí se demostró una reducción significativa de la mortalidad (24\%) con el tratamiento a largo plazo en prevención secundaria ${ }^{181}$. Los bloqueadores beta con actividad simpaticomimética intrínseca parecen ofrecer menos protección y se ha señalado que el agente más utilizado, el atenolol, no está suficientemente validado en cuanto a la mortalidad tras infarto de miocardio ${ }^{181}$. A partir de estudios clínicos tras infarto de miocardio, se ha extrapolado que los bloqueadores beta pueden ser cardioprotectores incluso en pacientes con enfermedad coronaria estable, pero este extremo no ha sido comprobado en estudios controlados con placebo. Los estudios con bloqueadores beta tras infarto de miocardio se realizaron antes de la implementación de otras terapias más modernas de prevención secundaria, como el tratamiento con estatinas e IECA, lo que crea cierta incertidumbre sobre su eficacia cuando se los utiliza como parte de una estrategia terapéutica actual.

En los grandes estudios sobre el uso de bloqueadores beta en la angina estable (APSIS ${ }^{7}$ y TIBET $^{6}$ ) no se observó una diferencia significativa en los resultados de los pacientes tratados con bloqueadores beta o con bloqueadores de los canales del calcio (nifedipino o verapamilo). En un estudio más pequeño (ASIST, con unos 300 pacientes/año) en pacientes con síntomas mínimos de angina o asintomáticos, para comparar el efecto del atenolol con el de placebo, se demostró una incidencia superior del objetivo combinado, que incluía síntomas que requieren tratamiento en el grupo placebo $^{182}$. Aunque se confirmó así el efecto beneficioso de un determinado bloqueador beta, no se demostró si el tratamiento altera el pronóstico de los pacientes con angina estable.

Se ha demostrado que los bloqueadores beta-1 (metoprolol o bisoprolol) reducen eficazmente la incidencia de eventos cardiacos en pacientes con insuficiencia cardiaca congestiva ${ }^{183,184}$. El carvedilol, un bloqueador beta no selectivo que también bloquea los receptores alfa-1, reduce también el riesgo de muerte y hospitalización por causas cardiovasculares en pacientes con insuficiencia cardiaca ${ }^{185}$. Por último, hay evidencia del beneficio pronóstico del uso de bloqueadores beta en pacientes con angina e infarto de miocardio previo o insuficiencia cardiaca y, extrapolando estos datos, se puede recomendar el uso de bloqueadores beta como terapia antianginosa de primera línea en pacientes que no tengan contraindicaciones.

\section{Bloqueadores de los canales de calcio}

La reducción de la frecuencia cardiaca mediante el bloqueo de los canales de calcio puede mejorar el pronóstico de los pacientes tras el infarto de miocardio, como se demostró en el estudio DAVIT II (verapamilo) ${ }^{186}$ y en el análisis del subgrupo de pacientes sin signos de insuficiencia cardiaca del estudio MDPIT (diltiazem) ${ }^{187}$. Sin embargo, en estudios anteriores sobre nifedipino de acción corta no se observó beneficios en los objetivos «duros» en pacientes con cardiopatía isquémica, incluso se apreció un incremento del riesgo de muerte con la utilización de dosis altas de ese fármaco $^{188}$. Este hallazgo provocó un intenso debate sobre los antagonistas del calcio, en el que se señaló lo inapropiado del tratamiento con vasodilatadores de acción corta, como la dihidropiridina. En un metaanálisis sobre la seguridad del nifedipino en la angina estable, se señala que este fármaco es seguro ${ }^{189}$.

En el recientemente publicado estudio ACTION ${ }^{190}$, en el que se compara el tratamiento con nifedipino de acción prolongada y placebo durante 4,9 años de seguimiento de 7.665 pacientes con angina estable, no se observó un beneficio del tratamiento con nifedipino en el objetivo combinado de muerte, infarto de miocardio, angina pertinaz, accidente cerebral debilitante e insuficiencia cardiaca. El tratamiento con nifedipino tendió a aumentar la necesidad de revascularización periférica $(\mathrm{RR}=1,25 ; \mathrm{p}=0,073)$, pero redujo la necesidad de cirugía de bypass aortocoronario ( $\mathrm{RR}=0,79 ; \mathrm{p}=0,0021)$. 
Los autores concluyeron que el tratamiento con nifedipino es seguro y reduce la necesidad de intervenciones coronarias ${ }^{190}$. No obstante, la ausencia de efectos beneficiosos del nifedipino en los objetivos «duros» no cumple los requisitos de «seguridad cardiovascular». En el estudio CAMELOT $^{191}$ se comparó el tratamiento con amlodipino, enalapril o placebo en 1.991 pacientes con cardiopatía isquémica estable y una presión arterial normal durante 2 años de seguimiento. El tratamiento con amlodipino y enalapril bajó la presión arterial de forma similar y mostró una tendencia similar a la reducción de la incidencia de objetivos «duros», aunque estos resultados no fueron significativos.

Para finalizar, aunque no haya evidencia que apoye el uso de bloqueadores de los canales de calcio en relación con el pronóstico en la angina estable sin complicaciones, sí se podría utilizar antagonistas del calcio con efecto depresor de la frecuencia cardiaca como alternativa a los bloqueadores beta tras el infarto de miocardio en pacientes sin insuficiencia cardiaca y con intolerancia a los bloqueadores beta.

\section{Recomendaciones sobre el tratamiento farmacológico para mejorar el pronóstico en pacientes con angina estable}

Clase I

- Aspirina, $75 \mathrm{mg} / \mathrm{día}$, a todos los pacientes sin contraindicaciones específicas (como hemorragia gastrointestinal activa, alergia o intolerancia a la aspirina) (nivel de evidencia A).

- Tratamiento con estatinas a todos los pacientes con enfermedad coronaria (nivel de evidencia A).

- Tratamiento con IECA a todos los pacientes en los que está indicado, es decir, con hipertensión, insuficiencia cardiaca, disfunción del VI, infarto de miocardio previo con disfunción del VI o diabetes (nivel de evidencia A).

- Tratamiento con bloqueadores beta orales en pacientes con infarto de miocardio previo o insuficiencia cardiaca (nivel de evidencia A).

\section{Clase IIa}

- Tratamiento con IECA a todos los pacientes con angina y enfermedad coronaria confirmada (nivel de evidencia B).

- Clopidogrel como agente antiplaquetario alternativo para pacientes con angina estable que no pueden tomar aspirina (nivel de evidencia B).

- Tratamiento con estatinas en dosis altas a pacientes de alto riesgo (mortalidad cardiovascular anual > $2 \%$ ) con enfermedad coronaria confirmada (nivel de evidencia B).

\section{Clase IIb}

- Tratamiento con fibratos en pacientes con bajas concentraciones de HDL y altas de triglicéridos con diabetes o síndrome metabólico (nivel de evidencia B).

\section{Tratamiento farmacológico de los síntomas y la isquemia}

Los fármacos que reducen la demanda miocárdica de oxígeno y/o aumentan el flujo sanguíneo en zonas isquémicas pueden aliviar los síntomas anginosos y los signos de la isquemia (también de la isquemia asintomática). Los fármacos antianginosos utilizados más frecuentemente son los bloqueadores beta, los antagonistas del calcio y los nitratos orgánicos.

\section{Nitratos de acción corta}

Las formulaciones de acción rápida de la nitroglicerina proporcionan un alivio efectivo de los síntomas de la angina de pecho y se puede utilizarlas en la «profilaxis situacional». El alivio del dolor y los efectos antiisquémicos se producen por venodilatación y por la reducción del llenado diastólico (reducción de la presión intracardiaca), que promueve la perfusión subendocárdica. También pueden contribuir la vasodilatación coronaria y el antagonismo del vasoespasmo coronario. La tolerancia a los nitratos atenúa la respuesta a la nitroglicerina de acción rápida y, por tanto, se debe evitarla.

La nitroglicerina causa efectos secundarios vasodilatadores, como dolor de cabeza y rubor, que dependen de la dosis. La sobredosis puede causar hipotensión postural y activación reflexogénica simpática con taquicardia que desemboca en angina «paradójica». En caso de un ataque anginoso que no responde a la nitroglicerina de acción rápida, se considerará un posible infarto de miocardio. Por ello, los pacientes deben recibir instrucciones sobre el uso de este fármaco. La administración de nitratos de acción corta combinados con otra medicación antianginosa es una medida sencilla y efectiva para el tratamiento de los síntomas.

\section{Nitratos de acción prolongada (*)}

El tratamiento con nitratos de acción prolongada reduce la frecuencia y la severidad de los ataques de angina y puede incrementar la tolerancia al ejercicio. Los ensayos clínicos sobre el uso de estos fármacos tras el infarto de miocardio no han demostrado beneficios en el pronóstico.

Debido a la tolerancia a los nitratos, los pacientes tratados con nitratos de acción prolongada deben tener diariamente un período sin nitratos para preservar sus efectos terapéuticos. Esto se logra con dosis de nitra-

\footnotetext{
(*) A pesar de que la utilización de los nitratos de acción prolongada está muy difundida, los estudios no han demostrado que mejoren el pronóstico después de un infarto de miocardio, y se recomienda utilizarlos en un tercer paso para mejorar los síntomas y/o signos de isquemia. En consonancia con esta indicación, en España los nitratos de acción prolongada se utilizan en la práctica clínica diaria cuando los bloqueadores beta o los antagonistas del calcio no son eficaces (López de Sá E, Estevez A, Onaindía J, Rubio R, López-Sendón J. Papel de los nitratos en el tratamiento de la enfermedad coronaria. Rev Esp Cardiol. 2006;6 Supl:A41-50).
} 
tos de acción intermedia (dinitrato de isosorbida o formulaciones de mononitrato de isosorbida), a los intervalos oportunos, que proporcionen un perfil adecuado de concentración en plasma. El tratamiento continuo con nitroglicerina transdérmica no es efectivo; los pacientes deben retirar los parches durante parte del día o por la noche para conseguir un período libre de nitratos.

\section{Bloqueadores beta}

Los bloqueadores beta son efectivos en la reducción de los síntomas anginosos y la isquemia ${ }^{40,192-194}$. Estos fármacos reducen la demanda de oxígeno al reducir la tasa de frecuencia y la contractilidad cardiacas y la presión arterial. La mayoría de los bloqueadores beta reducen la frecuencia cardiaca tanto en reposo como durante el ejercicio, a excepción de aquellos con actividad agonista parcial, ya que sólo reducen la frecuencia cardiaca durante el ejercicio. La perfusión de las zonas isquémicas puede mejorar por la prolongación de la diástole (es decir, del tiempo de perfusión) y por la «inversión del fenómeno de robo coronario» debido al aumento de la resistencia vascular en zonas sin isquemia.

Se prefiere el uso de agentes selectivos beta-1 a los bloqueadores beta no selectivos, por las ventajas en los efectos secundarios y las precauciones. El metoprolol, el atenolol y el bisoprolol son bloqueadores beta- 1 con buena documentación como fármacos antianginosos y se los utiliza frecuentemente. Para alcanzar una eficacia de $24 \mathrm{~h}$ se puede administrar un bloqueador beta- 1 con vida media larga (como el bisoprolol) o una formulación que proporcione un perfil extenso de concentración en plasma prolongada (como el metropolol CR). En el caso de atenolol (con una vida media en plasma de 6-9 h), es recomendable administrarlo 2 veces al día, aunque si se incrementa la dosis, también aumenta la duración de la acción. Las dosis para obtener un efecto antianginoso completo son: bisoprolol, $10 \mathrm{mg}$ cada $24 \mathrm{~h}$; metoprolol CR, $200 \mathrm{mg}$ cada $24 \mathrm{~h}$; atenolol, $100 \mathrm{mg}$ cada $24 \mathrm{~h}$ (o $50 \mathrm{mg}$ cada $12 \mathrm{~h}$ ). El grado de acción de los bloqueadores beta se puede determinar mediante una prueba de esfuerzo. Los bloqueadores beta son fármacos antianginosos efectivos que aumentan la tolerancia al ejercicio y disminuyen la frecuencia de los síntomas y el consumo de nitratos de acción rápida. En el caso de pacientes con angina vasoespástica, los síntomas podrían acentuarse con esta terapia.

Entre los efectos secundarios de los bloqueadores beta se incluye la frialdad en las extremidades y bradicardia sintomática, ambas relacionadas con la inhibición cardiaca, y un aumento de los síntomas respiratorios en el asma y las enfermedades pulmonares obstructivas crónicas (menos frecuentes con los agentes beta-1). Los bloqueadores beta pueden causar fatiga, pero en los ensayos clínicos sólo se interrumpió el tratamiento por ese motivo en el $0,4 \%$ de los pacientes $^{195}$. De igual modo, la depresión no aumentó entre los pacientes tratados con bloqueadores beta y la disfunción sexual se observó en 5/1.000 pacientes/año (interrupción del tratamiento en 2/1.000) ${ }^{196}$. La calidad de vida, que se ha estudiado ampliamente en el tratamiento de la hipertensión, se conserva con el tratamiento de pacientes hipertensos con bloqueadores beta $^{196,197}$, pero este extremo no ha sido estudiado sistemáticamente en pacientes con angina estable ${ }^{198}$.

\section{Bloqueadores de los canales de calcio}

Los bloqueadores de los canales de calcio (BCC) son agentes antianginosos bien establecidos ${ }^{40,191-194}$. Se trata de una clase heterogénea de fármacos que dilatan las coronarias y otras arterias mediante la inhibición del influjo del calcio vía los canales tipo-L. Los BCC no selectivos o depresores de la frecuencia cardiaca (verapamilo y diltiazem) también reducen en alguna medida la contractilidad miocárdica, la frecuencia cardiaca y la conducción del nódulo auriculoventricu$\operatorname{lar}^{40,192}$. Incluso la dihidropiridina vasoselectiva (como el nifedipino, el amlodipino y el felodipino) pueden causar algo de cardiodepresión, pero este efecto se contrarresta mediante la activación cardiaca simpática reflexogénica con pequeños aumentos de la frecuencia cardiaca que remiten con el tiempo. No obstante, se puede observar algunos signos de la activación simpática incluso meses después del tratamiento con dihidropiridina ${ }^{199}$.

Son preferibles los BCC de acción prolongada (como el amlodipino) o las formulaciones de BCC de acción rápida y liberación prolongada (como nifedipino, felodipino, verapamilo y diltiazem), al objeto de minimizar las fluctuaciones de concentración en plasma y los efectos cardiovasculare ${ }^{200}$. Los efectos secundarios también dependen de la concentración y se relacionan fundamentalmente con respuestas vasodilatadoras arteriales (dolor de cabeza, rubor y edema de tobillo); estos efectos son más pronunciados con la dihidropiridina. El verapamilo puede provocar estreñimiento.

Los efectos antianginosos de los BCC obedecen a una disminución del trabajo cardiaco secundaria a la vasodilatación sistémica, su efecto vasodilatador coronario y la protección contra el vasoespasmo ${ }^{40,192}$. Los BCC son especialmente efectivos en pacientes con angina vasoespástica (o de Prinzmetal) ${ }^{40}$; no obstante, en algunos pacientes los antagonistas del calcio pueden acentuar la isquemia ${ }^{201}$.

En el estudio CAMELOT ${ }^{191}$ se demostró que el efecto angiantinoso del amlodipino redujo significativamente, comparado con placebo, la hospitalización por angina y también la necesidad de revascularización durante 2 años de seguimiento. El tratamiento con enalapril no tuvo relación con efectos similares en 
los resultados sobre la isquemia. En el estudio $\mathrm{CAPE}^{202}$, el tratamiento con amlodipino resultó en una modesta pero significativa reducción de la isquemia controlada con Holter (los efectos del tratamiento placebo fueron bastante pronunciados) tras 7 semanas de tratamiento. Los pacientes informaron de una mayor reducción de los ataques de angina (el 70 frente al $44 \%$ ) y una reducción del consumo de nitroglicerina durante la décima semana del tratamiento con amlodipino más pronunciada que en el grupo placebo (el 67 frente al 22\%). El perfil de los efectos secundarios con el amlodipino fue favorable en ambos estudios. En el estudio ACTION, aunque no se observó una reducción del objetivo primario (muerte, infarto agudo de miocardio, angina rebelde al tratamiento, insuficiencia cardiaca nueva y clara, accidente cerebral debilitante y revascularización periférica), el tratamiento con nifedipino tuvo relación con una reducción de la necesidad de CABG $(R R=0,79 ; p=0,002)^{190}$.

Los efectos antianginosos y antiisquémicos de los $\mathrm{BCC}$ son aditivos a los efectos de los bloqueadores beta en la mayoría de los pacientes, aunque no en todos. La dihidropiridina es apropiada para la terapia combinada con bloqueadores beta, ya que contrarresta la activación simpática cardiaca reflexogénica. Los BCC depresores de la frecuencia cardiaca pueden causar alteraciones en la conducción en pacientes predispuestos tratados con bloqueadores beta. Todos los antagonistas del calcio pueden precipitar una insuficiencia cardiaca en pacientes predispuestos; los intentos de utilizar dihidropiridina como tratamiento vasodilatador en la insuficiencia cardiaca han fracasado. Sin embargo, el amlodipino está indicado para el tratamiento de la angina o la hipertensión en pacientes con insuficiencia cardiaca compensada, si no siguen otras terapias (como nitratos o bloqueadores beta) $)^{203}$.

\section{Comparación de los bloqueadores beta y los antagonistas del calcio en el tratamiento de la angina estable}

En el estudio IMAGE 204 se comparó a pacientes con angina estable tratados con metoprolol CR (200 mg cada $24 \mathrm{~h}$ ) o con nifedipino SR (20 mg cada $12 \mathrm{~h}$ ) durante 6 semanas (140 pacientes en cada grupo). Ambos fármacos prolongaron la tolerancia al ejercicio respecto a la basal, con un mayor aumento en los pacientes del grupo metoprolol $(\mathrm{p}<0,05)$. Las respuestas a los dos fármacos fueron variables y difíciles de predecir. En el estudio APSIS, el tratamiento con verapamilo SR durante 1 mes fue ligeramente más efectivo que el metoprolol CR respecto al aumento de la tolerancia al ejercicio $^{205}$. Sin embargo, aunque en el estudio la isquemia inducida por el ejercicio era un predictor de eventos cardiovasculare ${ }^{205}$, los efectos del tratamiento a corto plazo en la isquemia inducida por el ejercicio no fue un predictor independiente de mejores resultados a largo plazo.

En el estudio TIBBS ${ }^{206}$, tanto el bisoprolol como el nifedipino mostraron efectos antiisquémicos y antianginosos, aunque el bisoprolol fue claramente superior. El estudio TIBET, a doble ciego y con grupos paralelos, comparó los efectos del atenolol, el nifedipino y la combinación de ambos en la isquemia inducida por ejercicio y la carga isquémica total. Ambas medicaciones, solas o combinadas, proporcionaron mejoras significativas en los parámetros de ejercicio y reducciones significativas en el desarrollo de la isquemia durante las actividades diarias comparadas con placebo, pero no se observó diferencias importantes entre los grupos de tratamiento en ninguno de los parámetros isquémicos evaluados. A causa de los efectos secundarios, se registraron significativamente más retiradas en el grupo de nifedipino que en el grupo de atenolol y el de tratamiento combinado ${ }^{6,207}$. Los metaanálisis comparativos de los efectos de los bloqueadores beta y los BCC en la angina estable indican que los primeros son más eficaces en la reducción de episodios anginosos ${ }^{208}$, pero que los efectos de ambos fármacos son similares en cuanto a la tolerancia al ejercicio y la isquemia ${ }^{40,208}$.

Por tanto, en ausencia de infarto de miocardio previo, los datos disponibles indican que la elección entre un bloqueador beta y un BCC en el tratamiento antianginoso se basará en la tolerancia individual del paciente y las enfermedades y los tratamientos concomitantes. $\mathrm{Si}$ estos factores se encuentran equilibrados, se recomienda un bloqueador beta como primera opción.

\section{Comparación de los nitratos con los bloqueadores beta y los bloqueadores de los canales del calcio}

Hay pocos estudios comparativos sobre los efectos antiaginosos y antiisquémicos de los nitratos de acción prolongada y los bloqueadores beta y los $\mathrm{BCC}$, y no disponemos de datos sobre los posibles efectos de los nitratos en la morbilidad en la angina estable ${ }^{208}$. En el metaanálisis de Heidenreich et $\mathrm{al}^{208}$ se observó una tendencia no significativa hacia el menor uso de nitroglicerina con bloqueadores beta y menos episodios de angina por semana con los BCC que con nitratos de acción prolongada. Por tanto, los nitratos de acción prolongada no ofrecen ventajas terapéuticas respecto a los bloqueadores beta o los BCC.

\section{Apertura de los canales de potasio}

El principal agente de esta clase de fármacos es el nicorandil, que por sus 2 fracciones moleculares tiene un mecanismo de doble de acción, es decir, es activador de los canales de potasio y actúa además como un nitrato (por su 
fracción de nitrato ${ }^{209}$. Para la prevención de la angina se administra, normalmente, $20 \mathrm{mg}$ cada $12 \mathrm{~h}$. El tratamiento indefinido puede desarrollar tolerancia al efecto antianginoso, pero no se ha observado problemas de tolerancia cruzada con nitratos. Aparte de sus propiedades antianginosas, se cree que el nicorandil tiene además un efecto cardioprotector. El estudio IONA (Impact Of Nicorandil in Angina), controlado con placebo, demostró una reducción significativa de eventos coronarios mayores en pacientes con angina estable con nicorandil añadido a su tratamiento ${ }^{76}$. No obstante, este resultado se obtuvo por los efectos del nicorandil administrado a «pacientes ingresados por dolor torácico», mientras que la reducción del riesgo de muerte cardiaca o infarto de miocardio no fatal durante 1,6 años de tratamiento no fue significativa ${ }^{76}$. Por este motivo, se ha puesto en duda la eficacia del tratamiento ${ }^{210}$. El nicorandil no se comercializa en todos los países.

\section{Otros medicamentos}

Los inhibidores del nódulo sinusal, como la ivabradina, tienen efectos cronotrópicos negativos tanto en reposo como durante el ejercicio, ofrecen una eficacia antianginosa probada y pueden ser utilizados como tratamiento alternativo para los pacientes con intolerancia a los bloqueadores beta ${ }^{171,211,212}$.

Los fármacos de acción metabólica protegen de la isquemia aumentando el metabolismo de la glucosa respecto al de los ácidos grasos. Se ha demostrado que tanto la trimetazidina ${ }^{213,214}$ como la ranolazina ${ }^{215,216}$ son agentes antianginosos eficaces. Se puede administrarlos en combinación con agentes de acción hemodinámica, ya que su efecto primario no se obtiene mediante la reducción de la frecuencia cardiaca o la presión arterial. La trimetazidina se comercializa hace varios años, aunque no en todos los países. La ranolazina está siendo objeto de numerosas investigaciones y su uso todavía no ha sido autorizado por la EMEA. Hasta la fecha no se ha determinado si estos fármacos influyen en el pronóstico de los pacientes con angina estable. La molsidomina es un vasodilatador con una acción similar a la de los nitratos orgánicos y, administrada en las dosis adecuadas, es un agente antiisquémico y antianginoso efectivo $^{217}$. No se comercializa en todos los países.

\section{Recomendaciones para el tratamiento farmacológico $(*)$}

El tratamiento farmacológico antianginoso debe estar adaptado a las necesidades individuales de cada paciente y, de la misma manera, se debe controlarlo. Se

(*) El objetivo del tratamiento farmacológico de la angina estable es no sólo mejorar la calidad de vida reduciendo la severidad y/o la frecuencia de los síntomas, sino también mejorar el pronóstico de los enfermos. Por ello, las Guías de la ESC recomiendan los fármacos antitrombóticos e hipolipemiantes en el tratamiento general de los enfermos con angina estable (fig. 4). prescribirá nitratos de acción rápida, según tolerancia, a todos los pacientes para el inmediato alivio de los síntomas agudos. Aunque se ha demostrado en ensayos clínicos que diferentes tipos de fármacos tienen efectos antianginosos aditivos, no se puede garantizarlos en todos y cada uno de los pacientes. La intensificación de la terapia antianginosa puede ser problemática, pues se ha demostrado ${ }^{218,219}$ que la combinación de 3 fármacos antianginosos proporciona menos protección sintomática que la combinación de 2 . Por ello, se optimizará la dosis de un fármaco antes de añadir otro; también se aconseja probar distintas combinaciones de 2 fármacos antes de implementar un régimen triple. Si no se obtiene los efectos esperados de un tratamiento, siempre conviene preguntarse si el paciente sigue adecuadamente las instrucciones.

La estrategia terapéutica que se describe a continuación (fig. 4) está indicada para el tratamiento farmacológico de la angina estable en pacientes que se considera aptos para tratamiento médico tras la valoración inicial y la estratificación del riesgo. Las siguientes recomendaciones constituyen una aproximación teórica al tratamiento antianginoso y los grados de evidencia se refieren a la eficacia antianginosa y antiisquémica, excepto cuando se indique lo contrario.

\section{Recomendaciones para el tratamiento farmacológico de los síntomas y la isquemia en pacientes con angina estable}

Clase I

- Prescribir nitroglicerina de acción rápida para el alivio de los síntomas agudos y profilaxis situacional, acompañada de explicaciones sobre las instrucciones de uso del tratamiento (nivel de evidencia B).

- Probar los efectos de un bloqueador beta-1 y aumentar la dosis gradualmente hasta alcanzar la dosis máxima; considerar la protección contra la isquemia durante las $24 \mathrm{~h}$ (nivel de evidencia A).

- En caso de intolerancia o ineficacia de los bloqueadores beta, probar monoterapia con un antagonista del calcio (nivel de evidencia A), un nitrato de acción prolongada (nivel de evidencia C) o nicorandil (nivel de evidencia $\mathrm{C}$ ).

- Si los efectos de la monoterapia con bloqueadores beta son insuficientes, agregar dihidropiridina BCC (nivel de evidencia B).

\section{Clase IIa}

- En caso de intolerancia a los bloqueadores beta, probar un inhibidor del nodo sinusal (nivel de evidencia B).

- Si la monoterapia con BCC o la terapia combinada (BCC con un bloqueador beta) no es eficaz, sustituir el $\mathrm{BCC}$ por un nitrato de acción prolongada o por nicorandil. Es preciso evitar la tolerancia a los nitratos (nivel de evidencia C). 


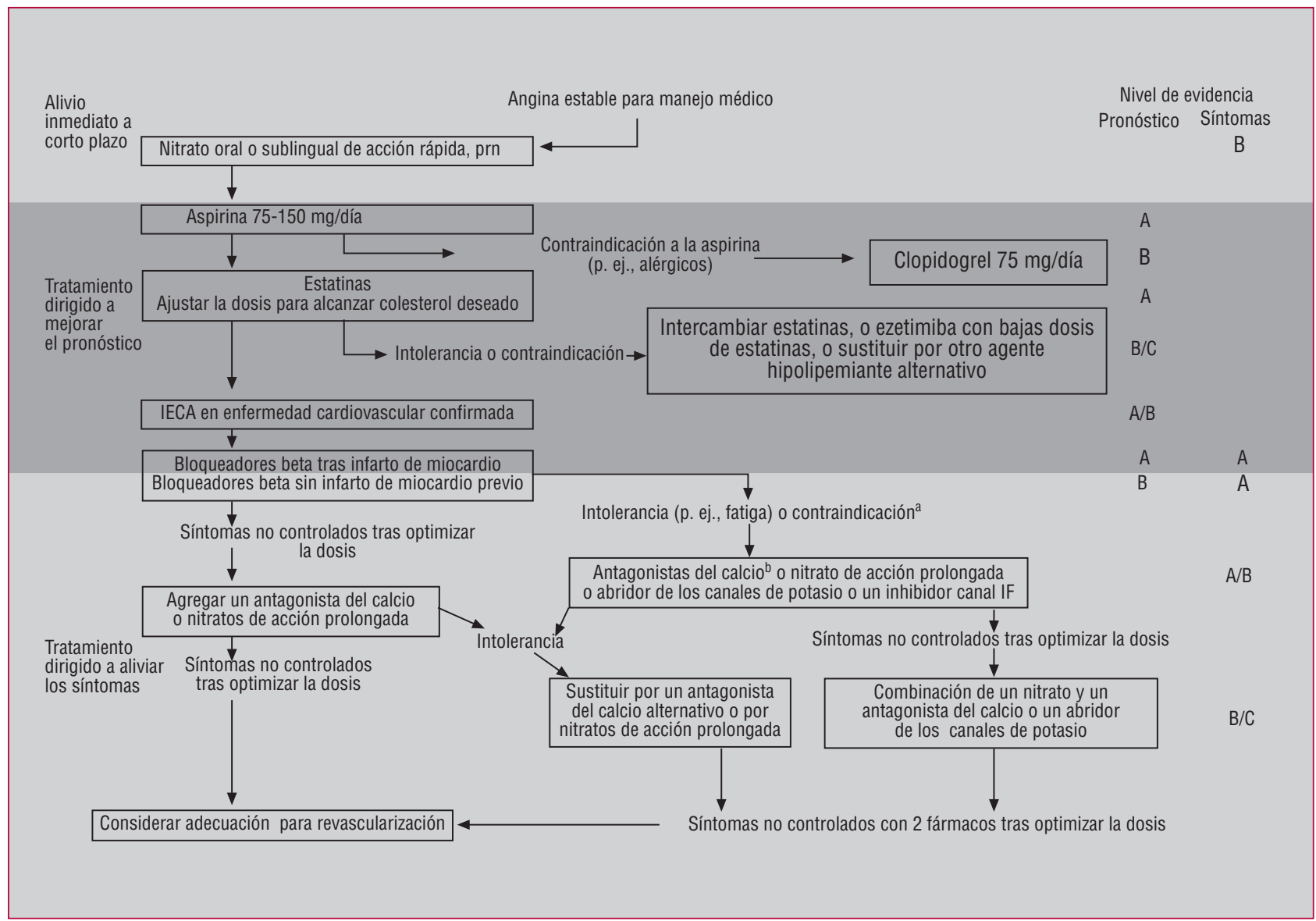

Fig. 4. Algoritmo del manejo médico de la angina estable. Se debe identificar y referir adecuadamente a los pacientes de alto riesgo a quienes se indica la revascularización solamente por el pronóstico.

aLas contraindicaciones relativas al tratamiento con bloqueadores beta incluyen asma, enfermedad vascular periférica sintomática y bloqueo cardiaco de primer grado.

'Evite administrar formulaciones de acción rápida de la dihidropiridina si no las combina con un bloqueador beta. La evidencia sobre el pronóstico se refiere a la evidencia de reducción de muerte de causa cardiovascular o cardiovascular e infarto de miocardio. La evidencia sobre los síntomas incluye la reducción de las revascularizaciones y reingresos por dolor torácico.

\section{Clase IIb}

- Se podrá utilizar agentes metabólicos, si están disponibles, como terapia añadida o como terapia de sustitución en caso de intolerancia al tratamiento convencional (nivel de evidencia B).

Sólo se considerará la terapia triple cuando la terapia doble óptima resulte insuficiente y después de analizar en profundidad los efectos de fármacos adicionales. Se considerará la posibilidad de revascularización en los pacientes cuyos síntomas no se pueda controlar eficazmente con doble terapia, también se considerará en pacientes que expresen claramente su preferencia por la revascularización en lugar del tratamiento farmacológico. En cada caso se explicará al paciente la necesidad de seguir el tratamiento farmacológico para mejorar el pronóstico y sus riesgos y beneficios, independientemente de que la revascularización esté indicada o no.
A pesar de las numerosas opciones terapéuticas descritas anteriormente, la angina rebelde al tratamiento sigue siendo un reto y las recomendaciones para su manejo se exponen más adelante separadamente.

\section{Consideraciones terapéuticas especiales: el síndrome $X$ y la angina vasoespástica}

Tratamiento del síndrome $X$. El tratamiento de este síndrome está dirigido al alivio de los sínto$\operatorname{mas}^{220}$. Dado que los nitratos son efectivos en la mitad de los pacientes, es razonable iniciar el tratamiento con nitratos de acción prolongada. Si los síntomas persisten, se añadirá antagonistas del calcio o bloqueadores beta. A pesar de que el bloqueo alfaadrenérgico aumenta la reserva vasodilatadora en pacientes con síndrome $\mathrm{X}$, estos fármacos son clínicamente ineficaces ${ }^{221,222}$. 
Se han publicado informes sobre otros fármacos, como el nicorandil y la trimetazidina, que pueden ser de utilidad en algunos pacientes.

Los IECA y las estatinas pueden revertir la disfunción endotelial subyacente y se debe considerarlos en los pacientes con síndrome $\mathrm{X}$ como parte del manejo de los factores de riesgo. Se dispone de indicios de que los IECA y las estatinas pueden ser eficaces en la reducción de la isquemia inducida por el ejercicio en este grupo de pacientes.

En estos pacientes, mantener los efectos terapéuticos a largo plazo constituye un reto que requiere un manejo multidisciplinario ${ }^{223}$. Podrían ser necesarios analgésicos como la imipramina o la aminofilina, psicoterapia, técnicas de electroestimulación y entrenamiento físico. Algunos estudios sobre THS transdérmica ${ }^{224,225}$ en pacientes posmenopáusicas han demostrado una mejoría en la función endotelial y en los síntomas; sin embargo, en vista de los datos recientemente publicados sobre efectos cardiovasculares adversos, se recomienda precaución a la hora de prescribir la THS con este propósito.

\section{Recomendaciones para el tratamiento farmacológico en el manejo de los síntomas de los pacientes con síndrome $X$}

\section{Clase I}

- Tratamiento con nitratos, bloqueadores beta y antagonistas del calcio, solos o combinados (nivel de evidencia B).

- Tratamiento con estatinas en pacientes con hiperlipemia (nivel de evidencia B).

- Tratamiento con IECA en pacientes con hipertensión (nivel de evidencia C).

\section{Clase IIa}

- Tratamiento tentativo con otros fármacos antianginosos como el nicorandil o agentes metabólicos (nivel de evidencia $\mathrm{C}$ ).

\section{Clase IIb}

- Aminofilina en caso de dolor persistente a pesar de las medidas de clase I (nivel de evidencia C).

- Imipramina en caso de dolor persistente a pesar de las medidas de clase I (nivel de evidencia C).

Tratamiento de la angina vasoespástica. En estos pacientes, la eliminación de los factores precipitantes, como el consumo de tabaco, es fundamental ${ }^{226}$. Los agentes más importantes del tratamiento farmacológico son los nitratos y los antagonistas del calcio. Aunque los nitratos son muy efectivos para prevenir el vasoespasmo, no previenen los ataques de angina en reposo de una forma tan eficiente ${ }^{129}$. Los bloqueadores de los canales de calcio son más eficaces para el alivio de los signos y síntomas del espasmo coronario y se administrarán a altas dosis (hasta $480 \mathrm{mg} /$ día de verapamilo, $260 \mathrm{mg} /$ día de diltiazem, $120 \mathrm{mg} /$ día de nifedipino). Sin embargo, mediante la administración de antagonistas del calcio se obtiene una resolución completa de los síntomas en sólo el 38\% de los pacientes ${ }^{129}$. En la mayoría de los casos es necesaria una terapia combinada con nitratos de acción prolongada y altas dosis de antagonistas del calcio para conseguir una mejoría de los síntomas. El papel de los bloqueadores beta es controvertido, aunque se ha informado de beneficios terapéuticos ocasionales ${ }^{227}$. El nicorandil, un activador de los canales de potasio, puede ser útil también en algunos pacientes con angina vasoespástica pertinaz ${ }^{228}$.

En aproximadamente la mitad de los pacientes de países occidentales, se ha observado una remisión espontánea de la vasoespasticidad tras la administración de tratamiento médico durante al menos 1 año ${ }^{229}$. Por tanto, es aceptable disminuir o interrumpir el tratamiento 6-12 meses después de que haya desaparecido la angina tratada. En caso de vasoespasmo por enfermedad coronaria significativa, se seguirá las recomendaciones de tratamiento para mejorar el pronóstico y se implementará las medidas de prevención secundaria.

\section{Recomendaciones para el tratamiento farmacológico de la angina vasoespástica}

\section{Clase I}

- Tratamiento con antagonistas del calcio y, si fuera preciso, nitratos en pacientes cuya coronariografía es normal o revela únicamente lesiones no obstructivas (nivel de evidencia B).

\section{REVASCULARIZACIÓN MIOCÁRDICA}

Existen 2 técnicas de revascularización bien establecidas para el tratamiento de la angina estable crónica producida por la aterosclerosis coronaria: la revascularización quirúrgica $(\mathrm{CABG})$ y las intervenciones coronarias percutáneas (ICP). En la actualidad, ambas técnicas están siendo objeto de un rápido desarrollo, en el caso de la primera, por la introducción de la cirugía mínimamente invasiva y la cirugía sin circulación extracorpórea, y en la segunda, por la implantación de stents liberadores de fármacos (SLF). Al igual que ocurre con el tratamiento farmacológico, los objetivos potenciales de la revascularización son dobles: por una parte, mejorar la supervivencia o la supervivencia libre de infarto y, por otra, reducir o eliminar los síntomas. El riesgo individual del paciente y su estado sintomático son los elementos fundamentales en el proceso de toma de decisiones.

\section{Cirugía de bypass aortocoronario}

Las principales indicaciones para la CABG son 2: pronósticas y sintomáticas. El beneficio pronóstico de la 
CABG se basa principalmente en la reducción de la mortalidad cardiaca, ya que se tiene menos evidencias de reducción del infarto de miocardio ${ }^{230,231}$. No se ha demostrado el beneficio pronóstico de la CABG comparada con tratamiento médico en pacientes de bajo riesgo (mortalidad anual $<1 \%)^{231}$. En un metaanálisis sobre cirugía cardiaca en el que se comparaba la $\mathrm{CABG}$ con el tratamiento médico, se demostró una mejora del pronóstico en pacientes de riesgo medio o elevado, pero incluso en los de riesgo medio se observó una tasa de mortalidad a los 5 años con tratamiento médico del $13,9 \%$ (mortalidad anual del 2,8\%), que actualmente se consideraría bastante elevada. Posteriormente, los datos observacionales del registro de Duke confirmaron que, en cuanto a la mortalidad, el beneficio a largo plazo de la cirugía se limitaba a los pacientes de alto riesgo ${ }^{232}$. Los análisis de datos procedentes de estudios observacionales y de estudios aleatorizados y controlados indican que, en presencia de determinados patrones de afección coronaria, la cirugía tiene relación con un mejor pronóstico que con el tratamiento médico ${ }^{104,231}$.

Entre dichos patrones de afección coronaria se encuentran los siguientes:

- Estenosis significativa del tronco común izquierdo.

- Estenosis proximal significativa de las 3 arterias coronarias principales.

- Estenosis significativa de 2 arterias coronarias importantes, incluida la estenosis crítica proximal de la descendente anterior izquierda.

En esos estudios, la estenosis significativa se definió como un $70 \%$ de las arterias coronarias mayores o un $50 \%$ del tronco común izquierdo. La presencia de una función del VI alterada aumenta la ventaja pronóstica absoluta de la cirugía respecto al tratamiento médico en todas las categorías. Esta información procede de 2 estudios importantes: el estudio European Coronary Artery y el North American CASS ${ }^{103,233}$.

Se ha demostrado que la cirugía reduce los síntomas y la isquemia y mejora la calidad de vida de los pacientes con angina crónica. Estos efectos son evidentes en una gama de subgrupos más amplia que en los que se ha demostrado un aumento de la supervivencia ${ }^{230}$. Sin embargo y a pesar de los avances en el tiempo, la morbilidad y la mortalidad operatorias son importantes factores que considerar. Por esta razón, se valorará en profundidad los riesgos y beneficios individuales tanto en los pacientes de bajo riesgo, en los que se indica la cirugía por los síntomas solamente, como en los pacientes de alto riesgo.

La mortalidad operatoria total de la CABG se encuentra entre el 1 y el 4\%,234-237, dependiendo de la población estudiada. Existen modelos de estratificación fiable del riesgo que permiten evaluar el riesgo individual de cada paciente ${ }^{238}$. Durante los últimos 20 años, el procedimiento estándar ha sido el implante de injerto de arteria torácica interna izquierda (ATII) en la descendente anterior izquierda y de vena safena para el resto de los injertos. La recurrencia de los síntomas en los casos de injerto de vena safena continúa siendo un problema clínico. En grandes estudios observacionales se ha demostrado que el uso de injertos de ATII mejora la supervivencia y reduce la incidencia del infarto de miocardio tardío y angina recurrente y la necesidad de intervenciones cardiacas posteriores ${ }^{239}$. Se ha utilizado también injertos de la arteria radial y la arteria gastroepiploica; entre éstos, se cuenta con más experiencia en los injertos de radial, con los que se ha observado tasas de permeabilidad $>90 \%$ en los primeros 3 años tras la cirugía.

En la cirugía de bypass aortocoronario, el uso de circulación extracorpórea (bypass cardiopulmonar) es la técnica utilizada más frecuentemente. Sin embargo, se espera que la llamada cirugía «sin bomba» pueda reducir la mortalidad y la morbilidad perioperatorias. Disponemos de estudios aleatorizados en los que se compara la cirugía sin bomba y la cirugía convencional en los que no se ha demostrado una diferencia en los resultados durante los primeros 1-3 años entre los 2 grupos $^{240,241}$. Más recientemente, en un estudio aleatorizado con seguimiento angiográfico a los 3 y 6 meses, Khan et $\mathrm{al}^{242}$ demostraron una reducción significativa de la permeabilidad del injerto (el 90 frente al 98\%) en el grupo de cirugía sin bomba. Estos estudios señalan que la cirugía sin bomba no es una panacea y se debe aplicarla de forma cautelosa y selectiva en pacientes con vasos adecuados al tratamiento y comorbilidad significativa.

\section{Intervención coronaria percutánea}

Aunque inicialmente la angioplastia coronaria transluminal percutánea se utilizaba únicamente para el tratamiento de enfermedad de un vaso, los avances en experiencia, equipos, materiales (especialmente stents) y terapias coadyuvantes han expandido el papel de este tipo de tratamiento en los últimos años. En pacientes con angina estable y una anatomía coronaria adecuada, el uso de stents y terapia coadyuvante permite que un especialista competente realice una ICP de un vaso o vasos múltiples con una alta probabilidad de éxito inicial del procedimiento y un aceptable perfil de ries$\mathrm{go}^{243}$. El riesgo de muerte por el procedimiento en la angioplastia habitual es aproximadamente de un 0,3$1 \%$, con posibles variaciones. Las ICP pueden ser una alternativa a la CABG para el tratamiento sintomático en la mayoría de los casos. Por la evidencia disponible, las ICP comparadas con el tratamiento médico no ofrecen beneficios sustanciales en la supervivencia de la angina estable ${ }^{244}$.

La evidencia derivada de ensayos clínicos indica que las ICP son más efectivas que el tratamiento médi- 
co en la reducción de eventos que afectan a la calidad de vida (angina de pecho, disnea, reingreso hospitalario o limitación de la capacidad de ejercicio). Los investigadores del estudio $\mathrm{ACME}^{245}$ demostraron un mejor control de los síntomas y una mayor capacidad de ejercicio en los pacientes tratados con ICP que en los sometidos a tratamiento médico. Las tasas de mortalidad e infarto de miocardio fueron similares en ambos grupos. Sin embargo, en los pacientes con enfermedad de 2 vasos los resultados a medio plazo no demostraron la superioridad de las ICP en el control de los síntomas comparadas con tratamiento médico (aumento similar del tiempo de ejercicio, ausencia de angina y mejoras en la calidad de vida en el seguimiento a los 6 meses), mientras que sí se demostró en los pacientes con enfermedad de un vaso ${ }^{246}$. Los resultados de este pequeño estudio $(n=328)$ indican que las ICP pueden ser menos efectivas para el control de los síntomas en los pacientes con enfermedad de 2 vasos y angina estable que en los pacientes con enfermedad de un vaso.

El estudio RITA-2 ${ }^{247}$ demostró que las ICP ofrecen un mayor control de los síntomas de isquemia y mejoran la capacidad de ejercicio respecto al tratamiento médico, pero que se relacionan con un mayor objetivo combinado de muerte e infarto de miocardio perioperatorio. En este estudio, se asignó aleatoriamente a un total de 1.018 pacientes con angina estable y cardiopatía isquémica multivaso $(62 \%)$ o enfermedad significativa del segmento proximal de la descendente anterior izquierda (34\%) a ICP o tratamiento médico, con una media de seguimiento de 2,7 años. Los pacientes cuyos síntomas no se controlaron mediante terapia médica óptima se cruzaron al grupo de revascularización miocárdica. En el estudio AVERT ${ }^{248}, 341$ pacientes con cardiopatía isquémica estable, función del VI normal y angina de clase I y/o II fueron asignados a ICP o tratamiento médico $(80 \mathrm{mg} / \mathrm{día}$ de atorvastatina). En el seguimiento a los 18 meses, el 13\% del grupo de atorvastatina presentó eventos isquémicos, comparado con el $21 \%$ en el grupo de ICP ( $p=0,048)$. El alivio de los síntomas de angina fue mayor en el grupo de ICP. Estos datos indican que en los pacientes de bajo riesgo con cardiopatía isquémica estable, el tratamiento médico, como una terapia hipolipemiante agresiva, puede ser tan eficaz como las ICP en la reducción de los eventos isquémicos, mientras que el ICP es más efectivo en el alivio de los síntomas.

\section{Implantación electiva de stents y stents liberadores de fármacos}

En un metaanálisis de 29 estudios, con una población total de 9.918 pacientes, no se observaron diferencias entre la implantación de stents habitual y la angioplastia convencional con balón en cuanto muerte o infarto de miocardio o la necesidad de CABG. En un metaanálisis ${ }^{249}$ más reciente, se demostró que la im- plantación de stents coronarios reduce la tasa de reestenosis y la necedidad de repetición de $\mathrm{ICP}^{250}$. Sin embargo, la reestenosis intra-stent continúa limitando la eficacia de las ICP en los pacientes con enfermedad coronaria estable y determina una necesidad de revascularización del vaso diana en un 5-25\%.

Desde la publicación de los resultados del estudio RAVEL $^{251}$, los SLF han concentrado el interés del ICP. Hasta la fecha se ha demostrado resultados positivos significativos con 3 fármacos (paclitaxel, sirolimus y su derivado everolimus) en estudios prospectivos aleatorizados. Esos estudios incluyen únicamente a pacientes con enfermedad de un vaso y angina estable o inestable. El uso de SLF, comparado con stents sin recubrir, ofrece efectos mejores y más persistentes en la reducción del riesgo de reestenosis y eventos cardiacos mayores, entre los que se incluye la revascularización del vaso diana. La incidencia registrada de eventos cardiacos mayores (MACE) durante 9 meses se sitúa entre el 7,1 y el 10,3\% con SLF, mientras que con stents $\sin$ recubrir es del 13,3 y el 18,9\%. La guía de práctica clínica de la ESC sobre ICP ofrece recomendaciones específicas sobre el uso de SLF ${ }^{252}$.

\section{Revascularización frente a tratamiento médico}

Aparte de los estudios en los que se compara exclusivamente los efectos de las ICP y los de la terapia médica o la cirugía frente a terapia médica, en varios estudios híbridos se ha investigado los efectos de la revascularización (ICP o cirugía) comparados con el tratamiento médico. El estudio Asymptomatic Cardiac Ischaemia Pilot ${ }^{253}$ (ACIP) proporciona información adicional sobre la comparación entre tratamiento médico y revascularización (ICP o CABG) en pacientes con cardiopatía isquémica e isquemia asintomática documentadas en la prueba de esfuerzo y ECG ambulatorio. En este pequeño estudio $(n=558)$, pacientes con síntomas mínimos pero con evidencia de isquemia documentada y candidatos a ICP o CABG fueron asignados de forma aleatoria a una de estas 3 estrategias: tratamiento farmacológico guiado por la angina, tratamiento farmacológico guiado por la angina y la isquemia o revascularización mediante ICP o CABG. A los 2 años de seguimiento, la tasa de muerte o infarto de miocardio en el grupo de revascularización fue del $4,7 \%$, comparada con el $8,8 \%$ del grupo de tratamiento guiado por la isquemia y el $12,1 \%$ del grupo guiado por la angina ( $\mathrm{p}<0,01$ para el grupo de revascularización comparado con el grupo de isquemia o angina). Los resultados del estudio ACIP indican que los pacientes de alto riesgo, asintomáticos o mínimamente sintomáticos pero con isquemia demostrable y cardiopatía isquémica significativa, tienen mejores resultados con la revascularización (ICP o CABG) que con tratamiento médico. 
En el estudio suizo TIME ${ }^{254}$, realizado con pacientes ancianos (media de edad, 80 años) con angina severa, se asignó aleatoriamente a los participantes a tratamiento invasivo inmediato o a continuación del tratamiento médico. Del grupo de terapia invasiva, el 52\% se sometió a ICP y el 21\%, a CABG. El tratamiento invasivo tuvo relación con una mejoría estadísticamente significativa de los síntomas a los 6 meses, pero esa diferencia no se mantuvo al año, en parte debido a una tasa de revascularización tardía del $48 \%$ del grupo de tratamiento médico. No se observaron diferencias significativas entre los dos grupos en relación con la tasa de mortalidad e infarto de miocardio. En el estudio Medicine, Angioplasty or Surgery (MASS) ${ }^{255}$, se asignó aleatoriamente a pacientes con angina estable y enfermedad aislada de la descendente anterior a tratamiento médico o ICP (stents incluidos) o CABG, con un objetivo combinado de muerte cardiaca, infarto de miocardio o angina pertinaz que requería repetición quirúrgica de revascularización. A los 3 años de seguimiento, este objetivo combinado se obtuvo en el $24 \%$ de los pacientes del grupo de ICP, en el 17\% del grupo de tratamiento médico y en el $3 \%$ de los pacientes quirúrgicos. La ausencia de diferencias significativas entre los 3 grupos respecto a la supervivencia total es un importante dato que considerar. La tasa de muerte o infarto de miocardio fue del $1 \%$ del grupo de CABG, el $2 \%$ del de ICP y el $1,4 \%$ del grupo de tratamiento médico.

\section{Intervención coronaria percutánea frente a cirugía}

Un gran número de ensayos clínicos han comparado el ICP con la cirugía, tanto antes como después de la introducción de stents ${ }^{236,256,257}$, en pacientes con enfermedad de un vaso o multivaso, al objeto de establecer la elección de la técnica de revascularización. El metaanálisis de los estudios realizados antes de $1995^{258}$, cuando el uso de stents coronarios era poco frecuente, no reveló diferencias significativas entre las estrategias terapéuticas en cuanto a la tasa de muerte o la tasa combinada de muerte e infarto de miocardio. La mortalidad durante el ingreso preoperatorio fue del 1,3\% del grupo de cirugía y el $1 \%$ del grupo de ICP. La necesidad de repetición de la revascularización fue significativamente más elevada en el grupo de ICP y, aunque los pacientes 1 año después de la CABG tenían menos posibilidades de sufrir angina que con la ICP, 3 años después esa diferencia no era estadísticamente significativa. Los resultados del estudio BARI, el más grande realizado para comparar ICP y CABG (no incluido en el metaanálisis antes citado), concordaron con esos hallazgos, aunque en cuanto a supervivencia se observó una ventaja con la cirugía de bypass en el subgrupo de pacientes diabéticos ${ }^{259}$.

Estudios más recientes, como el ARTS ${ }^{260}$ y el $\mathrm{SOS}^{256}$, han incorporado el uso de stents como parte de las ICP. En el ARTS $1^{260}$ se comparó la estrategia de la implantación múltiple de stents para lograr una revascularización completa y la cirugía en pacientes con enfermedad multivaso (EMV). No obstante, ese estudio no se realizó exclusivamente con pacientes con angina estable; en ambos grupos de tratamiento, el 37 y el $35 \%$, respectivamente, de los pacientes tenían angina inestable, el 57 y el $60 \%$, respectivamente, tenían angina estable, y el 6 y el 5\%, respectivamente, tenían isquemia asintomática. Un año después del procedimiento, la implantación selectiva de stents en pacientes con EMV tuvo resultados similares que la $\mathrm{CABG}$ en muerte, accidente cerebral e infarto de miocardio. Sin embargo, la implantación de stents se asoció a una mayor necesidad de repetición de la revascularización.

El metaanálisis en el que se incluyen los estudios con stents $^{234}$ señala un beneficio en la mortalidad con la CABG comparada con ICP a los 5 años, que se mantiene hasta los 8 años en pacientes con EMV, así como una menor incidencia de angina y una menor necesidad de repetición de la revascularización. El análisis de subgrupos de los estudios con o sin implantación de stents muestra una considerable heterogeneidad entre los grupos. Los estudios de la era previa al stent muestran una tendencia en la reducción de la mortalidad favorable a la CABG que no se observa en los estudios posteriores. En otro metaanálisis más reciente que incluye 4 estudios aleatorizados en los que se compara el uso de ICP con stents y cirugía de bypass $(\mathrm{n}=3.051)$, no se observó diferencias entre ambas estrategias de tratamiento en el objetivo primario combinado de muerte, infarto de miocardio o accidente cerebral al año. Sin embargo, los datos observacionales procedentes del New York Cardiac Registry (con más de 60.000 pacientes) indican que, para los pacientes con enfermedad de 2 o más vasos, la CABG se asoció con tasas ajustadas de supervivencia a largo plazo más elevadas que con la implantación de stents.

En resumen, dejando a un lado la población de alto riesgo, en la que se ha demostrado la superioridad pronóstica de la cirugía, y partiendo de la evidencia recogida por distintos estudios, se considera que las ICP y la cirugía son igualmente eficaces para el tratamiento de la angina. Tras la indicación de tratamiento médico inicial, se puede recomendar la revascularización en pacientes con anatomía adecuada que no responden adecuadamente al tratamiento médico, así como en pacientes individuales que, independientemente su edad, desean continuar con su actividad física normal (ejercicio físico regular).

En pacientes no diabéticos con enfermedad de uno o 2 vasos, sin estenosis de alto grado en la descendente anterior proximal, en los que la angioplastia de una o 2 lesiones tiene muchas probabilidades de éxito inicial, se prefiere realizar una ICP por consideraciones como su naturaleza menos invasiva y el bajo riesgo inicial del procedimiento, además de la ausencia de ventajas de la CABG en la supervivencia de pacientes de bajo 
riesgo. Se tendrá en cuenta las circunstancias individuales del paciente y sus preferencias a la hora de planificar el tratamiento.

En pacientes asintomáticos, la única indicación de ICP sería para reducir la posibilidad de complicaciones isquémicas en el futuro. La evidencia para recomendar esta estrategia está limitada a los pacientes con evidencia objetiva de isquemia extensa, en los que la revascularización (ICP o cirugía) podría reducir el riesgo de muerte por el tratamiento médico basado en la angina (estudio ACIP $)^{253}$. Sólo se considerará una ICP en pacientes ligeramente sintomáticos si presentan alto riesgo de isquemia y cardiopatía isquémica anatómica severa y se considera que hay gran probabilidad de éxito del procedimiento y bajo riesgo de morbilidad y mortalidad.

\section{Subgrupos específicos de pacientes y lesiones}

Los pacientes con la función del VI severamente deprimida y/o con alto riesgo quirúrgico, enfermedad del tronco común izquierdo, diabetes y enfermedad multivaso o cirugía previa de bypass aortocoronario requieren una atención especial a la hora de considerar las opciones de revascularización.

Los pacientes con un riesgo quirúrgico excesivamente elevado podrían beneficiarse de la revascularización mediante ICP, especialmente cuando se pueda demostrar una viabilidad residual en el miocardio disfuncional perfundido por el vaso o los vasos a tratar. Hoy en día se están desarrollando 2 estudios aleatorizados importantes, el estudio STICH $^{261}$ y el HEART $\mathrm{UK}^{262}$, sobre este tema.

Aunque el ICP en la enfermedad de tronco común izquierdo es factible y se haya obtenido buenos resultados en los registros comparativos de SLF y stents no recubiertos $^{263}$, la cirugía continúa siendo la técnica de elección mientras se espera a los resultados de futuros estudios.

El análisis de subgrupos de estudios aleatorizados ha demostrado una reducción de la mortalidad con la cirugía de bypass comparada con ICP en pacientes diabéticos con $\mathrm{EMV}^{264,265}$. El estudio BARI fue el mayor y el único en el que se detectó una diferencia significativa de la mortalidad entre ambos grupos de tratamiento en los pacientes diabéticos ${ }^{259,266}$. Una limitación de estos estudios es que se realizaron antes de la generalización del uso de SLF o del tratamiento antiplaquetario coadyuvante perioperatorio, aunque en la actualidad se están desarrollando 2 estudios importantes, el BARI 2 en la diabetes (BARI 2D) y el FREEDOM (Future Revascularization Evaluation in Patients with Diabetes Mellitus). Por el momento y considerando la evidencia disponible, el ICP se utilizará con reservas en pacientes diabéticos con EMV hasta que se conozca los resultados de otros estudios.

No existen ensayos clínicos aleatorizados y controlados en pacientes con injertos previos de bypass. Cuan- do la anatomía lo permita y según los síntomas, se considerará la posibilidad de una reintervención quirúrgica, aunque el riesgo de la operación es 3 veces mayor que en la cirugía inicial. Además, en los pacientes con injerto permeable de mamaria, se tiene el riesgo adicional de dañar ese injerto en la cirugía. Por otro lado, el ICP puede realizarse tras la cirugía de revascularización previa, tanto en injertos de safena como arteriales o en el árbol coronario nativo en segmentos distales al injerto y puede ser una buena alternativa a la repetición de la cirugía para el alivio de los síntomas.

Por último, en el caso de oclusiones totales que no pueden ser cruzadas, y en pacientes con afección multivaso, el procedimiento podría finalizar con una revascularización incompleta, que se evitaría si el paciente fuera referido a cirugía de bypass aortocoronario.

\section{Indicaciones para la revascularización}

En general, los pacientes con indicación de angiograma coronario en los que el cateterismo revela estenosis coronaria severa son potenciales candidatos a revascularización miocárdica. Además, un paciente es potencial candidato a revascularización si:

- El tratamiento médico no controla los síntomas a satisfacción del paciente.

- Las pruebas no invasivas revelan una zona sustancial de miocardio en riesgo.

- Hay alta probabilidad de éxito del procedimiento con un riesgo de morbilidad y mortalidad aceptable.

- El paciente prefiere una intervención en lugar de tratamiento médico y está informado de los riesgos de este tipo de tratamiento.

Se evaluará la adecuada respuesta al tratamiento en consulta con el paciente. Para algunos pacientes los síntomas de clase I (angina secundaria a esfuerzo extenuante pero no durante las actividades físicas normales) son tolerables, mientras que otros prefieren la desaparición total de los síntomas. Las recomendaciones para la revascularización según los síntomas (tabla 6) tienen en consideración el grado de severidad de los síntomas para los que existe evidencia y así se debe interpretarlas, y no como una recomendación de revascularización en toda la gama sintomática. También se debe sopesar de forma individualizada para cada paciente qué se considera un riesgo aceptable de morbilidad y mortalidad. Idealmente, no se aconsejará a los pacientes un procedimiento con una mortalidad que exceda la mortalidad anual estimada para el paciente, excepto cuando exista evidencia de un beneficio pronóstico sustancial a largo plazo o cuando los síntomas tengan serio impacto en la calidad de vida del paciente a pesar de seguir una terapia médica óptima.

La elección del método de revascularización se basará en: 

rias.

- El riesgo de morbilidad y mortalidad perioperato-

- La probabilidad de éxito, incluidos factores como que las lesiones sean técnicamente adecuadas para angioplastia o cirugía de bypass.

- Riesgo de reestenosis u oclusión del injerto.

- La posibilidad de resvascularización completa. En caso de ICP en la EMV, ¿hay alta probabilidad de que la ICP proporcione una completa revascularización o, cuando menos, similar a la de la CABG?

- Diabetes.

- Experiencia del centro hospitalario en cirugía cardiaca y en intervencionismo cardiaco.

- Las preferencias del paciente.

Entre la contraindicaciones a la revascularización miocárdica se incluye:

- Pacientes con cardiopatía isquémica en uno o 2 vasos sin estenosis significativa de la descendente anterior izquierda, con síntomas leves o asintomáticos, en los que no se haya probado una terapia médica adecuada o que no tengan isquemia demostrada o presenten sólo una zona limitada de isquemia/viabilidad documentada por pruebas no invasivas.

- Estenosis coronaria límite (50-70\%), en localización diferente del tronco común izquierdo e isquemia no demostrable mediante pruebas no invasivas.

- Estenosis coronaria no significativa $(<50 \%)$.

- Alto riesgo de morbilidad o mortalidad por el procedimiento (riesgo de mortalidad $>10-15 \%$ ), excepto cuando se prevea una mejora significativa de la supervivencia o cuando la calidad de vida del paciente esté muy afectada.

Los continuos y rápidos avances en el campo del intervencionismo coronario y de la cirugía cardiaca, así como los importantes progresos en la terapia médica y en la prevención secundaria, han generado la necesidad de grandes estudios aleatorizados para comparar diferentes estrategias de tratamiento en grupos seleccionados de pacientes. En el manejo de la angina estable quedan muchas preguntas por contestar y otras nuevas aparecen con el desarrollo de nuevas modalidades de tratamiento, por lo que se hace imprescindible revisar y actualizar estas guías continuamente. Entre tanto, los médicos especializados deben mantenerse al día de lo publicado en relación con este tema.

\section{Recomendaciones sobre la revascularización para mejorar el pronóstico en pacientes con angina estable}

\section{Clase I}

- CABG para cardiopatía isquémica significativa en el tronco común izquierdo o equivalentes (como este- nosis del segmento ostial/proximal de la descendente izquierda y circunfleja) (nivel de evidencia A).

- CABG para la estenosis significativa de las 3 grandes arterias coronarias, especialmente en pacientes con la función del VI afectada o con isquemia previa, extensa y reversible, documentada por pruebas funcionales (nivel de evidencia A).

- CABG para enfermedad de uno o 2 vasos con estenosis severa de la descendente anterior izquierda proximal, con isquemia reversible documentada por pruebas no invasivas (nivel de evidencia A).

- CABG para enfermedad significativa con la función del VI afectada y viabilidad demostrada por pruebas no invasivas (nivel de evidencia B).

\section{Clase IIa}

- CABG para cardiopatía isquémica de uno o 2 vasos sin estenosis significativa en la descendente anterior izquierda proximal, en pacientes que han sobrevivido a un episodio de muerte súbita o de taquicardia ventricular mantenida (nivel de evidencia B).

- CABG para enfermedad significativa de 3 vasos en pacientes diabéticos con isquemia reversible documentada por pruebas funcionales (nivel de evidencia $\mathrm{C}$ ).

- ICP o CABG para pacientes con isquemia reversible documentada por pruebas funcionales y evidencia de frecuentes episodios de isquemia durante las actividades diarias (nivel de evidencia C).

\section{Recomendaciones sobre la revascularización para mejorar los síntomas en pacientes con angina estable}

\section{Clase I}

- CABG en la enfermedad multivaso técnicamente adecuada para revascularización quirúrgica de pacientes con síntomas moderados/severos no controlados mediante terapia médica, en quienes los riesgos de la cirugía no sobrepasan a los beneficios potenciales (nivel de evidencia A).

- ICP para enfermedad de un vaso técnicamente adecuada para revascularización percutánea de pacientes con síntomas moderados/severos no controlados mediante terapia médica, en quienes los riesgos del procedimiento no sobrepasan a los beneficios potenciales (nivel de evidencia A).

- ICP en la enfermedad multivaso sin anatomía coronaria de riesgo elevado, técnicamente factible para la revascularización percutánea de pacientes con síntomas moderados/severos no controlados mediante terapia médica, en quienes los riesgos del procedimiento no sobrepasan a los beneficios potenciales (nivel de evidencia A).

\section{Clase IIa}

- ICP en la enfermedad de un vaso técnicamente factible para la revascularización percutánea de pa- 
cientes con síntomas leves/moderados, pero que el paciente considera inaceptables, siempre que los riesgos del procedimiento no sobrepasen a los beneficios potenciales (nivel de evidencia A).

- CABG para enfermedad de un vaso técnicamente adecuada para la revascularización quirúrgica de pacientes con síntomas moderados/severos no controlados mediante terapia médica, en quienes los riesgos de la cirugía no sobrepasan a los beneficios potenciales (nivel de evidencia A).

- CABG en enfermedad multivaso técnicamente viable para revascularización quirúrgica en pacientes con síntomas leves/moderados, pero que el paciente considera inaceptables, siempre que los riesgos de la cirugía no sobrepasen a los beneficios potenciales (nivel de evidencia A).

- PCI para enfermedad multivaso técnicamente factible para la revascularización percutánea de pacientes con síntomas leves/moderados, pero que el paciente considera inaceptables, siempre que los riesgos del procedimiento no sobrepasen a los beneficios potenciales (nivel de evidencia A).

\section{Clase IIb}

- CABG para enfermedad de un vaso técnicamente factible para la revascularización quirúrgica de pacientes con síntomas leves/moderados, pero que el paciente considera inaceptables, siempre que los riesgos de la cirugía no sobrepasen a los beneficios potenciales (nivel de evidencia B).

\section{SUBGRUPOS ESPECIALES}

\section{Mujeres}

La valoración del dolor torácico en la mujer resulta en muchos aspectos más compleja que en el varón, tanto por diferencias sexuales en la presentación y la manifestación de la enfermedad ${ }^{267}$ como por la preponderancia de datos procedentes de varones en la literatura médica.

Son numerosas las diferencias en la epidemiología y las manifestaciones primarias de la cardiopatía isquémica (CI) en la mujer y en el hombre. La angina estable es la primera manifestación de CI más frecuente en la mujer, mientras que el infarto agudo de miocardio (IAM) o la muerte súbita lo son en el varón ${ }^{3,268,269}$. Además, aunque la incidencia de IAM o muerte por CI es en general más alta en el varón que en la mujer en todos los segmentos de edad, la incidencia de angina en la mujer pasa de ser más baja en las primeras décadas de vida a ser mayor que la de los varones en los grupos de edad posmenopáusicos. De ahí que no resulte sorprendente que, en la población general, algunos estudios hayan comunicado una prevalencia de angina, estimada mediante el cuestionario de Rose, mayor en mujeres de mediana edad y ancianas que en los varo- nes de edad comparable ${ }^{270-274}$. Sin embargo, en estudios realizados en la población general, la incidencia de CI fatal es más alta en los varones con angina que en las mujeres con angina, lo que podría explicarse en parte como el resultado de haber clasificado incorrectamente la angina como enfermedad coronaria en un porcentaje de mujeres.

El diagnóstico de angina es más difícil en las mujeres que en los varones por distintos motivos. Si bien los síntomas atípicos son más frecuentes en las mujeres que en los varones, el propio calificativo de «atípicos» se da tomando como referencia los síntomas descritos por los varones. Además, la percepción del dolor por el paciente y el lenguaje utilizado para comunicar los síntomas difieren entre varones y mujeres ${ }^{275}$.

Para complicar aún más el problema, la correlación existente entre síntomas y obstrucción luminal «significativa» documentada en la coronariografía es más débil en las mujeres que en los varones. En el Coronary Artery Surgery Study ${ }^{276}$ se documentaron estenosis coronarias significativas en el $62 \%$ de las mujeres con angina típica, en el $40 \%$ de las mujeres con angina atípica y en el $4 \%$ de las mujeres con dolor de etiología no isquémica, un hecho que ilustra que la prevalencia de CI confirmada angiográficamente es más baja en las mujeres que en los varones en todas las formas de dolor torácico, incluidos las formas típica y atípica de la angina y el dolor torácico no cardiaco.

Cuando la ergometría se utiliza como método de detección de enfermedad coronaria significativa, la aparición de falsos positivos es mayor en las mujeres $(38-67 \%)$ que en los varones $(7-44 \%)^{277}$-en gran parte como resultado de una probabilidad de enfermedad pretest más baja ${ }^{31}$, si bien las mujeres presentan menos falsos negativos ${ }^{278}$. Como resultado, la prueba tiene un poder predictivo negativo muy alto, lo que quiere decir que un resultado negativo de la ergometría permite descartar de forma fiable una CI. Las dificultades para diagnosticar lesiones coronarias obstructivas mediante ergometría llevaron a proponer el uso de las técnicas de imagen como alternativa a la prueba de esfuerzo convencional. Resultaría lógico pensar que en las circunstancias antedichas la gammagrafía de perfusión miocárdica o la ecocardiografía serían buenos complementos de la ergometría convencional. Sin embargo, en las mujeres la sensibilidad de la gammagrafía cardiaca con talio puede ser menor que en los varones ${ }^{279}$. Los artefactos resultantes de la atenuación causada por las mamas, que se presentan normalmente en la cara anterior, pueden constituir un problema importante al interpretar las gammagrafías realizadas en la mujer. En este sentido, la ecocardiografía de estrés o farmacológica puede ser de utilidad para evitar artefactos específicamente causados por dicha atenuación por las mamas. De hecho, numerosos estudios han mostrado que, en mujeres con sospecha o certeza de CI, la ecocardiografía 
de estrés tiene un valor predictivo de desarrollo de eventos cardiacos independiente $e^{4,5,280,281}$.

A pesar de sus limitaciones en la mujer, se ha demostrado que la realización del ECG de esfuerzo reduce el número de pruebas diagnósticas sin que haya pérdida de precisión diagnóstica. De hecho, en sólo un $30 \%$ de las mujeres (aquellas en las que no se alcanzó el diagnóstico de CI o se lo excluyó con certeza) es preciso realizar otras pruebas ${ }^{282}$. Aunque aún está por definir la estrategia óptima para el diagnóstico de la CI en la mujer, el Grupo de Trabajo considera que no existe evidencia suficiente que haga recomendable sustituir en todas las mujeres en estudio por posible CI la ergometría convencional por las técnicas de imagen con estrés. En muchas mujeres con baja probabilidad de enfermedad pretest, se considera suficiente una ergometría negativa, sin que sean necesarias técnicas de imagen con estrés adicionales ${ }^{282}$.

Es importante recalcar que la disponibilidad de la coronariografía para las mujeres con evidencia objetiva en tests no invasivos de isquemia moderada o severa debe ser idéntica que para los varones. Además, la limitada inclusión de mujeres en los ensayos clínicos sobre prevención secundaria disponibles hasta la fecha no justifica una aplicación de dichas guías a las mujeres diferente que a los varones, una vez que se ha diagnosticado CI.

Es sabido que las mujeres tienen más morbilidad y mortalidad que los varones tras un infarto de miocardio, y algunos autores han indicado que un tratamiento menos intenso podría ser la causa de la menor supervivencia de la mujer tras el infarto de miocardio ${ }^{283}$. En una revisión de 27 estudios se concluyó que los motivos tras el aumento temprano de la mortalidad en la mujer eran la edad y la presencia de otras características clínicas de base desfavorables ${ }^{284}$. En investigaciones posteriores, se documentó una interacción entre el sexo y la edad, con un exceso de mortalidad del 50\% en las mujeres más jóvenes ( $<50$ años) que disminuye con la edad ${ }^{285}$.

Los informes sobre cómo el sexo de pacientes estables repercute en la utilización de pruebas y tratamientos, y por ende en la evolución clínica, muestran resultados igualmente divergentes. En un reciente estudio holandés, se realizó durante un período de 16 años (1981-1997) un seguimiento de 1.894 pacientes (1.526 varones, 368 mujeres) con CI documentada angiográficamente. Durante el seguimiento, el número de angioplastias coronarias aumentó significativamente tanto en los varones (del 11,6 al 23,2\%) como en las mujeres (del 17,6 al 28,0\%), mientras que el número de revascularizaciones coronarias quirúrgicas disminuyó en los varones del 34,9 al 29,5\% y en las mujeres del 42,6 al 30,6\% ${ }^{286}$. Sin embargo, la interpretación de este y otros registros basados en la coronariografía está limitada por un sesgo intrínseco en la solicitud de dicha prueba. Los datos del Euro Heart Survey sobre angina estable obtenidos en 2003 indican que hay un sesgo contra la utilización en la mujer no sólo de la coronariografía, sino también de la ergometría, aun tras realizar un ajuste por factores de edad, otras enfermedades concomitantes, intensidad de los síntomas y, en el caso de la coronariografía, los resultados de la ergometría ${ }^{287}$. En el mismo estudio las mujeres tenían menos posibilidades de revascularización coronaria y de recibir un tratamiento de prevención secundaria efectivo. Estos hallazgos señalan que las dificultades diagnósticas percibidas y la limitada documentación específica sobre la mujer y el tratamiento de la angina, posiblemente en conjunción con aspectos sociales más complejos, han perpetuado una situación en la que, con frecuencia, la mujer con angina estable es objeto de una valoración y un tratamiento deficientes.

\section{Diabetes mellitus}

Tanto la diabetes insulinodependiente (tipo 1) como la no insulinodependiente (tipo 2) conllevan un mayor riesgo de CI. Además, la mortalidad de la CI es 3 veces mayor en los varones diabéticos, y de 2 a 5 veces mayor en las mujeres diabéticas que en los pacientes no diabéticos ajustados por la edad y el sexo ${ }^{288}$. Además, varios estudios epidemiológicos indican que en los pacientes con diabetes se cumple que a mayores concentraciones de glucosa en sangre se produce una mayor incidencia de $\mathrm{CI}^{289,290}$.

Las manifestaciones clínicas de la CI son similares en el paciente diabético y en el no diabético, principalmente en forma de angina, IAM e insuficiencia cardiaca, si bien dichos síntomas suelen darse a una edad más temprana en el diabético. En general se acepta que la prevalencia de la isquemia asintomática es mayor en el paciente diabético. En cualquier caso, teniendo en cuenta la importante variabilidad en los criterios de inclusión y exclusión, así como de los métodos de evaluación que se han aplicado en los estudios previos, resulta difícil realizar de forma precisa una estimación del aumento de la prevalencia de la isquemia asintomática $^{291}$.

Hay un creciente interés en la aplicación de la gammagrafía de perfusión miocárdica y otras pruebas diagnósticas en el diagnóstico de la isquemia asintomática en el diabético ${ }^{292}$. Se tiene evidencia de que los pacientes diabéticos pueden presentar una disfunción ventricular subclínica que influya negativamente en la capacidad de esfuerzo ${ }^{293}$, un objetivo importante en la prueba ergométrica, pero no está claro cuál es la relevancia de dicha observación para la información diagnóstica y pronóstica que proporciona la prueba de esfuerzo convencional en los pacientes sintomáticos. Por tanto, la valoración cardiaca de los pacientes diabéticos con isquemia sintomática debería realizarse de forma similar a la realizada en los no diabéticos, con indicaciones similares para la ergometría, gammagrafía 
de perfusión cardiaca y coronariografía. Dado que la CI motiva el $80 \%$ de la mortalidad de los pacientes con diabetes mellitus ${ }^{294}$, se debería poner énfasis en la importancia del diagnóstico precoz y el tratamiento agresivo de esta población de pacientes.

Las estrategias para optimizar el cuidado de los pacientes con diabetes mellitus incluyen una dedicación intensa y persistente al control fisiológico de la glucemia, así como el de otros factores de riesgo como la dislipemia, la hipertensión, la afección renal, la obesidad y el tabaquismo. Se dispone de una amplia evidencia de que mantener a largo plazo una glucemia casi normal tiene un efecto protector y disminuye de forma significativa las complicaciones y la mortalidad de las diabetes tipo 1 y $2^{295}$.

Los tratamientos convencionales con nitratos, bloqueadores beta, bloqueadores de los canales del calcio, estatinas y agentes antiplaquetarios y la revascularización coronaria percutánea están indicados de forma similar en los pacientes diabéticos y en los no diabéticos. Además, los IECA están indicados en pacientes diabéticos con enfermedad vascular demostrada ${ }^{75}$. Los beneficios relativos de la revascularización coronaria percutánea y quirúrgica se tratan en detalle en la sección dedicada a la revascularización. Desgraciadamente, debido a las alteraciones metabólicas crónicas de la diabetes mellitus, en estos pacientes se produce normalmente una progresión continua de la enfermedad aterosclerótica, lo que lleva a formas diseminadas de aterosclerosis coronaria con tasas elevadas de afección multivaso y reestenosis. De ahí que, incluso tras realizar con éxito procedimientos invasivos, el buen control de los factores de riesgo cardiovascular y la glucemia resulten esenciales para el pronóstico a largo plazo ${ }^{296}$.

\section{Pacientes ancianos}

A partir de la edad de 75 años, la prevalencia de CI es idéntica en el hombre y en la mujer ${ }^{297}$. La enfermedad tiende a ser más difusa y con mayor severidad; la afección aterosclerótica del tronco común izquierdo y de las 3 ramas coronarias principales, así como la disfunción ventricular izquierda, son más frecuentes en el anciano. Valorar los cuadros de dolor torácico en el anciano puede resultar difícil debido a que con frecuencia presentan síntomas, como molestias torácicas, debilidad y disnea, o tienen enfermedades concomitantes que pueden parecerse al dolor anginoso. En la ancianidad, como norma, se produce una disminución del ejercicio y una menor expresión de los síntomas isquémicos ${ }^{298}$. En estudios poblacionales grandes con hombres y mujeres mayores de 65 años, se observó que los pacientes con angina típica y aquellos con síntomas atípicos presentaban una mortalidad similar a los 3 años ${ }^{299}$. La realización de la ergometría en el anciano plantea problemas añadidos. La capacidad funcional frecuentemente está comprometida por la debilidad muscular y la falta de entrenamien- to. Debe prestarse más atención a los riesgos mecánicos de la ergometría y considerar, cuando sea posible, el uso de protocolos de esfuerzo menos intenso. Las arritmias también se presentan con mayor frecuencia en la edad avanzada. La mayor prevalencia de enfermedad también implica que se produzca un mayor número de falsos negativos $^{300}$. También pueden producirse falsos positivos con más frecuencia debido a una mayor prevalencia de factores de confusión, como el infarto previo, la hipertrofia ventricular izquierda secundaria a enfermedad valvular, la hipertensión y los trastornos de conducción. Pese a estas diferencias, la prueba de esfuerzo también es importante en el anciano. El Grupo de Trabajo de la ESC considera que la prueba de esfuerzo con ECG debe ser la prueba inicial en la valoración del paciente anciano con sospecha de CI, y se puede reemplazarla por pruebas de imagen con estrés farmacológico en pacientes incapaces de realizar ejercicio físico.

Es importante recalcar que los pacientes ancianos con evidencia objetiva de isquemia severa o moderada en las pruebas no invasivas deben tener un acceso a la angiografía coronaria similar al de los pacientes jóvenes. Es preciso señalar también que esta técnica diagnóstica presenta sólo un pequeño incremento de riesgo (comparado con el de pacientes jóvenes) en el paciente anciano seleccionado para evaluación electiva ${ }^{70}$. Sin embargo, la edad $>75$ años es un importante predictor de riesgo de nefropatía inducida por el contraste ${ }^{301}$.

El tratamiento médico es más complejo en pacientes ancianos. Los cambios en la biodisponibilidad de los fármacos, su eliminación y su sensibilidad hacen necesaria la modificación de la dosis cuando se administra al paciente anciano ${ }^{302}$.

Otras cuestiones que considerar cuando prescribimos un tratamiento a un paciente anciano son el riesgo de interacción de los fármacos, la polifarmacia y el adecuado cumplimiento del tratamiento. En cualquier caso, en este grupo de pacientes la medicación antianginosa es tan eficaz en la reducción de los síntomas y las estatinas ofrecen tanto beneficio pronóstico ${ }^{160}$ como en pacientes jóvenes. Cuando consideramos los síntomas y el pronóstico, los pacientes ancianos obtienen de la terapia médica, la angioplastia y la cirugía de bypass el mismo beneficio que la población joven ${ }^{303-305}$.

\section{Angina crónica rebelde al tratamiento}

Mediante el tratamiento farmacológico y los procedimientos de revascularización, bien CABG, bien angioplastia transluminal, se puede tratar a la mayoría de los pacientes con enfermedad isquémica. Sin embargo, los tratamientos convencionales no impiden que algunos pacientes permanezcan seriamente limitados por la angina de pecho. El problema de la angina crónica pertinaz fue tratado en un informe del Joint Study Group de la ESC sobre el tratamiento de la angina rebelde al tratamiento publicado en $2002^{306}$. 
La angina estable crónica y pertinaz se define de forma clínica como la angina estable resultante de isquemia por enfermedad coronaria avanzada, no controlable mediante la combinación de tratamiento farmacológico máximo, cirugía de bypass e intervencionismo coronario. Se debe excluir las causas no cardiacas del dolor torácico y, cuando sea preciso, se considera terapia de conducta cognitiva, evaluación psicológica y/o consulta de psiquiatría.

La angina crónica pertinaz requiere la optimización del tratamiento médico mediante la administración de diferentes fármacos en las dosis máximas toleradas. Este tema ha sido estudiado en profundidad por el Joint Study Group de la ESC. En los últimos años se ha investigado y se sigue investigando sobre nuevos conceptos terapéuticos, pero no todos ellos han resultado de utilidad:

- Técnicas de neuromodulación (estimulación nerviosa eléctrica transcutánea y estimulación de la columna vertebral).

- Anestesia epidural torácica.

- Simpatectomía torácica endoscópica.

- Bloqueo de ganglio estrellado.

- Láser transmiocárdico o percutáneo.

- Angiogénesis.

- Contrapulsación externa (EECP).

- Trasplante cardiaco.

- Fármacos moduladores del metabolismo.

La estimulación eléctrica transcutánea y la estimulación de la columna vertebral son métodos bien establecidos en varios centros para el manejo de la angina pertinaz, con efectos positivos en los síntomas y un favorable perfil de efectos secundarios ${ }^{307-309}$. Estas técnicas ejercen un efecto analgésico favorable, pero no mejoran la isquemia miocárdica, aunque se ha observado un aumento del tiempo medio de ejercicio en la prueba de esfuerzo en cinta sin fin. El número de informes publicados y de pacientes incluidos en ensayos clínicos es pequeño y por el momento se desconoce los efectos de estas técnicas a largo plazo.

En varios estudios se ha comparado la revascularización transmiocárdica por láser con la terapia médica. En uno de ellos (275 pacientes con síntomas de clase IV de la CCS), el $76 \%$ de los pacientes sometidos a este tratamiento mejoraron 2 o más clases funcionales al año de seguimiento, frente al $32 \%(\mathrm{p}<0,001)$ de los pacientes que recibieron sólo terapia médica ${ }^{310}$. No se observó diferencias significativas en la mortalidad de ambos grupos. Sin embargo, estudios posteriores sobre revascularización transmiocárdica (quirúrgica o percutánea) no confirmaron este beneficio ${ }^{311,312}$.

\section{CONCLUSIONES Y RECOMENDACIONES}

1. La angina de pecho secundaria a la aterosclerosis coronaria es una afección frecuente e incapacitante.
Aunque es compatible con la longevidad, se produce un aumento del riesgo de progresión a infarto de miocardio y/o muerte. Con un manejo adecuado, se puede controlar los síntomas y mejorar el pronóstico sustancialmente.

2. Todo paciente con sospecha de angina estable requiere valoración cardiológica precoz y adecuada que asegure un diagnóstico correcto y la evaluación del pronóstico. Como mínimo, es preciso realizar historia clínica, exploración física, evaluación de los factores de riesgo y un ECG en reposo.

3. Para confirmar el diagnóstico y planificar el manejo del paciente, se seguirá una estrategia inicial no invasiva, con ECG de esfuerzo, ecograma de estrés o tomografía de perfusión miocárdica. Esto permite determinar la probabilidad y la severidad de la enfermedad coronaria en pacientes con síntomas leves o moderados y estratificar el riesgo adecuadamente. En muchos pacientes se procederá a realizar una coronariografía, aunque una estrategia invasiva inicial sin pruebas funcionales previas raramente está indicada y sólo se considerará en pacientes con un nuevo episodio de síntomas severos o incontrolados.

4. El ECG de esfuerzo se debe interpretar prestando atención a la respuesta hemodinámica, la carga de trabajo alcanzada y las características clínicas del individuo, así como los síntomas y la respuesta del segmento ST. Serán necesarias pruebas alternativas cuando no se pueda realizar o interpretar el ECG y cuando el diagnóstico sea incierto o la evaluación funcional sea inadecuada.

5. Aparte de su papel en la valoración inicial de los síntomas de la angina estable, la tomografía de perfusión miocárdica y la ECG de estrés son herramientas útiles para demostrar la extensión y la localización de la isquemia miocárdica.

6. La ECG y otras modalidades no invasivas de diagnóstico por imagen, como la resonancia magnética, son útiles en la valoración de la función ventricular.

7. La interpretación del dolor torácico es especialmente difícil en las mujeres jóvenes y de mediana edad. Los síntomas considerados característicos de la angina estable constituyen un indicador fiable de obstrucción coronaria en los varones, pero no en mujeres jóvenes. Este problema gana en complejidad cuando consideramos la alta prevalencia del espasmo coronario y del síndrome $\mathrm{X}$ en las mujeres con dolor torácico, así como la frecuencia con que se producen falsos positivos en la ergometría. Sin embargo, esta complejidad no debe impedir el estudio y el tratamiento adecuado de las mujeres, especialmente el uso de pruebas no invasivas para la estratificación del riesgo y las terapias de prevención secundaria.

8. Tras la evaluación inicial del riesgo, se intentará una corrección de los factores de riesgo implementando modificaciones en el estilo de vida además del tratamiento médico indicado. A todos los pacientes con en- 
fermedad coronaria, se recomendará un estricto control de la diabetes y el peso, además de que abandonen el tabaquismo. El control de la presión arterial también es sumamente importante. Un buen manejo de los factores de riesgo puede modificar la valoración inicial de riesgo.

9. En cuanto al tratamiento farmacológico específico, los nitratos de acción rápida, si se los tolera, pueden proporcionar un alivio inmediato de los síntomas. Siempre que no haya contraindicaciones o intolerancia, los pacientes con angina estable deben ser tratados con aspirina (75 mg/día) y estatinas. Como terapia de primera línea se utilizarán bloqueadores beta o, como alternativa, bloqueadores de los canales del calcio o nitratos de acción prolongada para obtener efectos antianginosos $\mathrm{y}$, como se ha descrito anteriormente, con terapia adicional si fuera preciso. Los IECA están indicados en pacientes con disfunción ventricular, hipertensión o diabetes concomitantes, y habrá que considerarlos también para pacientes con otro perfil de riesgo. Se recomienda el uso de bloqueadores beta en pacientes que ya tuvieron un infarto de miocardio y en pacientes con disfunción ventricular, excepto cuando esté contraindicado.

10. El tratamiento con fármacos antianginosos debería ajustarse a las necesidades particulares de cada paciente, con un seguimiento particularizado. Se debe optimizar la dosis de cada medicamento antes de añadir un nuevo fármaco, y es recomendable cambiar a una combinación de fármacos distinta antes que iniciar un tratamiento farmacológico triple.

11. En caso de que no se haya realizado la coronariografía en la estratificación pronóstica, se debe indicarla con vistas a una posible revascularización en pacientes con síntomas no controlados y rebeldes al tratamiento médico.

12. La revascularización coronaria percutánea es un tratamiento efectivo de la angina estable, y está indicada en pacientes que presentan estenosis anatómicamente favorables y angina no controlada satisfactoriamente con fármacos. Si bien la reestenosis sigue siendo un problema, su relevancia ha disminuido gracias a los avances en la tecnología de los stents. No hay evidencia de que la revascularización coronaria percutánea reduzca el riesgo de muerte en pacientes con angina estable, en comparación con el tratamiento médico o quirúrgico.

13. La cirugía de revascularización coronaria es muy efectiva en el control de los síntomas de la angina estable y disminuye el riesgo de muerte a largo plazo en algunos subgrupos de pacientes, como los pacientes con estenosis del tronco común izquierdo o el segmento proximal de la arteria descendente anterior y los pacientes con afección severa de 3 vasos, especialmente si hay disfunción ventricular izquierda.

14. Hay indicios de que entre la aplicación de una práctica óptima y la práctica habitual en el manejo de la angina estable todavía media una distancia. En concreto, en muchos pacientes con angina estable no se indica la realización de pruebas funcionales que permitan confirmar el diagnóstico y establecer el pronóstico. Además, hay una gran variabilidad en las tasas de prescripción de aspirina y estatinas. Dadas las amplias variaciones en la calidad de los cuidados médicos proporcionados a los pacientes con angina, resulta prioritario auditar distintos aspectos del manejo de esta enfermedad. Tal y como se viene practicando en algunos países, se debería crear y mantener registros locales, regionales y nacionales sobre los resultados de las ICP y la cirugía coronaria.

\section{BIBLIOGRAFÍA}

1. Recommendations of the Task Force of the European Society of Cardiology. Management of stable angina pectoris. Eur Heart J. 1997;18:394-413.

2. De Backer G, Ambrosioni E, Borch-Johnsen K, Brotons C, Cifkova R, Dallongeville J, et al. European guidelines on cardiovascular disease prevention in clinical practice: third joint task force of European and other societies on cardiovascular disease prevention in clinical practice (constituted by representatives of eight societies and by invited experts). Eur J Cardiovasc Prev Rehabil. 2003;10:S1-10.

3. Kannel WB, Feinleib M. Natural history of angina pectoris in the Framingham study. Prognosis and survival. Am J Cardiol. 1972;29:154-63.

4. Murabito JM, Evans JC, Larson MG, Levy D. Prognosis after the onset of coronary heart disease. An investigation of differences in outcome between the sexes according to initial coronary disease presentation. Circulation. 1993;88:2548-55.

5. Juul-Moller S, Edvardsson N, Jahnmatz B, Rosen A, Sorensen $\mathrm{S}$, Omblus R. Double-blind trial of aspirin in primary prevention of myocardial infarction in patients with stable chronic angina pectoris. The Swedish Angina Pectoris Aspirin Trial (SAPAT) Group. Lancet. 1992;340:1421-5.

6. Dargie HJ, Ford I, Fox KM. Total Ischaemic Burden European Trial (TIBET). Effects of ischaemia and treatment with atenolol, nifedipine SR and their combination on outcome in patients with chronic stable angina. The TIBET Study Group. Eur Heart J. 1996;17:104-12.

7. Rehnqvist N, Hjemdahl P, Billing E, Bjorkander I, Eriksson SV, Forslund L, et al. Effects of metoprolol vs. verapamil in patients with stable angina pectoris. The Angina Prognosis Study in Stockholm (APSIS). Eur Heart J. 1996;17:76-81.

8. Pepine CJ, Handberg EM, Cooper-DeHoff RM, Marks RG, Kowey $\mathrm{P}$, Messerli FH, et al. A calcium antagonist vs. a non-calcium antagonist hypertension treatment strategy for patients with coronary artery disease. The International Verapamil-Trandolapril Study (INVEST): a randomized controlled trial. JAMA. 2003;290:2805-16.

9. Henderson RA, Pocock SJ, Clayton TC, Knight R, Fox KA, Julian DG, et al. 7 year outcome in the RITA-2 trial: coronary angioplasty versus medical therapy. J Am Coll Cardiol. 2003;42:1161-70.

10. Brunelli C, Cristofani R, L'Abbate A. Long-term survival in medically treated patients with ischaemic heart disease and prognostic importance of clinical and electrocardiographic data (the Italian CNR Multicentre Prospective Study OD1). Eur Heart J. 1989;10:292-303. 
11. Diamond AG. A clinically relevant classification of chest discomfort. J Am Coll Cardiol. 1983;1:574-5.

12. Campeau L. Grading of angina pectoris [carta]. Circulation. 1976;54:522-3.

13. Hlatky MA, Boineau RE, Higginbotham MB, Lee KL, Mark DB, Califf RM, et al. A brief self-administered questionnaire to determine functional capacity (the Duke Activity Status Index). Am J Cardiol. 1989;64:651-4.

14. Spertus JA, Winder JA, Dewhurst TA, Deyo RA, Prodzinski J, McDonell M, et al. Development and evaluation of the Seattle Angina Questionnaire: a new functional status measure for coronary artery disease. J Am Coll Cardiol. 1995;25:333-41.

15. Spertus JA, Jones P, McDonell M, Fan V, Fihn SD. Health status predicts long-term outcome in outpatients with coronary disease. Circulation. 2002;106:43-9.

16. Malik S, Wong ND, Franklin SS, Kamath TV, L'Italien GJ, Pio $\mathrm{JR}$, et al. Impact of the metabolic syndrome on mortality from coronary heart disease, cardiovascular disease, and all causes in United States adults. Circulation. 2004;110:1245-50.

17. Girman CJ, Rhodes T, Mercuri M, Pyorala K, Kjekshus J, Pedersen TR, et al. The metabolic syndrome and risk of major coronary events in the Scandinavian Simvastatin Survival Study (4S) and the Air Force/Texas Coronary Atherosclerosis Prevention Study (AFCAPS/TexCAPS). Am J Cardiol. 2004;93:13641.

18. Horne BD, Anderson JL, John JM, Weaver A, Bair TL, Jensen $\mathrm{KR}$, et al. Which white blood cell subtypes predict increased cardiovascular risk? J Am Coll Cardiol. 2005;45:1638-43.

19. Guclu F, Ozmen B, Hekimsoy Z, Kirmaz C. Effects of a statin group drug, pravastatin, on the insulin resistance in patients with metabolic syndrome. Biomed Pharmacother. 2004;58:614-8.

20. Haverkate F, Thompson SG, Pyke SD, Gallimore JR, Pepys $\mathrm{MB}$. Production of C-reactive protein and risk of coronary events in stable and unstable angina. European Concerted Action on Thrombosis and Disabilities Angina Pectoris Study Group. Lancet. 1997;349:462-6.

21. Blake GJ, Ridker PM. Inflammatory bio-markers and cardiovascular risk prediction. J Intern Med. 2002;252:283-94.

22. Pearson AT. New tools for coronary risk assessment: what are their advantages and limitations? Circulation. 2002;105:886-92.

23. Bogaty PBJ, Boyer L, Simard S, Joseph L, Bertrand F, Dagenais GR. Fluctuating inflammatory markers in patients with stable ischaemic heart disease. Arch Intern Med. 2005;165:221-6.

24. Kragelund CGB, Kober L, Hildebrandt P, Steffensen R. N-terminal pro-B-type natriuretic peptide and long-term mortality in stable coronary heart disease. New Engl J Med. 2005;352:66675.

25. Andreotti F, Becker FC. Atherothrombotic disorders: new insights from hematology. Circulation. 2005;111:1855-63.

26. Gianrossi R, Detrano R, Mulvihill D, Lehmann K, Dubach P, Colombo A, et al. Exercise-induced ST depression in the diagnosis of coronary artery disease. A meta-analysis. Circulation. 1989;80:87-98.

27. Kwok Y, Kim C, Grady D, Segal M, Redberg R. Meta-analysis of exercise testing to detect coronary artery disease in women. Am J Cardiol. 1999;83:660-6.

28. Gibson SR. The diagnostic and prognostic value of exercise electrocardiography in asymptomatic subjects and stable symptomatic patients. Curr Opin Cardiol. 1991;6:536-46.

29. Ashley EA, Myers J, Froelicher V. Exercise testing in clinical medicine. Lancet. 2000;356:1592-7.

30. Hung J, Chaitman BR, Lam J, Lesperance J, Dupras G, Fines P, et al. Non-invasive diagnostic test choices for the evaluation of coronary artery disease in women: a multivariate comparison of cardiac fluoroscopy, exercise electrocardiography and exercise thallium myocardial perfusion scintigraphy. J Am Coll Cardiol. 1984:4:8-16.

31. Diamond GA, Forrester JS. Analysis of probability as an aid in the clinical diagnosis of coronary-artery disease. N Engl J Med. 1979;300:1350-8.
32. Lauer SM. Exercise electrocardiogram testing and prognosis. Novel markers and predictive instruments. Cardiol Clin. 2001;19:401-14.

33. Elamin MS, Boyle R, Kardash MM, Smith DR, Stoker JB, Whitaker W, et al. Accurate detection of coronary heart disease by new exercise test. Br Heart J. 1982;48:311-20.

34. Yamada H, Do D, Morise A, Atwood JE, Froelicher V. Review of studies using multivariable analysis of clinical and exercise test data to predict angiographic coronary artery disease. Prog Cardiovasc Dis. 1997:39:457-81.

35. Borg G, Holmgren A, Lindblad I. Quantitative evaluation of chest pain. Acta Med Scand. 1981;644 Suppl:43-5.

36. ESC Working Group on Exercise Physiology, Physiopathology and Electrocardiography. Guidelines for cardiac exercise testing. Eur Heart J. 1993;14:969-88.

37. Davidavicius G, Kowalski M, Williams RI, D’Hooge J, Di Salvo G, Pierre-Justin G, et al. Can regional strain and strain rate measurement be performed during both dobutamine and exercise echocardiography, and do regional deformation responses differ with different forms of stress testing? J Am Soc Echocardiogr. 2003;16:299-308.

38. Cheitlin MD, Alpert JS, Armstrong WF, Aurigemma GP, Beller GA, Bierman FZ, et al. ACC/AHA guidelines for the clinical application of echocardiography: executive summary. A report of the American College of Cardiology/American Heart Association Task Force on practice guidelines (Committee on Clinical Application of Echocardiography). Developed in collaboration with the American Society of Echocardiography. J Am Coll Cardiol. 1997;29:862-79.

39. Marwick HT. Current status of stress echocardiography for diagnosis and prognostic assessment of coronary artery disease. Coron Artery Dis. 1998;9:411-26.

40. Gibbons RJ, Chatterjee K, Daley J, Douglas JS, Fihn SD, Gardin JM, et al. ACC/AHA/ACP-ASIM guidelines for the management of patients with chronic stable angina: a report of the American College of Cardiology/American Heart Association Task Force on Practice Guidelines (Committee on Management of Patients With Chronic Stable Angina). J Am Coll Cardiol. 1999;33:2092-197.

41. Schinkel AF, Bax JJ, Geleijnse ML, Boersma E, Elhendy A, Roelandt JR, et al. Noninvasive evaluation of ischaemic heart disease: myocardial perfusion imaging or stress echocardiography? Eur Heart J. 2003;24:789-800.

42. Korosoglou G, Labadze N, Hansen A, Selter C, Giannitsis E, Katus $\mathrm{H}$, et al. Usefulness of real-time myocardial perfusion imaging in the evaluation of patients with first time chest pain. Am J Cardiol. 2004;94:1225-31.

43. Madler CF, Payne N, Wilkenshoff U, Cohen A, Derumeaux GA, Pierard LA, et al. Non-invasive diagnosis of coronary artery disease by quantitative stress echocardiography: optimal diagnostic models using off-line tissue Doppler in the MYDISE study. Eur Heart J. 2003;24:1584-94.

44. Marwick TH, Case C, Leano R, Short L, Baglin T, Cain P, et al. Use of tissue Doppler imaging to facilitate the prediction of events in patients with abnormal left ventricular function by dobutamine echocardiography. Am J Cardiol. 2004;93:142-6.

45. Ritchie JL, Bateman TM, Bonow RO, Crawford MH, Gibbons RJ, Hall RJ, et al. Guidelines for clinical use of cardiac radionuclide imaging. Report of the American College of Cardiology/American Heart Association Task Force on Assessment of Diagnostic and Therapeutic Cardiovascular Procedures (Committee on Radionuclide Imaging), developed in collaboration with the American Society of Nuclear Cardiology. J Am Coll Cardiol. 1995;25:521-47.

46. Underwood SR, Anagnostopoulos C, Cerqueira M, Ell PJ, Flint EJ, Harbinson M, et al. Myocardial perfusion scintigraphy: the evidence. Eur J Nucl Med Mol Imag. 2004;31:261-91.

47. Marwick TH, Shaw LJ, Lauer MS, Kesler K, Hachamovitch R, Heller GV, et al. The noninvasive prediction of cardiac mortality in men and women with known or suspected coronary artery 
disease. Economics of Noninvasive Diagnosis (END) Study Group. Am J Med. 1999;106:172-8.

48. Shaw LJ, Hachamovitch R, Redberg RF. Current evidence on diagnostic testing in women with suspected coronary artery disease: choosing the appropriate test. Cardiol Rev. 2000;8:65-74.

49. Elhendy A, van Domburg RT, Bax JJ, Nierop PR, Valkema R, Geleijnse ML, et al. Dobutamineatropine stress myocardial perfusion SPECT imaging in the diagnosis of graft stenosis after coronary artery bypass grafting. J Nucl Cardiol. 1998;5:491-7.

50. Shapira I, Heller I, Kornizky Y, Topilsky M, Isakov A. The value of stress thallium-201 single photon emission CT imaging as a predictor of outcome and long-term prognosis after CABG. J Med. 2001;32:271-82.

51. Underwood SR, Bax JJ, Vom Dahl J, Henein MY, Knuuti J, Van Rossum AC, et al. Imaging techniques for the assessment of myocardial hibernation. Report of a Study Group of the European Society of Cardiology. Eur Heart J. 2004;25:815-36.

52. Nagel EL, Bocksch HB, Klein W, Vogel C, Frantz U, Ellmer E, et al. Noninvasive diagnosis of ischemia induced wall motion abnormalities with the use of high dose dobutamine stress MRI. Comparison with dobutamine stress echocardiography. Circulation. 1999;99:763-70.

53. Pennell DJ, Sechtem UP, Higgins CB, Manning WJ, Pohost GM, Rademakers FE, et al. Clinical indications for cardiovascular magnetic resonance (CMR): Consensus Panel report. Eur Heart J. 2004;25:1940-65.

54. Xu M, McHaffie DJ. Nonspecific systolic murmurs: an audit of the clinical value of echocardiography. $N$ Z Med J. 1993;106:54-6.

55. Nagueh SF, Bachinski LL, Meyer D, Hill R, Zoghbi WA, Tam JW, et al. Tissue Doppler imaging consistently detects myocardial abnormalities in patients with hypertrophic cardiomyopathy and provides a novel means for an early diagnosis before and independently of hypertrophy. Circulation. 2001;104:128-30.

56. Mottram PM, Marwick TH. Assessment of diastolic function: what the general cardiologist needs to know. Heart. 2005;91:681-95.

57. Yip G, Abraham T, Belohlavek M, Khandheria BK. Clinical applications of strain rate imaging. J Am Soc Echocardiogr. 2003;16:1334-42.

58. Gill JB, Cairns JA, Roberts RS, Costantini L, Sealey BJ, Fallen EF, et al. Prognostic importance of myocardial ischemia detected by ambulatory monitoring early after acute myocardial infarction. N Engl J Med. 1996;334:65-70.

59. Cohn PF, Fox KM, Daly C. Silent myocardial ischemia. Circulation. 2003;108:1263-77.

60. Mulcahy D, Knight C, Patel D, Curzen N, Cunningham D, Wright C, et al. Detection of ambulatory ischaemia is not of practical clinical value in the routine management of patients with stable angina. A long-term follow-up study. Eur Heart J. $1995 ; 16: 317-24$

61. Agatston AS, Janowitz WR, Hildner FJ, Zusmer NR, Viamonte M Jr, Detrano R. Quantification of coronary artery calcium using ultrafast computed tomography. J Am Coll Cardiol. 1990;15:827-32.

62. O'Rourke RA, Brundage BH, Froelicher VF, Greenland P, Grundy SM, Hachamovitch R, et al. American College of Cardiology/American Heart Association Expert Consensus Document on electron-beam computed tomography for the diagnosis and prognosis of coronary artery disease. J Am Coll Cardiol. 2000;36:326-40.

63. Daly C, Saravanan P, Fox K. Is calcium the clue? Eur Heart J. 2002;23:1562-5

64. De Feyter PJ, Nieman K. Noninvasive multi-slice computed tomography coronary angiography: an emerging clinical modality. J Am Coll Cardiol. 2004:44:1238-40.

65. Hoffmann MH, Shi H, Schmitz BL, Schmid FT, Lieberknecht $\mathrm{M}$, Schulze R, et al. Noninvasive coronary angiography with multislice computed tomography. JAMA. 2005;293:2471-8.
66. Raff GL, Gallagher MJ, O’Neill WW, Goldstein JA. Diagnostic accuracy of noninvasive coronary angiography using 64-slice spiral computed tomography. J Am Coll Cardiol. 2005;46:5527.

67. Leschka S, Alkadhi H, Plass A, Desbiolles L, GrunenfelderJ, Marincek B, et al. Accuracy of MSCT coronary angiography with 64-slice technology: first experience. Eur Heart J. 2005;26:1482-7.

68. Spaulding CM, Joly LM, Rosenberg A, Monchi M, Weber SN, Dhainaut JF, et al. Immediate coronary angiography in survivors of out-of-hospital cardiac arrest. N Engl J Med. 1997;336:162933.

69. Borger van der Burg AE, Bax JJ, Boersma E, Bootsma M, Van Erven L, Van der Wall EE, et al. Impact of percutaneous coronary intervention or coronary artery bypass grafting on outcome after nonfatal cardiac arrest outside the hospital. Am J Cardiol. 2003;91:785-9.

70. Noto TJ Jr, Johnson LW, Krone R, Weaver WF, Clark DA, Kramer JR Jr, et al. Cardiac catheterization 1990: a report of the Registry of the Society for Cardiac Angiography and Interventions (SCA\&I). Cathet Cardiovasc Diagn. 1991;24:75-83.

71. De Backer G, Ambrosioni E, Borch-Johnsen K, Brotons C, Cifkova R, Dallongeville J, et al. European guidelines on cardiovascular disease prevention in clinical practice. Third Joint Task Force of European and Other Societies on Cardiovascular Disease Prevention in Clinical Practice. Eur Heart J. 2003;24:1601-10.

72. Califf RM, Armstrong PW, Carver JR, D'Agostino RB, Strauss WE. 27th Bethesda Conference: matching the intensity of risk factor management with the hazard for coronary disease events. Task Force 5. Stratification of patients into high, medium and low risk subgroups for purposes of risk factor management. J Am Coll Cardiol. 1996;27:1007-19.

73. Hense WH. Risk factor scoring for coronary heart disease. BMJ. 2003:327:1238-9.

74. Braunwald E, Domanski MJ, Fowler SE, Geller NL, Gersh BJ, Hsia J, et al. Angiotensin converting-enzyme inhibition in stable coronary artery disease. N Engl J Med. 2004;351:2058-68.

75. Heart Outcomes Prevention Evaluation Study Investigators. Effects of ramipril on cardiovascular and microvascular outcomes in people with diabetes mellitus: results of the HOPE study and MICRO-HOPE substudy. Lancet. 2000;355:253-9.

76. The IONA Study Group. Effect of nicorandil on coronary events in patients with stable angina: the Impact Of Nicorandil in Angina (IONA) randomised trial. Lancet. 2002;359:1269-75.

77. Weiner DA, Ryan TJ, McCabe CH, Chaitman BR, Sheffield LT, Ferguson JC, et al. Prognostic importance of a clinical profile and exercise test in medically treated patients with coronary artery disease. J Am Coll Cardiol. 1984;3:772-9.

78. Harris PJ, Harrell FE Jr, Lee KL, Behar VS, Rosati RA. Survival in medically treated coronary artery disease. Circulation. 1979;60:1259-69.

79. Hammermeister KE, DeRouen TA, Dodge HT. Variables predictive of survival in patients with coronary disease. Selection by univariate and multivariate analyses from the clinical, electrocardiographic, exercise, arteriographic, and quantitative angiographic evaluations. Circulation. 1979;59:421-30.

80. Califf RM, Mark DB, Harrell FE Jr, Hlatky MA, Lee KL, Rosati $\mathrm{RA}$, et al. Importance of clinical measures of ischemia in the prognosis of patients with documented coronary artery disease. J Am Coll Cardiol. 1988;11:20-6.

81. Hultgren HN, Peduzzi P. Relation of severity of symptoms to prognosis in stable angina pectoris. Am J Cardiol. 1984;54:98893.

82. Pryor DB, Shaw L, McCants CB, Lee KL, Mark DB, Harrell FE $\mathrm{Jr}$, et al. Value of the history and physical in identifying patients at increased risk for coronary artery disease. Ann Intern Med. 1993;118:81-90.

83. Morris CK, Ueshima K, Kawaguchi T, Hideg A, Froelicher VF. The prognostic value of exercise capacity: a review of the literature. Am Heart J. 1991;122:1423-31. 
84. Mark DB, Shaw L, Harrell FE Jr, Hlatky MA, Lee KL, Bengtson JR, et al. Prognostic value of a treadmill exercise score in outpatients with suspected coronary artery disease. N Engl J Med. 1991;325:849-53.

85. Dagenais GR, Rouleau JR, Christen A, Fabia J. Survival of patients with a strongly positive exercise electrocardiogram. Circulation. 1982;65:452-6.

86. McNeer JF, Margolis JR, Lee KL, Kisslo JA, Peter RH, Kong $\mathrm{Y}$, et al. The role of the exercise test in the evaluation of patients for ischaemic heart disease. Circulation. 1978;57:64-70.

87. Morrow K, Morris CK, Froelicher VF, Hideg A, Hunter D, Johnson E, et al. Prediction of cardiovascular death in men undergoing noninvasive evaluation for coronary artery disease. Ann Intern Med. 1993;118:689-95.

88. Mark DB, Hlatky MA, Harrell FE Jr, Lee KL, Califf RM, Pryor DB. Exercise treadmill score for predicting prognosis in coronary artery disease. Ann Intern Med. 1987;106:793-800.

89. Prakash M, Myers J, Froelicher VF, Marcus R, Do D, Kalisetti $\mathrm{D}$, et al. Clinical and exercise test predictors of all-cause mortality: results from 6000 consecutive referred male patients. Chest. 2001;120:1003-13.

90. Marwick TH, Mehta R, Arheart K, Lauer MS. Use of exercise echocardiography for prognostic evaluation of patients with known or suspected coronary artery disease. J Am Coll Cardiol. 1997;30:83-90.

91. Geleijnse ML, Elhendy A, Van Domburg RT, Cornel JH, Rambaldi R, Salustri A, et al. Cardiac imaging for risk stratification with dobutamine-atropine stress testing in patients with chest pain. Echocardiography, perfusion scintigraphy, or both? Circulation. 1997;96:137-47.

92. Olmos LI, Dakik H, Gordon R, Dunn JK, Verani MS, Quinones $\mathrm{MA}$, et al. Long-term prognostic value of exercise echocardiography compared with exercise ${ }^{201} \mathrm{Tl}, \mathrm{ECG}$, and clinical variables in patients evaluated for coronary artery disease. Circulation. 1998;98:2679-86.

93. Hachamovitch R, Berman DS, Shaw LJ, Kiat H, Cohen I, Cabico JA, et al. Incremental prognostic value of myocardial perfusion single photon emission computed tomography for the prediction of cardiac death: differential stratification for risk of cardiac death and myocardial infarction. Circulation. 1998;97:535-43.

94. Brown AK. Prognostic value of thallium-201 myocardial perfusion imaging. A diagnostic tool comes of age. Circulation. 1991;83:363-81

95. Mock MB, Ringqvist I, Fisher LD, Davis KB, Chaitman BR, Kouchoukos NT, et al. Survival of medically treated patients in the coronary artery surgery study (CASS) registry. Circulation. 1982;66:562-8.

96. Emond M, Mock MB, Davis KB, Fisher LD, Holmes DR Jr, Chaitman BR, et al. Long-term survival of medically treated patients in the Coronary Artery Surgery Study (CASS) Registry. Circulation. 1994;90:2645-57.

97. McDonagh TA, Morrison CE, Lawrence A, Ford I, Tunstall-Pedoe H, McMurray JJ, et al. Symptomatic and asymptomatic left ventricular systolic dysfunction in an urban population. Lancet. 1997;350:829-33.

98. Raymond I, Pedersen F, Steensgaard-Hansen F, Green A, Busch-Sorensen M, Tuxen C, et al. Prevalence of impaired left ventricular systolic function and heart failure in a middle aged and elderly urban population segment of Copenhagen. Heart. 2003;89:1422-9.

99. Mosterd A, Hoes AW, De Bruyne MC, Deckers JW, Linker DT, Hofman A, et al. Prevalence of heart failure and left ventricular dysfunction in the general population: the Rotterdam Study. Eur Heart J. 1999;20:447-55.

100. Daly C, Norrie J, Murdoch DL, Ford I, Dargie HJ, Fox K. The value of routine non-invasive tests to predict clinical outcome in stable angina. Eur Heart J. 2003;24:532-40.

101. Cuspidi C, Ambrosioni E, Mancia G, Pessina AC, Trimarco B, Zanchetti A. Role of echocardiography and carotid ultrasono- graphy in stratifying risk in patients with essential hypertension: the Assessment of Prognostic Risk Observational Survey. J Hypertens. 2002;20:1307-14.

102. The European Society of Hypertension and the European Society of Cardiology. Guidelines on the management of arterial hypertension. J Hypertens. 2003;21:1011-53.

103. European Coronary Surgery Study Group. Long-term results of prospective randomised study of coronary artery bypass surgery in stable angina pectoris. Lancet. 1982;2:1173-80.

104. Mark DB, Nelson CL, Califf RM, Harrell FE Jr, Lee KL, Jones $\mathrm{RH}$, et al. Continuing evolution of therapy for coronary artery disease. Initial results from the era of coronary angioplasty. Circulation. 1994;89:2015-25.

105. Kennedy JW, Killip T, Fisher LD, Alderman EL, Gillespie MJ, Mock MB. The clinical spectrum of coronary artery disease and its surgical and medical management, 1974-1979. The Coronary Artery Surgery study. Circulation. 1982;66:III16-23.

106. Kemp HG Jr. Left ventricular function in patients with the anginal syndrome and normal coronary arteriograms. Am J Cardiol 1973;32:375-6.

107. Cosin-Sales JC, Pizzi S, Brown JC, Kaski. C-reactive protein, clinical presentation, and ischaemic activity in patients with chest pain and normal coronary angiograms. J Am Coll Cardiol. 2003;41:1468-74.

108. Cannon RO III, Epstein SE. «Microvascular angina» as a cause of chest pain with angiographically normal coronary arteries. Am J Cardiol. 1988;61:1338-43.

109. Luscher FT. The endothelium and cardiovascular disease -a complex relation. N Engl J Med. 1994;330:1081-3.

110. Oki T, Tabata T, Yamada H, Wakatsuki T, Mishiro Y, Abe M, et al. Left ventricular diastolic properties of hypertensive patients measured by pulsed tissue Doppler imaging. J Am Soc Echocardiogr. 1998;11:1106-12.

111. Diamond JA, Phillips RA. Hypertensive heart disease. Hypertens Res. 2005;28:191-202.

112. Schafer S, Kelm M, Mingers S, Strauer BE. Left ventricular remodeling impairs coronary flow reserve in hypertensive patients. J Hypertens. 2002;20:1431-7.

113. Preik M, Kelm M, Strauer BE. Management of the hypertensive patient with coronary insufficiency but without atherosclerosis. Curr Opin Cardiol. 2003;18:255-9.

114. Kaski JC, Rosano GM, Collins P, Nihoyannopoulos P, Maseri A, Poole-Wilson PA. Cardiac syndrome X: clinical characteristics and left ventricular function. Long-term follow-up study. J Am Coll Cardiol. 1995;25:807-14.

115. Atienza F, Velasco JA, Brown S, Ridocci F, Kaski JC. Assessment of quality of life in patients with chest pain and normal coronary arteriogram (syndrome $\mathrm{X}$ ) using a specific questionnaire. Clin Cardiol. 1999;22:283-90.

116. Bugiardini R, Bairey Merz CN. Angina with «normal» coronary arteries: a changing philosophy. JAMA. 2005;293:477-84.

117. Johnson BD, Shaw LJ, Buchthal SD, Bairey Merz CN, Kim HW, Scott KN, et al. Prognosis in women with myocardial ischemia in the absence of obstructive coronary disease: results from the National Institutes of Health-National Heart, Lung, and Blood Institute-Sponsored Women's Ischemia Syndrome Evaluation (WISE). Circulation. 2004;109:2993-9.

118. Bugiardini R, Manfrini O, Pizzi C, Fontana F, Morgagni G. Endothelial function predicts future development of coronary artery disease: a study of women with chest pain and normal coronary angiograms. Circulation. 2004;109:2518-23.

119. Prinzmetal M, Kennamer R, Merliss R, Wada T, Bor N. Angina pectoris. I. A variant form of angina pectoris: preliminary report. Am J Med. 1959;27:375-88.

120. MacAlpin NR. Cardiac arrest and sudden unexpected death in variant angina: complications of coronary spasm that can occur in the absence of severe organic coronary stenosis. Am Heart J. 1993; $125: 1011-7$

121. Bory M, Pierron F, Panagides D, Bonnet JL, Yvorra S, Desfossez L. Coronary artery spasm in patients with normal or near 
normal coronary arteries. Long-term follow-up of 277 patients. Eur Heart J. 1996;17:1015-21.

122. Yamagishi M, Ito K, Tsutsui H, Miyazaki S, Goto Y, Nagaya N, et al. Lesion severity and hypercholesterolemia determine longterm prognosis of vasoespastic angina treated with calcium channel antagonists. Circ J. 2003;67:1029-35.

123. Matsubara T, Tamura Y, Yamazoe M, Hori T, Konno T, Ida T, et al. Correlation between arteriographic and electrocardiographic features during spasm in the left anterior descending coronary artery. Coronary Artery Dis. 1997;8:525-35.

124. Koh KK, Moon TH, Song JH, Park GS, Lee KH, Cho SK, et al. Comparison of clinical and laboratory findings between patients with diffuse three vessel coronary artery spasm and other types of coronary artery spasm. Cathet Cardiovasc Diagn. 1996;37:132-9.

125. Sueda S, Kohno H, Fukuda H, Inoue K, Suzuki J, Watanabe K, et al. Clinical and angiographical characteristics of acetylcholine-induced spasm: relationship to dose of intracoronary injection of acetylcholine. Coronary Artery Dis. 2002;13:231-6.

126. Onaka H, Hirota Y, Shimada S, Kita Y, Sakai Y, Kawakami Y, et al. Clinical observation of spontaneous anginal attacks and multivessel spasm in variant angina pectoris with normal coronary arteries: evaluation by $24 \mathrm{~h}$ 12-lead electrocardiography with computer analysis. J Am Coll Cardiol. 1996;27:38-44.

127. Sueda S, Saeki H, Otani T, Ochi N, Kukita H, Kawada H, et al. Investigation of the most effective provocation test for patients with coronary spastic angina: usefulness of accelerated exercise following hyperventilation. Jpn Circ J. 1999;63:85-90.

128. Yasue H, Horio Y, Nakamura N, Fujii H, Imoto N, Sonoda R, et al. Induction of coronary artery spasm by acetylcholine in patients with variant angina: possible role of the parasympathetic nervous system in the pathogenesis of coronary artery spasm. Circulation. 1986;74:955-63.

129. Sueda S, Kohno H, Fukuda H, Watanabe K, Ochi N, Kawada H, et al. Limitations of medical therapy in patients with pure coronary spastic angina. Chest. 2003;123:380-6.

130. Sueda S, Kohno H, Fukuda H, Ochi N, Kawada H, Hayashi Y, et al. Frequency of provoked coronary spasms in patients undergoing coronary arteriography using a spasm provocation test via intracoronary administration of ergonovine. Angiology. 2004;55:403-11.

131. Smith GD, Shipley MJ, Marmot MG, Rose G. Plasma cholesterol concentration and mortality. The Whitehall Study. JAMA. 1992;267:70-6

132. Doll R, Peto R, Hall E, Wheatley K, Gray R. Alcohol and coronary heart disease reduction among British doctors: confounding or causality? Eur Heart J. 1997;18:23-5.

133. Gruppo Italiano per lo Studio della Sopravvivenza nell'Infarto miocardico. Dietary supplementation with n-3 polyunsaturated fatty acids and vitamin $\mathrm{E}$ after myocardial infarction: results of the GISSI Prevenzione trial. Lancet. 1999;354:447-55.

134. Kris-Etherton PM, Harris WS, Appel LJ. Fish consumption, fish oil, omega- 3 fatty acids, and cardiovascular disease. Arterioscler Thromb Vasc Biol. 2003;23:e20-e30.

135. He K, Song Y, Daviglus ML, Liu K, Van Horn L, Dyer AR, et al. Accumulated evidence on fish consumption and coronary heart disease mortality: a meta-analysis of cohort studies. Circulation. 2004;109:2705-11.

136. American Diabetes Association. Standards of medical care for patients with diabetes mellitus. Diab Care. 2003;26 Suppl 1:S33-50.

137. Inzucchi SE, Amatruda JM. Lipid management in patients with diabetes: translating guidelinesinto action. Diab Care. 2003;26:1309-11.

138. Gaede P, Vedel P, Larsen N, Jensen GV, Parving HH, Pedersen $\mathrm{O}$. Multifactorial intervention and cardiovascular disease in patients with type 2 diabetes. N Engl J Med. 2003;348:383-93.

139. Dormandy JA, Charbonnel B, Eckland DJ, Erdmann E, MassiBenedetti M, Moules IK, et al. Secondary prevention of macrovascular events in patients with type 2 diabetes in the PROactive
Study (PROspective pioglitAzone Clinical Trial In macroVascular Events): a randomised controlled trial. Lancet. 2005;366: 1279-89.

140. Fox KM, Thadani U, Ma PT, Nash SD, Keating Z, Czorniak $\mathrm{MA}$, et al. Sildenafil citrate does not reduce exercise tolerance in men with erectile dysfunction and chronic stable angina. Eur Heart J. 2003;24:2206-12.

141. Patrono C, Coller B, FitzGerald GA, Hirsh J, Roth G. Plateletactive drugs: the relationships among dose, effectiveness, and side effects: the Seventh ACCP Conference on Antithrombotic and Thrombolytic Therapy. Chest. 2004;126 Suppl 3:S234-64.

142. Antithrombotic Trialists' Collaboration. Collaborative metaanalysis of randomised trials of antiplatelet therapy for prevention of death, myocardial infarction, and stroke in high risk patients. BMJ. 2002;324:71-86.

143. Sudlow C, Baigent C. The adverse effects of different doses of aspirin: a systematic review of randomised trials and observational studies [resumen]. Stroke. 2000;31:2869.

144. Antiplatelet Trialists' Collaboration. Collaborative overview of randomised trials of antiplatelet therapy -I: prevention of death, myocardial infarction, and stroke by prolonged antiplatelet therapy in various categories of patients. BMJ. 1994;308:81-106.

145. Fitzgerald AG. Coxibs and cardiovascular disease. N Engl J Med. 2004;351:1709-11.

146. Bresalier RS, Sandler RS, Quan H, Bolognese JA, Oxenius B, Horgan K, et al. Cardiovascular events associated with rofecoxib in a colorectal adenoma chemoprevention trial. N Engl J Med. 2005;352:1092-102.

147. Juni P, Nartey L, Reichenbach S, Sterchi R, Dieppe PA, Egger M. Risk of cardiovascular events and rofecoxib: cumulative meta-analysis. Lancet. 2004:364:2021-9.

148. Bennett JS, Daugherty A, Herrington D, Greenland P, Roberts $\mathrm{H}$, Taubert KA. The use of nonsteroidal anti-inflammatory drugs (NSAIDs): a science advisory from the American Heart Association. Circulation. 2005;111:1713-6.

149. Cronberg S, Wallmark E, Soderberg I. Effect on platelet aggregation of oral administration of 10 non-steroidal analgesics to humans. Scand J Haematol. 1984;33:155-9.

150. CAPRIE Steering Committee. A randomised, blinded, trial of clopidogrel versus aspirin in patients at risk of ischaemic events (CAPRIE). Lancet. 1996;348:1329-39.

151. Chan KF. Helicobacter pylori and nonsteroidal anti-inflammatory drugs. Gastroenterol Clin North Am. 2001;30:937-52.

152. Chan FK, Ching JY, Hung LC, Wong VW, Leung VK, Kung $\mathrm{NN}$, et al. Clopidogrel vs. aspirin and esomeprazole to prevent recurrent ulcer bleeding. N Engl J Med. 2005;352:238-44.

153. McKee SA, Sane DC, Deliargyris EN. Aspirin resistance in cardiovascular disease: a review of prevalence, mechanisms, and clinical significance. Thromb Haemost. 2002;88:711-5.

154. Patrono C. Aspirin resistance: definition, mechanisms and clinical readouts. J Thromb Haemost. 2003;1:1710-3.

155. Wiviott SD, Antman EM. Clopidogrel resistance: a new chapter in a fast-moving story. Circulation. 2004;109:3064-7.

156. Grundy SM, Cleeman JI, Merz CN, Brewer HB Jr, Clark LT, Hunninghake DB, et al. Implications of recent clinical trials for the National Cholesterol Education Program Adult Treatment Panel III Guidelines. J Am Coll Cardiol. 2004;44:720-32.

157. The Scandinavian Simvastatin Survival Study (4S). Randomised trial of cholesterol lowering in 4444 patients with coronary heart disease. Lancet. 1994;344:1383-9.

158. Sacks FM, Tonkin AM, Shepherd J, Braunwald E, Cobbe S, Hawkins CM, et al. Effect of pravastatin on coronary disease events in subgroups defined by coronary risk factors: the Prospective Pravastatin Pooling Project. Circulation. 2000;102:1893900.

159. The Long-Term Intervention with Pravastatin in Ischaemic Disease (LIPID) Study Group. Prevention of cardiovascular events and death with pravastatin in patients with coronary heart disease and a broad range of initial cholesterol levels. N Engl J Med. 1998;339:1349-57. 
160. Shepherd J, Blauw GJ, Murphy MB, Bollen EL, Buckley BM, Cobbe SM, et al. Pravastatin in elderly individuals at risk of vascular disease (PROSPER): a randomised controlled trial. Lancet. 2002;360:1623-30.

161. Heart Protection Study Collaborative Group. MRC/BHF Heart Protection Study of cholesterol lowering with simvastatin in 20 536 high-risk individuals: a randomised placebo-controlled trial. Lancet. 2002;360:7-22.

162. Collins R, Armitage J, Parish S, Sleigh P, Peto R. MRC/BHF Heart Protection Study of cholesterol-lowering with simvastatin in 5963 people with diabetes: a randomised placebo-controlled trial. Lancet. 2003;361:2005-16.

163. Colhoun HM, Betteridge DJ, Durrington PN, Hitman GA, Neil HA, Livingstone SJ, et al. Primary prevention of cardiovascular disease with atorvastatin in type 2 diabetes in the Collaborative Atorvastatin Diabetes Study (CARDS): multicentre randomised placebo-controlled trial. Lancet. 2004;364:685-96.

164. Sever PS, Dahlof B, Poulter NR, Wedel H, Beevers G, Caulfield $\mathrm{M}$, et al. Prevention of coronary and stroke events with atorvastatin in hypertensive patients who have average or lower-thanaverage cholesterol concentrations, in the Anglo-Scandinavian Cardiac Outcomes Trial-Lipid Lowering Arm (ASCOT-LLA): a multicentre randomised controlled trial. Lancet. 2003;361:114958.

165. Pasceri V, Patti G, Nusca A, Pristipino C, Richichi G, Di Sciascio G. Randomized trial of atorvastatin for reduction of myocardial damage during coronary intervention: results from the ARMYDA (Atorvastatin for Reduction of MYocardial Damage during Angioplasty) study. Circulation. 2004;110:674-8

166. Baigent C, Keech A, Kearney PM, Blackwell L, Buck G, Pollicino $\mathrm{C}$, et al. Efficacy and safety of cholesterol-lowering treatment: prospective meta-analysis of data from 90056 participants in 14 randomised trials of statins. Lancet. 2005;366: 1267-78.

167. LaRosa JC, Grundy SM, Waters DD, Shear C, Barter P, Fruchart JC, et al. Intensive lipid lowering with atorvastatin in patients with stable coronary disease. N Engl J Med. 2005;352: 1425-35.

168. Wierzbicki SA. Ezetimibe: a new addition to lipid-lowering therapy. Int J Clin Pract. 2003;57:653-5.

169. Brousseau ME, Schaefer E, Wolfe ML, Blodon LT, Digenio AG, Clark RW, et al. Effects of an inhibitor of cholesteryl ester transfer protein on HDL cholesterol. N Engl J Med. 2004;350:1491-4.

170. Yusuf S, Sleight P, Pogue J, Bosch J, Davies R, Dagenais G. Effects of an angiotensin-converting-enzyme inhibitor, ramipril, on cardiovascular events in high-risk patients. The Heart Outcomes Prevention Evaluation Study Investigators. N Engl J Med. 2000;342:145-53.

171. Fox MK. Efficacy of perindopril in reduction of cardiovascular events among patients with stable coronary artery disease: randomised, double-blind, placebo-controlled, multicentre trial (the EUROPA study). Lancet. 2003;362:782-8.

172. Faggiotto A, Paoletti R. State-of-the-art lecture. Statins and blockers of the renin-angiotensin system: vascular protection beyond their primary mode of action. Hypertension. 1999;34:98796.

173. Lonn EM, Yusuf S, Jha P, Montague TJ, Teo KK, Benedict CR, et al. Emerging role of angiotensin-converting enzyme inhibitors in cardiac and vascular protection. Circulation. 1994;90:2056-69.

174. Hulley S, Grady D, Bush T, Furberg C, Herrington D, Riggs B, et al. Randomized trial of estrogen plus progestin for secondary prevention of coronary heart disease in postmenopausal women. Heart and Estrogen/progestin Replacement Study (HERS) Research Group. JAMA. 1998;280:605-13.

175. Grady D, Herrington D, Bittner V, Blumenthal R, Davidson M, Hlatky M, et al. Cardiovascular disease outcomes during 6.8 years of hormone therapy: Heart and Estrogen/progestin Replacement Study follow-up (HERS II). JAMA. 2002;288:49-57.
176. Rossouw JE, Anderson GL, Prentice RL, LaCroix AZ, Kooperberg C, Stefanick ML, et al. Risks and benefits of estrogen plus progestin in healthy postmenopausal women: principal results from the women's health initiative randomized controlled trial. JAMA. 2002;288:321-33.

177. Manson JE, Hsia J, Johnson KC, Rossouw JE, Assaf AR, Lasser $\mathrm{NL}$, et al. Estrogen plus progestin and the risk of coronary heart disease. N Engl J Med. 2003;349:523-34.

178. Mosca L, Appel LJ, Benjamin EJ, Berra K, Chandra-Strobos N, Fabunmi RP, et al.. Evidence-based guidelines for cardiovascular disease prevention in women. Circulation. 2004;109:672-93.

179. Hersh AL, Stefanick ML, Stafford RS. National use of postmenopausal hormone therapy: annual trends and response to recent evidence. JAMA. 2004;291:47-53

180. Yusuf S, Wittes J, Friedman L. Overview of results of randomized clinical trials in heart disease. I. Treatments following myocardial infarction. JAMA. 1988;260:2088-93.

181. Freemantle N, Urdahl H, Eastaugh J, Hobbs FD. What is the place of beta-blockade in patients who have experienced a myocardial infarction with preserved left ventricular function? Evidence and (mis)interpretation. Prog Cardiovasc Dis. 2002;44:243-50.

182. Pepine CJ, Cohn PF, Deedwania PC, Gibson RS, Handberg E, Hill JA, et al. Effects of treatment on outcome in mildly symptomatic patients with ischemia during daily life. The Atenolol Silent Ischemia Study (ASIST). Circulation. 1994:90:762-8.

183. Metoprolol CR/XL Randomised Intervention Trial in Congestive Heart Failure (MERIT-HF). Effect of metoprolol CR/XL in chronic heart failure. Lancet. 1999;353:2001-7.

184. The Cardiac Insufficiency Bisoprolol Study II (CIBIS-II): a randomised trial. Lancet. 1999;353:9-13.

185. Packer M, Bristow MR, Cohn JN, Colucci WS, Fowler MB, Gilbert EM, et al. The effect of carvedilol on morbidity and mortality in patients with chronic heart failure. U.S. Carvedilol Heart Failure Study Group. N Engl J Med. 1996;334:1349-55.

186. The Danish Verapamil Infarction Trial II -DAVIT II. Effect of verapamil on mortality and major events after acute myocardial infarction. Am J Cardiol. 1990;66:779-85.

187. The Multicenter Diltiazem Postinfarction Trial Research Group. The effect of diltiazem on mortality and reinfarction after myocardial infarction. N Engl J Med. 1988;319:385-92.

188. Furberg CD, Psaty BM, Meyer JV. Nifedipine. Dose-related increase in mortality in patients with coronary heart disease. Circulation. 1995;92:1326-31.

189. Stason WB, Schmid CH, Niedzwiecki D, Whiting GW, Caubet JF, Cory D, et al. Safety of nifedipine in angina pectoris: a metaanalysis. Hypertension. 1999;33:24-31.

190. Poole-Wilson PA, Lubsen J, Kirwan BA, Van Dalen FJ, Wagener G, Danchin N, et al. Effect of long-acting nifedipine on mortality and cardiovascular morbidity in patients with stable angina requiring treatment (ACTION trial): randomised controlled trial. Lancet. 2004:364:849-57.

191. Nissen SE, Tuzcu EM, Libby P, Thompson PD, Ghali M, Garza $\mathrm{D}$, et al. Effect of antihypertensive agents on cardiovascular events in patients with coronary disease and normal blood pressure: the CAMELOT study: a randomized controlled trial. JAMA. 2004;292:2217-25.

192. Kerins DM. Drugs used for the treatment of myocardial ischaemia. En: Goodman and Gilmans. The Pharmacological Basis of Therapeutics. 10. ${ }^{\mathrm{a}}$ ed. New York: McGraw-Hill; 2001.

193. Savonitto S, Ardissino D. Selection of drug therapy in stable angina pectoris. Cardiovasc Drugs Ther. 1998;12:197-210.

194. Thadani U. Treatment of stable angina. Curr Opin Cardiol. 1999;14:349-58.

195. Ko DT, Hebert PR, Coffey CS, Sedrakyan A, Curtis JP, Krumholz HM. Beta-blocker therapy and symptoms of depression, fatigue, and sexual dysfunction. JAMA. 2002;288:351-7.

196. Hjemdahl P, Wiklund IK. Quality of life on antihypertensive drug therapy: scientific end-point or marketing exercise? J Hypertens. 1992;10:1437-46. 
197. Neaton JD, Grimm RH Jr, Prineas RJ, Stamler J, Grandits GA, Elmer PJ, et al. Treatment of mild hypertension study: Final results: Treatment of Mild Hypertension Study Research Group. JAMA. 1993;270:713-24.

198. Gibbons RJ, Abrams J, Chatterjee K, Daley J, Deedwania PC, Douglas JS, et al. ACC/AHA 2002 guideline update for the management of patients with chronic stable angina -summary article: a report of the American College of Cardiology/American Heart Association Task Force on practice guidelines (Committee on the Management of Patients With Chronic Stable Angina). J Am Coll Cardiol. 2003;41:159-68.

199. Hjemdahl P, Wallen NH. Calcium antagonist treatment, sympathetic activity and platelet function. Eur Heart J. 1997;18 Suppl A:A36-50.

200. Karlson BW, Emanuelsson H, Herlitz J, Nilsson JE, Olsson G. Evaluation of the antianginal effect of nifedipine: influence of formulation dependent pharmacokinetics. Eur J Clin Pharmacol. 1991;40:501-6.

201. Waters D. Proischemic complications of dihydropyridine calcium channel blockers. Circulation. 1991;84:2598-600.

202. Deanfield JE, Detry JM, Lichtlen PR, Magnani B, Sellier P, Thaulow E. Amlodipine reduces transient myocardial ischemia in patients with coronary artery disease: double-blind Circadian Anti-Ischemia Program in Europe (CAPE Trial). J Am Coll Cardiol. 1994;24:1460-7.

203. Packer M, O'Connor CM, Ghali JK, Pressler ML, Carson PE, Belkin RN, et al. Effect of amlodipine on morbidity and mortality in severe chronic heart failure. Prospective Randomized Amlodipine Survival Evaluation Study Group. N Engl J Med. 1996;335:1107-14.

204. Ardissino D, Savonitto S, Egstrup K, Rasmussen K, Bae EA, Omland T, et al. Selection of medical treatment in stable angina pectoris: results of the International Multicenter Angina Exercise (IMAGE) Study. J Am Coll Cardiol. 1995;25:1516-21.

205. Forslund L, Hjemdahl P, Held C, Bjorkander I, Eriksson SV, Brodin U, et al. Prognostic implications of results from exercise testing in patients with chronic stable angina pectoris treated with metoprolol or verapamil. A report from the Angina Prognosis Study In Stockholm (APSIS). Eur Heart J. 2000;21:90110.

206. Arnim Tv. Medical treatment to reduce total ischaemic burden: total ischaemic burden bisoprolol study (TIBBS), a multicenter trial comparing bisoprolol and nifedipine. The TIBBS Investigators. J Am Coll Cardiol. 1995;25:231-8

207. Fox KM, Mulcahy D, Findlay I, Ford I, Dargie HJ. The Total Ischaemic Burden European Trial (TIBET). Effects of atenolol, nifedipine SR and their combination on the exercise test and the total ischaemic burden in 608 patients with stable angina. The TIBET Study Group. Eur Heart J. 1996;17:96-103.

208. Heidenreich PA, McDonald KM, Hastie T, Fadel B, Hagan V, Lee BK, et al. Meta-analysis of trials comparing beta-blockers, calcium antagonists, and nitrates for stable angina. JAMA 1999;281:1927-36

209. Markham A, Plosker GL, Goa KL. Nicorandil. An updated review of its use in ischaemic heart disease with emphasis on its cardioprotective effects. Drugs. 2000;60:955-74.

210. Nicorandilfor angina -an update. Drug Ther Bull. 2003;41:86-8.

211. Borer JS, Fox K, Jaillon P, Lerebours G. Antianginal and antiischemic effects of ivabradine, an I(f) inhibitor, in stable angina: a randomized, double-blind, multicentered, placebo-controlled trial. Circulation. 2003;107:817-23.

212. Tardif JC, Ford I, Tendera M, Bourassa MG, Fox K. Efficacy of ivabradine, a new selective If inhibitor, compared with atenolol in patients with chronic stable angina. Eur Heart J. 2005;26: 2529-36.

213. Marzilli M, Klein WW. Efficacy and tolerability of trimetazidine in stable angina: a meta-analysis of randomized, doubleblind, controlled trials. Coronary Artery Dis. 2003;14:171-9.

214. Chazov EI, Lepakchin VK, Zharova EA, Fitilev SB, Levin AM, Rumiantzeva EG, et al. Trimetazidine in Angina Combination
Therapy -the TACT study: trimetazidine versus conventional treatment in patients with stable angina pectoris in a randomized, placebo-controlled, multicenter study. Am J Ther. 2005; 12:35-42.

215. Chaitman BR, Skettino SL, Parker JO, Hanley P, Meluzin J, Kuch J, et al. Anti-ischaemic effects and long-term survival during ranolazine monotherapy in patients with chronic severe angina. J Am Coll Cardiol. 2004;43:1375-82.

216. Chaitman BR, Pepine CJ, Parker JO, Skopal J, Chumakova G, Kuch J, et al. Effects of ranolazine with atenolol, amlodipine, or diltiazem on exercise tolerance and angina frequency in patients with severe chronic angina: a randomized controlled trial. JAMA. 2004;291:309-16.

217. Messin R, Opolski G, Fenyvesi T, Carreer-Bruhwyler F, Dubois $\mathrm{C}$, Famaey JP, et al. Efficacy and safety of molsidomine once-aday in patients with stable angina pectoris. Int $\mathrm{J}$ Cardiol. 2005;98:79-89.

218. Tolins M, Weir EK, Chesler E, Pierpont GL. «Maximal» drug therapy is not necessarily optimal in chronic angina pectoris. J Am Coll Cardiol. 1984;3:1051-7.

219. Jackson G. Stable angina: maximal medical therapy is not the same as optimal medical therapy. Int J Clin Pract. 2000;54:351.

220. Kaski JC, Valenzuela Garcia LF. Therapeutic options for the management of patients with cardiac syndrome X. Eur Heart J. 2001;22:283-93

221. Botker HE, Sonne HS, Schmitz O, Nielsen TT. Effects of doxazosin on exercise-induced angina pectoris, ST-segment depression, and insulin sensitivity in patients with syndrome X. Am J Cardiol. 1998;82:1352-6.

222. Galassi AR, Kaski JC, Pupita G, Vejar M, Crea F, Maseri A. Lack of evidence for alpha-adrenergic receptor-mediated mechanisms in the genesis of ischemia in syndrome X. Am J Cardiol. 1989;64:264-9.

223. Kaski CJ. Pathophysiology and management of patients with chest pain and normal coronary arteriograms (cardiac syndrome X). Circulation. 2004;109:568-72.

224. Sitges M, Heras M, Roig E, Duran M, Masotti M, Zurbano MJ, et al. Acute and mid-term combined hormone replacement therapy improves endothelial function in post-menopausal women with angina and angiographically normal coronary arteries. Eur Heart J. 2001;22:2116-24

225. Rosano GM, Peters NS, Lefroy D, Lindsay DC, Sarrel PM, Collins $\mathrm{P}$, et al. 17-beta-Estradiol therapy lessens angina in postmenopausal women with syndrome X. J Am Coll Cardiol. 1996;28:1500-5.

226. Chevalier P, Dacosta A, Defaye P, Chalvidan T, Bonnefoy E, Kirkorian G, et al. Arrhythmic cardiac arrest due to isolated coronary artery spasm: long-term outcome of seven resuscitated patients. J Am Coll Cardiol. 1998;31:57-61.

227. Ricci DR, Orlick AE, Cipriano PR, Guthaner DF, Harrison DC. Altered adrenergic activity in coronary arterial spasm: insight into mechanism based on study of coronary hemodynamics and the electrocardiogram. Am J Cardiol. 1979;43:1073-9.

228. Lablanche JM, Bauters C, McFadden EP, Quandalle P, Bertrand ME. Potassium channel activators in vasoespastic angina. Eur Heart J. 1993;14 Suppl B:22-4.

229. Waters DD, Bouchard A, Theroux P. Spontaneous remission is a frequent outcome of variant angina. J Am Coll Cardiol. 1983;2:195-9.

230. Rihal CS, Raco DL, Gersh BJ, Yusuf S. Indications for coronary artery bypass surgery and percutaneous coronary intervention in chronic stable angina: review of the evidence and methodological considerations. Circulation. 2003;108:2439-45.

231. Yusuf S, Zucker D, Peduzzi P, Fisher LD, Takaro T, Kennedy JW, et al. Effect of coronary artery bypass graft surgery on survival: overview of 10-year results from randomised trials by the Coronary Artery Bypass Graft Surgery Trialists Collaboration. Lancet. 1994;344:563-70.

232. Jones RH, Kesler K, Phillips HR III, Mark DB, Smith PK, Nelson CL, et al. Long-term survival benefits of coronary artery by- 
pass grafting and percutaneous transluminal angioplasty in patients with coronary artery disease. J Thorac Cardiovasc Surg. 1996;111:1013-25.

233. Myocardial infarction and mortality in the coronary artery surgery study (CASS) randomized trial. $\mathrm{N}$ Engl $\mathrm{J}$ Med. 1984;310:750-8.

234. Hoffman SN, TenBrook JA, Wolf MP, Pauker SG, Salem DN, Wong JB. A meta-analysis of randomized controlled trials comparing coronary artery bypass graft with percutaneous transluminal coronary angioplasty: one- to 8 year outcomes. J Am Coll Cardiol. 2003;41:1293-304.

235. Hamm CW, Reimers J, Ischinger T, Rupprecht HJ, Berger J, Bleifeld W. A randomized study of coronary angioplasty compared with bypass surgery in patients with symptomatic multivessel coronary disease. German Angioplasty Bypass Surgery Investigation (GABI). N Engl J Med. 1994; 331:1037-43.

236. Rodriguez A, Rodriguez Alemparte M, Baldi J, Navia J, Delacasa A, Vogel D, et al. Coronary stenting versus coronary bypass surgery in patients with multiple vessel disease and significant proximal LAD stenosis: results from the ERACI II study. Heart. 2003;89:184-8.

237. Goy JJ, Eeckhout E, Moret C, Burnand B, Vogt P, Stauffer JC, et al. 5 year outcome in patients with isolated proximal left anterior descending coronary artery stenosis treated by angioplasty or left internal mammary artery grafting. A prospective trial. Circulation. 1999;99:3255-9.

238. Nilsson J, Algotsson L, Hoglund P, Luhrs C, Brandt J. Early mortality in coronary bypass surgery: the EuroSCORE versus The Society of Thoracic Surgeons risk algorithm. Ann Thorac Surg. 2004;77:1235-9; comentario: 1239-40.

239. Cameron A, Davis KB, Green G, Schaff HV. Coronary bypass surgery with internal-thoracic-artery grafts -effects on survival over a 15-year period. N Engl J Med. 1996;334:216-9.

240. Van Dijk D, Nierich AP, Jansen EW, Nathoe HM, Suyker WJ, Diephuis JC, et al. Early outcome after off-pump versus onpump coronary bypass surgery: results from a randomized study. Circulation. 2001;104:1761-6.

241. Angelini GD, Taylor FC, Reeves BC, Ascione R. Early and midterm outcome after off-pump and on-pump surgery in Beating Heart Against Cardioplegic Arrest Studies (BHACAS 1 and 2): a pooled analysis of two randomised controlled trials. Lancet. 2002;359:1194-9.

242. Khan NE, De Souza A, Mister R, Flather M, Clague J, Davies S, et al. A randomized comparison of off-pump and on-pump multivessel coronary-artery bypass surgery. N Engl J Med. 2004;350:21-8.

243. Smith SC Jr, Dove JT, Jacobs AK, Kennedy JW, Kereiakes D, Kern MJ, et al. ACC/AHA guidelines of percutaneous coronary interventions (revision of the 1993 PTCA guidelines) -executive summary. A report of the American College of Cardiology/American Heart Association Task Force on Practice Guidelines (committee to revise the 1993 guidelines for percutaneous transluminal coronary angioplasty). J Am Coll Cardiol. 2001;37:2215-39.

244. Bucher HC, Hengstler P, Schindler C, Guyatt GH. Percutaneous transluminal coronary angioplasty versus medical treatment for non-acute coronary heart disease: meta-analysis of randomised controlled trials. BMJ. 2000;321:73-7.

245. Parisi AF, Folland ED, Hartigan P. A comparison of angioplasty with medical therapy in the treatment of single-vessel coronary artery disease. Veterans Affairs ACME Investigators. N Engl J Med. 1992;326:10-6.

246. Folland ED, Hartigan PM, Parisi AF. Percutaneous transluminal coronary angioplasty versus medical therapy for stable angina pectoris: outcomes for patients with double-vessel versus singlevessel coronary artery disease in a Veterans Affairs Cooperative randomized trial. Veterans Affairs ACME Investigators. J Am Coll Cardiol. 1997;29:1505-11.

247. RITA-2 trial participants. Coronary angioplasty versus medical therapy for angina: the second Randomised Intervention Treatment of Angina (RITA-2) trial. Lancet. 1997;350:461-8.
248. Pitt B, Waters D, Brown WV, Van Boven AJ, Schwartz L, Title LM, et al. Aggressive lipid-lowering therapy compared with angioplasty in stable coronary artery disease. Atorvastatin versus Revascularization Treatment Investigators. N Engl J Med. 1999;341:70-6.

249. Al Suwaidi J, Holmes DR Jr, Salam AM, Lennon R, Berger PB. Impact of coronary artery stents on mortality and nonfatal myocardial infarction: meta-analysis of randomized trials comparing a strategy of routine stenting with that of balloon angioplasty. Am Heart J. 2004;147:815-22.

250. Brophy JM, Belisle P, Joseph L. Evidence for use of coronary stents. A hierarchical bayesian meta-analysis. Ann Intern Med. 2003; $138: 777-86$

251. Morice MC, Serruys PW, Sousa JE, Fajadet J, Ban Hayashi E, Perin M, et al. A randomized comparison of a sirolimus-eluting stent with a standard stent for coronary revascularization. N Engl J Med. 2002;346:1773-80.

252. Silber S, Albertsson P, Aviles FF, Camici PG, Colombo A, Hamm C, et al. Guidelines for percutaneous coronary interventions. The Task Force for Percutaneous Coronary Interventions of the European Society of Cardiology. Eur Heart J. 2005;26:804-47.

253. Davies RF, Goldberg AD, Forman S, Pepine CJ, Knatterud GL, Geller N, et al. Asymptomatic Cardiac Ischemia Pilot (ACIP) study 2 year follow-up: outcomes of patients randomized to initial strategies of medical therapy versus revascularization. Circulation. 1997;95:2037-43.

254. Pfisterer ME, Kiowski W, Brunner H, Burckhardt D, Burkart F. Long-term benefit of 1-year amiodarone treatment for persistent complex ventricular arrhythmias after myocardial infarction. Circulation. 1993;87:309-11.

255. Hueb WA, Bellotti G, De Oliveira SA, Arie S, De Albuquerque $\mathrm{CP}$, Jatene $\mathrm{AD}$, et al. The Medicine, Angioplasty or Surgery Study (MASS): a prospective, randomized trial of medical therapy, balloon angioplasty or bypass surgery for single proximal left anterior descending artery stenoses. J Am Coll Cardiol. 1995;26:1600-5.

256. The SoS Investigators. Coronary artery bypass surgery versus percutaneous coronary intervention with stent implantation in patients with multivessel coronary artery disease (the Stent or Surgery trial): a randomised controlled trial. Lancet. 2002;360:965-70.

257. Goy JJ, Kaufmann U, Goy-Eggenberger D, Garachemani A, Hurni M, Carrel T, et al. A prospective randomized trial comparing stenting to internal mammary artery grafting for proximal, isolated de novo left anterior coronary artery stenosis: the SIMA trial. Stenting versus Internal Mammary Artery. Mayo Clin Proc. 2000;75:1116-23.

258. Pocock SJ, Henderson RA, Rickards AF, Hampton JR, King SB III, Hamm CW, et al. Meta-analysis of randomised trials comparing coronary angioplasty with bypass surgery. Lancet. 1995;346:1184-9.

259. The Bypass Angioplasty Revascularization Investigation (BARI) Investigators. Comparison of coronary bypass surgery with angioplasty in patients with multivessel disease. $\mathrm{N}$ Engl J Med. 1996;335:217-25.

260. Serruys PW, Unger F, Sousa JE, Jatene A, Bonnier HJ, Schonberger JP, et al. Comparison of coronary-artery bypass surgery and stenting for the treatment of multivessel disease. N Engl J Med. 2001;344:1117-24.

261. Joyce D, Loebe M, Noon GP, McRee S, Southard R, Thompson $\mathrm{L}$, et al. Revascularization and ventricular restoration in patients with ischaemic heart failure: the STICH trial. Curr Opin Cardiol. 2003;18:454-7.

262. Cleland JG, Freemantle N, Ball SG, Bonser RS, Camici P, Chattopadhyay $\mathrm{S}$, et al. The heart failure revascularisation trial (HEART): rationale, design and methodology. Eur J Heart Fail. 2003;5:295-303.

263. Park SJ, Kim YH, Lee BK, Lee SW, Lee CW, Hong MK, et al. Sirolimus-eluting stent implantation for unprotected left main 
coronary artery stenosis: comparison with bare metal stent implantation. J Am Coll Cardiol. 2005;45:351-6.

264. Flaherty JD, Davidson CJ. Diabetes and coronary revascularization. JAMA. 2005;293:1501-8.

265. Brooks RC, Detre KM. Clinical trials of revascularization therapy in diabetics. Curr Opin Cardiol. 2000;15:287-92.

266. The BARI Investigators. 7 year outcome in the Bypass Angioplasty Revascularization Investigation (BARI) by treatment and diabetic status. J Am Coll Cardiol. 2000;35:1122-9.

267. Douglas PS, Ginsburg GS. The evaluation of chest pain in women. N Engl J Med. 1996;334:1311-5.

268. Lerner DJ, Kannel WB. Patterns of coronary heart disease morbidity and mortality in the sexes: a 26-year follow-up of the Framingham population. Am Heart J. 1986;111:383-90.

269. Reunanen A, Suhonen O, Aromaa A, Knekt P, Pyorala K. Incidence of different manifestations of coronary heart disease in middle-aged Finnish men and women. Acta Med Scand. 1985;218:19-26.

270. Smith WC, Kenicer MB, Tunstall-Pedoe H, Clark EC, Crombie IK. Prevalence of coronary heart disease in Scotland: Scottish Heart Health Study. Br Heart J. 1990;64:295-8.

271. Mittelmark MB, Psaty BM, Rautaharju PM, Fried LP, Borhani NO, Tracy RP, et al. Prevalence of cardiovascular diseases among older adults. The Cardiovascular Health Study. Am J Epidemiol. 1993;137:311-7.

272. Ford ES, Giles WH, Croft JB. Prevalence of nonfatal coronary heart disease among American adults. Am Heart J. 2000;139:371-7.

273. Campbell MJ, Elwood PC, Abbas S, Waters WE. Chest pain in women: a study of prevalence and mortality follow up in south Wales. J Epidemiol Community Health. 1984;38:17-20.

274. Shaper AG, Cook DG, Walker M, Macfarlane PW. Prevalence of ischaemic heart disease in middle aged British men. Br Heart J. 1984;51:595-605.

275. Philpott S, Boynton PM, Feder G, Hemingway H. Gender differences in descriptions of angina symptoms and health problems immediately prior to angiography: the ACRE study. Appropriateness of Coronary Revascularisation study. Soc Sci Med. 2001;52:1565-75.

276. Chaitman BR, Bourassa MG, Davis K, Rogers WJ, Tyras DH, Berger R, et al. Angiographic prevalence of high-risk coronary artery disease in patient subsets (CASS). Circulation. 1981;64:360-7.

277. Gibbons RJ, Balady GJ, Bricker JT, Chaitman BR, Fletcher GF, Froelicher VF, et al. ACC/AHA 2002 guideline update for exercise testing: summary article. A report of the American College of Cardiology/American Heart Association Task Force on Practice Guidelines (Committee to Update the 1997 Exercise Testing Guidelines). J Am Coll Cardiol. 2002;40:1531-40.

278. Villareal RP, Wilansky WJ. Noninvasive diagnostic testing. En: Wilansky WJ, editor. Heart Disease in Women. Philadelphia: Churchill Livingstone; 2002. p. 149-57.

279. Osbakken MD, Okada RD, Boucher CA, Strauss HW, Pohost GM. Comparison of exercise perfusion and ventricular function imaging: an analysis of factors affecting the diagnostic accuracy of each technique. J Am Coll Cardiol. 1984;3:272-83.

280. Dodi C, Cortigiani L, Masini M, Olivotto I, Azzarelli A, Nannini E. The incremental prognostic value of pharmacological stress echo over exercise electrocardiography in women with chest pain of unknown origin. Eur Heart J. 2001;22:145-52.

281. Cortigiani L, Dodi C, Paolini EA, Bernardi D, Bruno G, Nannini E. Prognostic value of pharmacological stress echocardiography in women with chest pain and unknown coronary artery disease. J Am Coll Cardiol. 1998;32:1975-81.

282. Melin JA, Wijns W, Vanbutsele RJ, Robert A, De Coster P, Brasseur LA, et al. Alternative diagnostic strategies for coronary artery disease in women: demonstration of the usefulness and efficiency of probability analysis. Circulation. 1985;71:535-42.

283. Clarke KW, Gray D, Keating NA, Hampton JR. Do women with acute myocardial infarction receive the same treatment as men? BMJ. 1994;309:563-6.
284. Vaccarino V, Krumholz HM, Berkman LF, Horwitz RI. Sex differences in mortality after myocardial infarction. Is there evidence for an increased risk for women? Circulation. 1995;91:1861-71.

285. Vaccarino V, Krumholz HM, Yarzebski J, Gore JM, Goldberg RJ. Sex differences in 2-year mortality after hospital discharge for myocardial infarction. Ann Intern Med. 2001;134:173-81.

286. Roeters van Lennep JE, Zwinderman AH, Roeters van Lennep HW, Westerveld HE, Plokker HW, Voors AA, et al. Gender differences in diagnosis and treatment of coronary artery disease from 1981 to 1997 . No evidence for the Yentl syndrome. Eur Heart J. 2000;21:911-8.

287. Daly CA, Clemens F, Sendon JL, Tavazzi L, Boersma E, Danchin $\mathrm{N}$, et al. Gender differences in the presentation and mangement of stable angina from the Euro Heart Survey. Circulation. 2006;113:490-8.

288. Haffner SM. Coronary heart disease in patients with diabetes. $\mathrm{N}$ Engl J Med. 2000;342:1040-2.

289. Turner RC, Millns H, Neil HA, Stratton IM, Manley SE, Matthews DR, et al. Risk factors for coronary artery disease in noninsulin dependent diabetes mellitus: United Kingdom Prospective Diabetes Study (UKPDS: 23). BMJ. 1998;316:823-8.

290. Wei M, Gaskill SP, Haffner SM, Stern MP. Effects of diabetes and level of glycemia on all-cause and cardiovascular mortality. The San Antonio Heart Study. Diab Care. 1998;21:1167-72.

291. Young LH, Jose P, Chyun D. Diagnosis of CAD in patients with diabetes: who to evaluate. Curr Diab Rep. 2003;3:19-27.

292. Anand DV, Lim E, Lahiri A, Bax JJ. The role of non-invasive imaging in the risk stratification of asymptomatic diabetic subjects [publicación electrónica antes de imprenta]. Eur Heart J. 2005; doi:10.1093/eurheartj/ehi441.

293. Fang ZY, Sharman J, Prins JB, Marwick TH. Determinants of exercise capacity in patients with type 2 diabetes. Diab Care. 2005;28:1643-8

294. The American Association of Clinical Endocrinologists. Medical Guidelines for the management of diabetes mellitus: the AACE System of intensive diabetes self-management -2002 update. Endocr Pract Suppl;8 Suppl:40-82.

295. UK Prospective Diabetes Study (UKPDS) Group. Intensive blood-glucose control with sulphonylureas or insulin compared with conventional treatment and risk of complications in patients with type 2 diabetes (UKPDS 33). Lancet. 1998;352:83753.

296. Blendea MC, McFarlane SI, Isenovic ER, Gick G, Sowers JR. Heart disease in diabetic patients. Curr Diab Rep. 2003;3:223-9.

297. Lernfelt B, Landahl S, Svanborg A. Coronary heart disease at 70,75 and 79 years of age: a longitudinal study with special reference to sex differences and mortality. Age Ageing. 1990;19:297-303.

298. Kurita A, Takase B, Uehata A, Maruyama T, Nishioka T, Sugahara $\mathrm{H}$, et al. Painless myocardial ischemia in elderly patients compared with middle-aged patients and its relation to treadmill testing and coronary hemodynamics. Clin Cardiol. 1991;14:88690.

299. LaCroix AZ, Guralnik JM, Curb JD, Wallace RB, Ostfeld AM, Hennekens $\mathrm{CH}$. Chest pain and coronary heart disease mortality among older men and women in three communities. Circulation. 1990;81:437-46

300. Kasser IS, Bruce RA. Comparative effects of aging and coronary heart disease on submaximal and maximal exercise. Circulation. 1969;39:759-74.

301. Mehran R, Aymong ED, Nikolsky E, Lasic Z, Iakovou I, Fahy $\mathrm{M}$, et al. A simple risk score for prediction of contrast-induced nephropathy after percutaneous coronary intervention: development and initial validation. J Am Coll Cardiol. 2004;44:1393-9.

302. Montamat SC, Cusack BJ, Vestal RE. Management of drug therapy in the elderly. N Engl J Med. 1989;321:303-9.

303. Gundersen T, Abrahamsen AM, Kjekshus J, Ronnevik PK. Timolol related reduction in mortality and reinfarction in patients ages 65-75 years surviving acute myocardial infarction. Prepa- 
red for the Norwegian Multicentre Study Group. Circulation. 1982;66:1179-84.

304. Metzger JP, Tabone X, Georges JL, Gueniche C, Detienne JP, Le Feuvre C, et al. Coronary angioplasty in patients 75 years and older; comparison with coronary bypass surgery. Eur Heart J. 1994;15:213-7.

305. Bonnier H, De Vries C, Michels R, El Gamal M. Initial and long-term results of coronary angioplasty and coronary bypass surgery in patients of 75 or older. $\mathrm{Br}$ Heart $\mathrm{J}$. 1993;70:122-5.

306. Mannheimer C, Camici P, Chester MR, Collins A, DeJongste $\mathrm{M}$, Eliasson $\mathrm{T}$, et al. The problem of chronic refractory angina; report from the ESC Joint Study Group on the Treatment of Refractory Angina. Eur Heart J. 2002;23:355-70.

307. Yang EH, Barsness GW, Gersh BJ, Chandrasekaran K, Lerman A. Current and future treatment strategies for refractory angina. Mayo Clin Proc. 2004;79:1284-92.
308. Faircloth ME, Redwood SR, Marber MS. Strategies for refractory angina -electric not eclectic? Int J Clin Pract. 2004;58:650-2.

309. Kim MC, Kini A, Sharma SK. Refractory angina pectoris: mechanism and therapeutic options. J Am Coll Cardiol. 2002;39:923-34.

310. Allen KB, Dowling RD, Angell WW, Gangahar DM, Fudge TL, Richenbacher $\mathrm{W}$, et al. Transmyocardial revascularization: 5year follow-up of a prospective, randomized multicenter trial. Ann Thorac Surg. 2004;77:1228-34.

311. Schneider J, Diegeler A, Krakor R, Walther T, Kluge R, Mohr FW. Transmyocardial laser revascularization with the holmium:YAG laser: loss of symptomatic improvement after 2 years. Eur J Cardiothorac Surg. 2001;19:164-9.

312. Schofield PM, Sharples LD, Caine N, Burns S, Tait S, Wistow $\mathrm{T}$, et al. Transmyocardial laser revascularisation in patients with refractory angina: a randomised controlled trial. Lancet. 1999;353:519-24. 